Pontifícia Universidade Católica $_{\text {man }}$

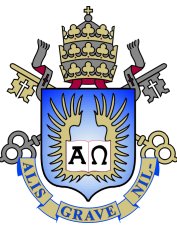

Aparajita Das

History shapes development: Culture, institutions and regional disparities in India

Tese de Doutorado

Thesis presented to the Programa de Pós-graduação em Economia of PUC-Rio in partial fulfillment of the requirements for the degree of Doutor em Economia.

Advisor: Prof. Juliano Assunção

Rio de Janeiro

December 2018 


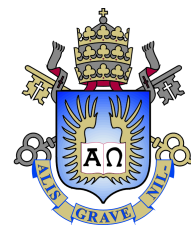

Aparajita Das

\section{History shapes development: Culture, institutions and regional disparities in India}

Thesis presented to the Programa de Pós-graduação em Economia of PUC-Rio in partial fulfillment of the requirements for the degree of Doutor em Economia. Approved by the undersigned Examination Committee.

Prof. Juliano Assunção

Advisor

Dept. of Economics - PUC-Rio

Prof. Arthur Amorim Bragança

Dept. of Economics - PUC-Rio

Prof. Claudio Ferraz

Dept. of Economics - PUC-Rio

Prof. Lakshmi lyer

Dept. of Economics - University of Notre Dame

Prof. Rudi Rocha de Castro

School of Business Administration - FGV-EAEASP

Prof. Augusto Cesar Pinheiro da Silva

Vice Dean of Graduate Studies Centro de Ciências Sociais - PUC-Rio

Rio de Janeiro, December the 10th, 2018 
All rights reserved.

\section{Aparajita Das}

Graduated with honors from Princeton University in 2012. Obtained a master's degree from the University of Chicago in 2013.

Bibliographic data

Das, Aparajita

History shapes development: Culture, institutions and regional disparities in India / Aparajita Das; advisor: Juliano Assunção. - Rio de janeiro: PUC-Rio, Departamento de Economia, 2018.

v., $131 \mathrm{f}$ : il. color. ; $30 \mathrm{~cm}$

Tese (doutorado) - Pontifícia Universidade Católica do Rio de Janeiro, Departamento de Economia.

Inclui bibliografia

1. Economia - Teses. 2. Desenvolvimento Econômico Teses. 3. Instituições;. 4. Cultura;. 5. História colonial;. 6. Índia;. 7. Agricultura;. 8. Religião.. I. Assunção, Juliano. II. Pontifícia Universidade Católica do Rio de Janeiro. Departamento de Economia. III. Título.

CDD: 330 


\section{Acknowledgments}

I am grateful to my advisor, Juliano Assunção, whose thoughtful and patient guidance, often over hectic schedules and long time differences, helped to bring this work to fruition. I am thankful to all the authors to whom I owe an intellectual debt. In particular, I would like to thank Lakshmi Iyer for her generous feedback on Paper 1 of this dissertation. I am grateful for the company and friendship of the students with whom my path crossed in the department. They made this journey so much more enjoyable. I am also thankful for my other friends in Rio, especially my neighbors in Vidigal. Despite not having the privilege of education, they were always full of encouragement for my academic endeavours. I owe them a special thanks for teaching me all the gírias any foreigner ever needs to know. Last, but not least, this work would not have been possible without the unconditional support of my family, who always believe in the method to my madness.

This study was financed in part by the Coordenação de Aperfeiçiamento de Pessoal do Nível Superior - Brasil (CAPES) - Finance Code 001. 


\section{Abstract}

Das, Aparajita; Assunção, Juliano (Advisor). History shapes development: Culture, institutions and regional disparities in India. Rio de Janeiro, 2018. 131p. Tese de Doutorado Departamento de Economia, Pontifícia Universidade Católica do Rio de Janeiro.

This thesis consists of three papers examining the impact of history on long-run development processes through the channels of institution and culture. The first paper studies land revenue institutions in colonial India and identifies a multi-channel mechanism through which variations in that institution have long-run consequences for agricultural investment and productivity. The second paper examines the relationship between various dimensions of cultural diversity and growth in Indian districts using an instrumental variables strategy. These results find the strongest impacts for religious diversity. The significant impact of religious diversity in increasing productivity and reducing poverty may be due to increased emphasis on secular institutions in the face of religious competition. The last paper studies the formation of cultural values as a channel through which development outcomes may be impacted by initial conditions. We find that inherent geographical traits render certain regions more likely to be agricultural, male-dominated societies with a lower propensity to worship female deities, which in turn leads to worse female literacy outcomes.

\section{Keywords}

Institutions; Culture; Colonial history; India; Agriculture; Religion. 


\section{Resumo}

\section{Das, Aparajita; Assunção, Juliano. História e desenvolvimento:}

cultura, instituições e disparidades regionais na Índia. Rio de Janeiro, 2018. 131p. Tese de Doutorado - Departamento de Economia, Pontifícia Universidade Católica do Rio de Janeiro.

Essa tese contém três artigos sobre o impacto da história sobre desenvolvimento econômico de longo prazo, através dos canais de instituições e cultura. O primeiro artigo estuda instituições de administração da terra na Índia colonial e identifica mecanismos através de que variações naquela instituição têm consequências de longo prazo sobre investimento e produtividade agrícola. O segundo artigo estuda a relação entre várias dimensões de diversidade cultural e crescimento em distritos Indianos, usando uma estratégia de variáveis instrumentais. Esses resultados acham os mais fortes impactos para diversidade religiosa. O impacto significativo da diversidade religiosa em melhorar produtividade e reduzir pobreza pode ser resultado da ênfase maior sobre instituições seculares em face da concorrência religiosa. O ultimo artigo examina a formação dos valores culturais como canal através de que desenvolvimento econômico pode ser impactado por condições iniciais. Achamos que traços geográficos inerentes tornam algumas regiões mais propensas a serem agrícolas. Essas regiões, dominados por homens, têm menos templos dedicados às divindades femininas e também têm piores índices da alfabetização feminina.

\section{Palavras-chave}

Instituições; Cultura; História colonial; Índia; Agricultura; Religião. 


\section{Table of contents}

1 Institutions and Incentives: The long-run impacts of colonial land revenue systems in India $\quad 13$

$\begin{array}{lll}1.1 & \text { Introduction } & 13\end{array}$

$\begin{array}{ll}1.2 \text { Historical context } & 15\end{array}$

$\begin{array}{ll}1.2 .1 & \text { India in the colonial period } \\ 1.2 .2 & 15\end{array}$

$\begin{array}{ll}1.2 .2 & \text { Institutional variation in land revenue } \\ 1.2 .3 & 16\end{array}$

$\begin{array}{ll}1.2 .3 \text { Abolition of land revenue } & 18\end{array}$

$\begin{array}{lll}1.3 \text { Data } & 19\end{array}$

$\begin{array}{ll}\text { 1.3.1 Unit of analysis } & 19\end{array}$

$\begin{array}{ll}\text { 1.3.2 Data sources } & 20\end{array}$

$\begin{array}{lll}1.4 & \text { Estimation strategy } & 23\end{array}$

$\begin{array}{lll}1.4 .1 & \text { Overview } & 23\end{array}$

$\begin{array}{ll}1.4 .2 \text { Middlemen } & 24\end{array}$

$\begin{array}{lll}\text { 1.4.3 Settlement criteria } & 26\end{array}$

1.4.4 Determinants of institutional variation 27

$\begin{array}{lll}1.5 \text { Results } & 29\end{array}$

1.5.1 Impact of middlemen $\quad 29$

1.5.2 Impact of settlement criteria 31

1.5.3 Explaining institutional choice 34

1.5.4 Controlling for determinants of institutional choice 36

$\begin{array}{lll}1.6 & \text { Discussion } & 38\end{array}$

1.6.1 Interpretation of results 38

$\begin{array}{ll}\text { 1.6.2 Impacts of settlement criteria } & 39\end{array}$

1.6.3 Impacts of agricultural middlemen 40

1.6.4 New technology and widening divergence 49

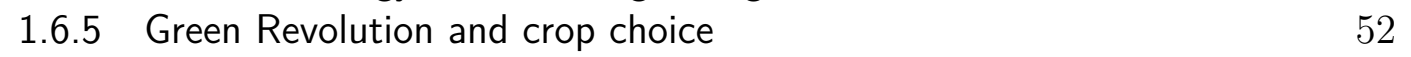

1.6.6 Relative importance of inputs over time 54

$\begin{array}{lll}1.7 \text { Conclusion } & 56\end{array}$

2 The melting pot effect: The impact of religious and linguistic diversity $\begin{array}{ll}\text { on growth and poverty } & 58\end{array}$

$\begin{array}{lll}2.1 & \text { Introduction } & 58\end{array}$

$\begin{array}{lll}2.2 & \text { Literature } & 60\end{array}$

$\begin{array}{lll}2.3 \text { Data } & 62\end{array}$

$\begin{array}{lll}2.3 .1 & \text { Data sources } & 62\end{array}$

$\begin{array}{lll}\text { 2.3.2 Distribution of fractionalization } & 65\end{array}$

$\begin{array}{lll}\text { 2.3.3 Religious fractionalization over time } & 67\end{array}$

$\begin{array}{ll}\text { 2.3.4 Diversity and growth } & 67\end{array}$

$\begin{array}{lll}2.4 & \text { Estimation strategy } & 71\end{array}$

$\begin{array}{lll}2.5 & \text { Results } & 74\end{array}$

$\begin{array}{lll}2.5 .1 & \text { Instrumental variables } & 74\end{array}$

$\begin{array}{lll}2.5 .2 & \text { Robustness checks } & 78\end{array}$

$\begin{array}{lll}\text { 2.5.2.1 The impact of the caste system } & 78\end{array}$

$\begin{array}{lll}\text { 2.5.2.2 Religious polarization } & 81\end{array}$ 
2.5.2.3 Controlling for additional impacts of past literacy 81

2.6 Discussion $\quad 82$

2.7 Conclusion $\quad 89$

3 Goddesses and growth: The formation of cultural values and their impact $\begin{array}{ll}\text { on development } & 91\end{array}$

3.1 Introduction $\quad 91$

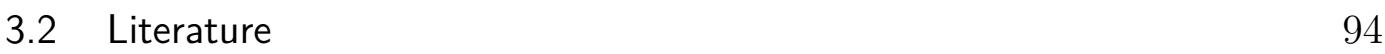

3.3 Historical context $\quad 96$

$\begin{array}{lll}3.4 & \text { Data } & 99\end{array}$

3.5 Estimation strategy 100

3.5.1 Formation of cultural values 100

$\begin{array}{ll}\text { 3.5.2 Shakti Peeth and female literacy } & 101\end{array}$

$\begin{array}{lll}3.6 & \text { Results } & 102\end{array}$

3.6.1 Formation of cultural values 102

3.6.2 Shakti Peeth and female literacy 104

3.7 Discussion 106

3.7.1 Shakti Peeth as an indicator of preference for female deities 106

$\begin{array}{ll}\text { 3.7.2 Agriculture and female-centric development } & 110\end{array}$

$\begin{array}{lll}3.8 \text { Conclusion } & 112\end{array}$

$\begin{array}{ll}\text { Bibliography } & 114\end{array}$

$\begin{array}{ll}\text { Appendices } & 119\end{array}$

A Appendices for Paper $1 \quad 120$

A.1 Comparison of historical data on landlord control 120

A.2 Results excluding Uttar Pradesh 121

B Appendices for Paper 2 122

$\begin{array}{ll}\text { B.1 Reduced form regressions } & 122\end{array}$

$\begin{array}{lll}\text { B.2 } & \text { First stage regressions } & 125\end{array}$

B.3 Results controlling for shares of different religions 126

B.4 Results excluding regions directly impacted by Partition 128

$\begin{array}{ll}\text { B.5 Impacts of religious diversity in the past } & 129\end{array}$

C Appendices for Paper $3 \quad 130$

C.1 Interaction between agriculture and Shakti peeth temples 130

C.2 List of Shakti peeth temples 131 


\section{List of figures}

Figure 1.1 Estimation strategy, Impact of land revenue institution 23

Figure 1.2 Colonial middlemen and post-Independence reform 43

Figure 1.3 Public gross fixed capital formation in agriculture 45

Figure 1.4 Average capital expenditure as a ratio of net sown area 47

Figure 1.5 Private gross fixed capital formation in agriculture 48

Figure 1.6 Agricultural credit utilization in 2011

Figure 2.1 Distribution of religious and linguistic fractionalization 66

$\begin{array}{lll}\text { Figure 2.2 Religious and linguistic fractionalization correlation } & 67\end{array}$

$\begin{array}{lll}\text { Figure 2.3 Religious fractionalization over time } & 68\end{array}$

Figure 3.1 Initial conditions and development outcomes for females 93 


\section{List of tables}

Table 1.1 Contemporary data summary statistics 20

Table 1.2 Historical data summary statistics 22

Table 1.3 Impact of middlemen on agricultural investments 1957-86 30

Table 1.4 Impact of middlemen on agricultural investments in 190431

Table 1.5 Impact of settlement criteria on agricultural investments $1957-86$

Table 1.6 Impact of settlement criteria on agricultural investments 1904

Table 1.7 Factors impacting non-middleman proportion $\quad 35$

Table 1.8 Middlemen and agricultural investments 1957-86 37

Table 1.9 Middlemen and agricultural investments in $1904 \quad 38$

Table 1.10 Differences in colonial revenue burden 41

Table 1.11 Land reforms and agricultural investments 1957-86 50

Table 1.12 Agricultural investments 1857-86, excluding Punjab and Haryana

Table 1.13 Irrigation over time 56

$\begin{array}{lll}\text { Table 2.1 Summary statistics } & 64\end{array}$

Table 2.2 Religious fractionalization 1901-2001 68

Table 2.3 Religious fractionalization and economic outcomes, OLS 69

Table 2.4 Linguistic fractionalization and economic outcomes, OLS 69

Table 2.5 Impact of religious and linguistic fractionalization on economic outcomes, OLS $\quad 70$

Table 2.6 Religious fractionalization and economic outcomes, IV $\quad 75$

Table 2.7 Linguistic fractionalization and economic outcomes, IV 76

Table 2.8 Impact of religious and linguistic fractionalization on economic outcomes, IV $\quad 77$

Table 2.9 Religious fractionalization and economic outcomes, IV estimates with additional controls for Hinduism and caste $\quad 80$

Table 2.10 Religious polarization and economic outcomes, IV 82

Table 2.11 Linguistic fractionalization and economic outcomes, IV estimates with additional controls $\quad 83$

Table 2.12 Comparison of fractionalization indices 85

$\begin{array}{lll}\text { Table } 3.1 & \text { Summary statistics } & 100\end{array}$

Table 3.2 Geographical factors and agricultural propensity 103

Table 3.3 Agricultural propensity and Shakti Peeth 103

Table 3.4 Agricultural population, rice cultivation, and Shakti temples 104

Table 3.5 Impact of Shakti temples on female literacy, DID 105

Table 3.6 Impact of Shakti temples on gender gap in literacy, DID 106

Table 3.7 Agricultural propensity and Shakti Peeth, controlling for overall number of temples 109

Table 3.8 Impact of agriculture on female-centric development indicators, IV 110

Table 3.9 Impact of agriculture on crimes against women, IV 111 
Table A.1 Historical data comparison

Table A.2 Agricultural investments 1957-86, excluding Uttar Pradesh

Table B.1 Impact of past religious fractionalization on current economic outcomes, reduced form

Table B.2 Impact of past linguistic minorities, institutions, literacy and population density on current economic outcomes, reduced form

Table B.3 Impact of historical indicators of diversity, institutions, literacy and population density on current economic outcomes, reduced form

Table B.4 Historical instruments for fractionalization (separate), first stage

Table B.5 Historical instruments for fractionalization (joint), first stage

Table B.6 Religious fractionalization and economic outcomes, IV estimates controlling for shares of different religions

Table B.7 Religious fractionalization and economic outcomes, IV estimates excluding Partition impacted regions

Table B.8 Religious diversity and literacy in 1901, OLS

Table B.9 Religious diversity and public goods provision in 1901, OLS129

Table C.1 Interaction between Shakti temples and agriculture $\quad 130$

Table C.2 Full list of Shakti peeth and their locations 
While we cannot live without history, we need not live within it either. 


\section{1 \\ Institutions and Incentives: The long-run impacts of colonial land revenue systems in India}

\section{1 \\ Introduction}

The role of institutions in development is a topic of considerable interest within economics, with long-standing debates about whether humanly devised constraints on social interactions can trump the effect of innate factors like geography and culture. Perhaps the biggest challenge in arguing for the primacy of institutions as a determinant of economic growth and development is in isolating the impact of particular institutions from the settings in which they arise. To address this problem, we focus on one specific institution in a single country, which enables locating institutional variation and a detailed institutional history, thus making it easier to argue for exogeneity. We focus on the historical system of collecting land revenue in colonial India and study the impact that two parallel variations in this institution have on agricultural investments in the colonial and post-Independence period.

In choosing the particular institution of land revenue in colonial India, we follow Banerjee and Iyer (2005) who find that landlord control in British India negatively impacts agricultural outcomes in the post-Independence period. As Banerjee and Iyer (2005) point out, the particular institution of colonial land revenue is particularly advantageous for studying the impact of institutions because it no longer exists. Any impacts it continues to have in the contemporary period serve as evidence of pure institutional overhang. Focusing on the effects of this specific institution thus help inform a broader case for the persistence of institutional impact on long-run outcomes.

Our novel historical data allows us to build on Banerjee and Iyer (2005) in several ways. Firstly, we expand their landlord analysis on several dimensions. We study both native ruled territories as well as directly ruled British territory, and both colonial and post-Independence periods. We are also able to separate the effects of different kinds of agricultural middlemen and thus study the impact of non-landowning middlemen in addition to landlords. Secondly, we have data on a parallel variation in the institution, namely, the settlement 
criteria, i.e. the criteria by which land revenue demand was determined, which ranges from subjective criteria such as the caste of the cultivator to objective criteria like crop type, as well as soil surveys meant to scientifically judge the productive potential of land in assigning a revenue rate. Examining this additional variation allows us to identify multiple channels through which the colonial institution has long-run impacts. Lastly, our data allows us to explicitly test the determinants of middleman control, effectively controlling for endogeneity concerns in this variation in the institution. This not only highlights the initial conditions that give rise to the institutional variation, but also shows that the institution has independent effects above and beyond the historical conditions of its origin. Thus we are able to outline a comprehensive multi-period, multi-channel model by which initial conditions impact long-run outcomes through an institutional mechanism.

Our results show that, controlling for geography and years of colonial rule, variations in the historical land revenue institution significantly impact long-run agricultural outcomes through two channels, the effects of which manifest at different times. While the settlement criteria channel has impacts in both colonial and post-Independence periods, the middleman channel has impacts that only manifest after the colonial period. These latter results are robust to binary measures of middleman control and to the inclusion of an additional set of controls comprising the determinants of middleman control. These include individual administrators, political events, date of conquest and a pre-existing landlord class, all of which are significant determinants of the proportion of middlemen in a given area.

In our discussion we outline the mechanisms by which each channel has impacts on agricultural outcomes. Settlement criteria appear to impact irrigation in the colonial period by determining how much of the residual profit remained with investors. In the post-Independence period, however, areas historically settled using a soil survey have an advantage in several inputs. We believe this is primarily due to increased security of tenure in these regions due to the extensive documentation of past soil surveys. We also discuss why the impact of the middleman channel manifests only after the formal abolition of the land revenue institution. We find that the answer lies primarily in the increased return to investment due to the removal of taxation on agricultural land upon Indian Independence. We find that areas that had historically been under the control of landlords fall behind in this period, which also witnessed the passing of a massive body of land reform legislation throughout the country. This divergence, caused by differences in public policy and private incentives, 
was further exacerbated during the Green Revolution ${ }^{1}$ in India. During this push towards higher productivity in the agricultural sector, some areas were much better placed to invest in and reap benefits from the new agricultural technology being promoted and incentivized nationally. We argue that the source of this advantage lies in the land revenue system from the previous period.

Though the historical setting of our experiment is unique, its findings shed light on general questions of how institutions come to be and how they continue to impact incentives long after they have ceased to exist. Not only do our results provide evidence for institutional persistence, but they in fact show a situation in which an institution can have impacts that amplify rather than fade over time. This helps us build a broader case for why institutions, rather than innate factors like geography, should be accorded primacy in the design of public policies oriented towards growth.

The remainder of this paper is structured as follows. Section 2 elaborates on the historical context of the land revenue system. Sections 3 and 4 describe our data and estimation strategy, respectively. Section 5 presents the main results, and is followed by a discussion in Section 6, which outlines the mechanisms we believe to be responsible for our findings. We end with concluding remarks in Section 7.

\section{2 \\ Historical context}

\subsection{1 \\ India in the colonial period}

During the colonial period, about half of Indian territory was under direct British colonial control ${ }^{2}$ while the remaining territory was made up of native-ruled princely states ${ }^{3}$. These princely states were autonomous regions that retained their Independence by forging alliances with the British. Though terms for such agreements varied, often the princely state was required to pay a tribute to the British and was subject to British policies on key matters such as defense. While administrative decisions such as how to collect land revenue

\footnotetext{
${ }^{1}$ The term Green Revolution refers to a push towards higher productivity in agriculture through the use of improved inputs such as high-yielding varieties of seeds, used in conjunction with chemical fertilizers, insecticides and pesticides.

${ }^{2}$ Though the French, Portuguese and the Dutch also held minor pockets of Indian territory, the British were the paramount colonial power on the Indian subcontinent from 1757 onwards.

${ }^{3}$ At the time of publication of our source, almost the entire territory of India fell under British India or princely states allied with the British. Only some tribal regions in the North East of the country remained unexplored in 1901.
} 
technically rested with the native chief, these rulers were susceptible to British influence as they relied on peaceful relations with the British to maintain their titles and privileges. As such, they may be considered as falling under indirect colonial rule. We look at variations in the land revenue institution in both the directly-ruled regions of British India as well as the indirectly-ruled princely states.

\subsection{2}

\section{Institutional variation in land revenue}

Land revenue systems under the British are generally classified by historians as falling under three broad categories: ryotwari, whereby revenue settlements were made directly with individual cultivators; zamindari, in which settlements were made with landlords ${ }^{4}$; and mahalwari, an umbrella term for several distinct village-based systems ${ }^{5}$. Rather than using these categories, which are too broad to pinpoint precise aspects of the institutional arrangement, we classify the revenue systems on the basis of two parallel variations - the presence of middlemen and the criteria used to determine the amount of land revenue to be assessed from each cultivator or landlord.To understand how these variations in the land revenue system remained consequential decades after land revenue collection ceased, we need to understand the context in which this institution originated and operated in colonial India.

Before the colonial period, each region had its own systems of land revenue collection determined by the native rulers of that region. When the British took over administrative control in a region, the decision of whether to maintain or change the existing land revenue collection system depended on a slew of factors including administrative ease, individual welfare, and political considerations. The source from which our data is derived, the Imperial Gazetteer of India, gives us a glimpse into these deliberations, which were often influenced by individual administrators or the particular political climate of a given region at a given time.

\footnotetext{
${ }^{4}$ The system was known as such in the east and south of the country, but other local variants, such as malguzari in Central India, are similar in principle.

${ }^{5}$ The word mahal means estate (house, district, neighborhood or quarter), and the term "complex mahals" has been used frequently in our source - particularly in the case of the province of Oudh —- as an all-encompassing term masking heterogeneity in the exact nature of land ownership, which could be joint or individual, hereditary or claimed. While land rights do not belong to an individual as in the zamindari system, the existence of middlemen is clear in many "complex mahals". Meanwhile, in other village-based systems, for example, in Punjab, administrative dealings were done with "peasant proprietors" who took on joint responsibility for the revenue payment of a village. While both systems are often conflated under the term mahalwari due to the village being the unit of the administration, they represent fundamentally different institutional arrangements.
} 
While the administrative cost of collecting from individual farmers was higher than that of collecting from a landlord or a village headman, dealing directly with individuals was preferable from a welfare perspective as it freed cultivators from the heavy rent demands of landlords. Furthermore, cutting out the middleman had potential productivity benefits as those who tilled their own lands, or lands on which they had secure rights, put in more effort and took greater interest in augmenting productivity than cultivators who bore the burden of rent payments to middlemen. Thus dealing directly with individuals rather than landlords or other middlemen made for a satisfied rural class and a more productive tax base, apart from reducing the share of rents paid to unproductive intermediaries. At the same time, landlords played an important role in maintaining political stability. In some regions, they were feudal noblemen who had earned their lands through royal favor or military grants. In others, they had usurped the land through force. In either case, they were often locally important entities and were often appeased by the British to avoid conflict. Though British administrators stripped landlords of their land in some regions, in many places the British chose to make concessions to landlords when it was politically advantageous. In several areas, landowning classes were rendered even more powerful because the British endowed their formerly customary rights with a legal basis.

Apart from the decision of who the revenue would be collected from, further variation existed in the manner in which revenue demand was assessed. We have grouped together these various criteria under the following categories: subjective, objective, and soil survey. Subjective criteria include caste privileges, whereby revenue demands were made the basis of individual landowners' caste status, and old rent rolls, which was often based less on past paperwork and more on the word of politically powerful entities in the village. Also part of this category is Permanent Settlement, which was a system first introduced in 1793 the eastern province of Bengal and then extended elsewhere. This system was based on an agreement with the landlord for a revenue rate that was fixed in perpetuity. This system was introduced partly as a bid to appease powerful landlords and partly because administrators believed that the long-term assurance of a low revenue rate would give landlords motivation to invest in the land. Thus the subjective criteria often entailed arbitrary rates that tended to favor the elite. In other areas, more objective criteria was used to determine the rate of revenue, such crop type or topography. In yet other places, the British embarked on scientific soil surveys and regularly ascertained revenue demands based on the productivity of soil circles in a given area. The settlement of areas based on a soil survey was an administratively 
costly process but avoided the arbitrary nature of some of the more subjective criteria, which were subject to influence by the politically powerful classes. Though soil surveys were more common in British India, some native states, such as Kashmir in 1887, borrowed British officers to carry out a "regular settlement".

Because of the nature of political events and the fact that senior administrators had influence on the governance of entire provinces, it was sometimes the case that districts within a given province tended to have similar systems in place. For example, the province of Bengal was dominated by powerful landlords with whom the government had made a longstanding arrangement under the Permanent Settlement of 1793. Similarly, much of the province of Madras Presidency moved away from landlord systems under the influence of the Governor Sir Thomas Munro, who was credited with the origin of the ryotwari system. Despite this tendency for some provinces to have a particular mode of land revenue assessment and collection, the decision of what system to implement was implemented at a much smaller scale, thus leaving considerable room for variation. It was not uncommon to have districts where some parts were administered under landlords and others under individual cultivators. Similarly, it was possible that different sub-regions of a district would have different criteria to assess the revenue demand. Thus there was considerable variation in the land revenue system at a local level.

The decision of which land revenue systems to institute had far-reaching political, administrative and economic consequences and was taken in each district of British India after a consideration of these factors. Similar variations in the institution could also be found in the native-ruled kingdoms, though with different considerations of the various factors involved since the relations of the native rulers with landlords or individual subjects in their kingdoms were dependent on unique historical ties and political contingencies in each region. As stated earlier, precolonial systems of land tenure had numerous variants, which were maintained in some cases and overhauled in others. The result was a large spectrum of institutional arrangements across the territory of India.

\subsection{3}

\section{Abolition of land revenue}

In independent India, land tax was no longer collected from agricultural land, thus effectively ending the institution of land revenue. The fact that land that had previously been liable for revenue was no longer under taxation meant that the return to investment on all agricultural land increased considerably at Independence. Additionally, in the decades following Independence, attempts 
were made to erase the legacy of inequality created by landlord systems through redistributive land reform ${ }^{6}$. Therefore, not only was the institution of land revenue abolished but deliberate attempts were made to erase some of its lasting impacts. However, as land reform was instituted at the state rather than national level, there was considerable heterogeneity in the legislation and implementation of reform across the country. We argue that during this period, coinciding with land reforms, the historical presence of middlemen led to distinct paths in public policy and private incentives, which in turn gave rise to the divergence of outcomes shown by our results. A policy meant to eliminate the lingering effects of certain land revenue arrangements thus paradoxically created the conditions for an additional channel through which the institution continued to impact long-run agricultural outcomes.

\section{3 \\ Data}

\subsection{1}

\section{Unit of analysis}

Our analysis uses a combination of historical and contemporary data at the district-level. Districts are administrative units that come below states or union territories. Following Banerjee and Iyer (2005), we use district boundaries from 1961, aggregating over future splits in districts ${ }^{7}$.

The primary reason for using district rather than state-level data is that present day district boundaries correspond well to older British districts, whereas present day states do not match as well to what were known as "provinces" in British India, for various reasons including the linguistic reorganization of states during the 1950s and the splitting of some states for political reasons. Districts can also be unambiguously mapped to their historical counterparts in territories formerly under princely states. Smaller princely states — such as Patiala in the Punjab - tended to be incorporated into the territory of independent India as individual districts,

\footnotetext{
${ }^{6}$ Land reform legislation in India can be categorized under four main types: the first type, tenancy reform, sought to improve contractual terms faced by tenants and provide them with greater security of tenure; the second type aimed to abolish intermediaries, such as landlords, in order to minimize what was perceived as unjust extraction of surplus; a third type of reform imposed ceilings on landholdings, with the intention of redistributing surplus land to the landless; the fourth and last type of land reform involved the consolidation of landholdings, which aimed to ensure that small parcels of land owned by an individual but situated at a distance could be consolidated into a single, more viable holding (Besley and Burgess 2000; Ghatak and Roy 2007).

${ }^{7}$ In 1961, there were 340 districts, while during the last census in 2011, there were 640 districts. The bulk of new districts result from the splitting of pre-existing districts for administrative ease.
} 
Table 1.1: Contemporary data summary statistics

\begin{tabular}{|c|c|c|c|c|c|c|}
\hline \multirow[b]{2}{*}{$\begin{array}{l}\text { DEPENDENT } \\
\text { VARIABLES } \\
\end{array}$} & \multicolumn{3}{|c|}{ Full sample } & \multicolumn{3}{|c|}{ British districts } \\
\hline & Mean & $\begin{array}{l}\text { Std. } \\
\text { Dev. }\end{array}$ & $\begin{array}{l}\text { Observations } \\
\text { (Districts) }\end{array}$ & Mean & $\begin{array}{l}\text { Std. } \\
\text { Dev. }\end{array}$ & $\begin{array}{c}\text { Observations } \\
\text { (Districts) }\end{array}$ \\
\hline Irrigation ( $\%$ area) & 0.243 & 0.219 & $8622(270)$ & 0.292 & 0.231 & $5248(164)$ \\
\hline Fertilizer $(\mathrm{kg} / \mathrm{ha})$ & 20.07 & 31.71 & $8622(270)$ & 23.97 & 34.59 & $5248(164)$ \\
\hline Rice $\left(\%\right.$ under $\left.\mathrm{HYV}^{a}\right)$ & 0.218 & 0.410 & $8215(264)$ & 0.219 & 0.383 & $5238(164)$ \\
\hline Wheat (\% under HYV) & 0.500 & 1.172 & $7718(260)$ & 0.470 & 0.989 & $4573(155)$ \\
\hline Other cereals ${ }^{b}$ ( $\%$ under HYV) & 0.174 & 0.850 & $8460(270)$ & 0.192 & 1.079 & $5092(164)$ \\
\hline
\end{tabular}

${ }^{a}$ HYV: high-yielding seed varieties; ${ }^{b}$ Includes maize, sorghum, pearl millet.

whereas larger princely states — for example, Hyderabad State — were made into several districts, the boundaries of which corresponded with the historical administrative sub-divisions used in those states. Consequently, in both British and native-ruled territories, the district is a unit that is relatively straightforward to match to its historical equivalent.

Furthermore, since many modern Indian states are composed of both former British districts and princely states, using states as a unit would not allow us to cleanly isolate institutions in British India from those in native-ruled territories. Also, as mentioned previously, though certain provinces or states might have tended towards certain land tenure systems, the decision of which land tenure system to use was made on a much smaller scale. For this reason, aggregating at a smaller unit not only gives us a larger sample size but also better allows us to capture the rich variation in the historical data.

\subsection{2 \\ Data sources}

Our data for the post-Independence period comes from the World Bank's India Agriculture and Climate Data Set. Table 1.1 describes the indicators of agricultural investments from this source, which has information on 270 districts $^{8}$ from 13 major states. Though the data source also includes data on agricultural yields, we focus here on investments due to the finding of Banerjee and Iyer (2005) that the effects on yields are explained by the effects on investments.

Though our post-Independence data is the same as that used in Banerjee and Iyer (2005), our colonial period data is distinct and was compiled for this

\footnotetext{
${ }^{8}$ The source says that this dataset encompasses 271 districts over 13 states; However, we believe that the correct number to aggregate to is 270 districts. The specific district which we believe was erroneously included as a separate 1961-district is Valsad in Gujarat, which was only separated from Surat district in 1964.
} 
dissertation. It was coded using the Imperial Gazetteer of India, a 26-volume administrative record written by officials in India - primarily officers who had worked as Census Superintendents of their Provinces of States in 1901 and published by the British government of India in the year $1909^{9}$. These volumes are encyclopedic and cover all territories that comprised India at the time $^{10}$, including areas not administered by the British. While the entries on British districts include detailed and standardized administrative information up to the years 1903-4, in most cases the entries on non-British states are also rich with detail and contain quantitative and qualitative descriptions of the land revenue administration in the given princely state. The history, culture, demographics, and geography of each region is also described in considerable depth. Our key variables from the historical period are described in Table 1.2.

The comprehensive nature of of the Imperial Gazetteer of India gives our data a few advantages over the data used in Banerjee and Iyer (2005). First, we are able to study agricultural inputs in the colonial period, which allows us to test whether the institutional impact began in the colonial period itself or only after the abolishing of the institution. In particular, our data on irrigation in both periods is useful because it allows us to see the long-term investment patterns in that input. Second, we have detailed information about non-British territories. Not only does this nearly double our sample size and the territory covered by the data, it also allows us to distinguish between institutions in British India and those in native territories. Third, Banerjee and Iyer (2005) have district-level information on the proportion of villages, estates or area under the revenue liability of landlords for five states. For the remaining six states they assign the non-landlord measure as zero or one depending on the dominant land revenue system. Since our source allows us to calculate the non-middleman proportion for almost all districts in our sample, it is better able to capture the precise variation in land revenue systems. Fourth, the detailed data on the land revenue system of each district allows us to look at a parallel variation, that is, the settlement criteria used to assess the land revenue demand, in addition to the presence of middlemen. Fifth, due to its detailed report on the prevailing revenue arrangements, our source allows us to distinguish between different types of middlemen. This allows us to see whether a village headman who receives, on average, a 5 to $10 \%$ commission has similar

\footnotetext{
${ }^{9} \mathrm{~A} 9$-volume version was first published in 1881, with an augmented version issued in 1885-87. New editions published in 1908, 1909, 1931. We use the 1909 edition, which was digitized by the Digital South Asia Library at the University of Chicago.

${ }^{10}$ This excludes a few pockets of Northeast India that remained unexplored in 1901. However the territory of British India includes regions that are now in Pakistan and Bangladesh, as well as some in Sri Lanka (then known as Ceylon) and Afghanistan. These have not been included in our analysis.
} 
impacts as a landlord, who may set the rents as much as 8 to 9 times the revenue amount. Fifth, the detailed administrative and political history of each district provided in our source allows us to codify the historical factors contributing to the choice of land revenue institution. Thus we are able to quantitatively test the sources of institutional variation outlined in Banerjee and Iyer (2005). Last, non-landlord control in Banerjee and Iyer (2005) is calculated using data from various sources dating from the 1870 s or 1880 s, whereas we calculate comparable measures of non-middleman and non-landlord control from a single data source reporting information from 1903-4. While the empirical strategy employed in both papers assumes that the historical measure of middleman or landlord control remains constant between the historical and contemporary period, the detailed commentary available in our source makes it clear that it was not uncommon for administrators to make changes to the arrangements of land revenue collection, thus affecting our measure. Because of this potential flux, when attempting to reach a reasonable estimate for a long-term measure of middleman control, it may be preferable to calculate the measure for the entire cross-section from a single point in time, especially from later in the colonial period when we are likely to be capturing the finalized institutional arrangement. A more detailed comparison of the historical data from both papers can be found in Table A.1 in Appendix A.

Table 1.2: Historical data summary statistics

\begin{tabular}{|c|c|c|c|c|c|c|}
\hline & \multicolumn{3}{|c|}{ Full sample } & \multicolumn{3}{|c|}{ British districts } \\
\hline & Mean & $\begin{array}{l}\text { Std. } \\
\text { Dev. }\end{array}$ & $\begin{array}{c}\text { Obs./ } \\
\text { Districts }\end{array}$ & Mean & $\begin{array}{l}\text { Std. } \\
\text { Dev. }\end{array}$ & $\begin{array}{c}\text { Obs./ } \\
\text { Districts }\end{array}$ \\
\hline \multicolumn{7}{|l|}{ DEPENDENT VARIABLES } \\
\hline Irrigation ( $\%$ area $)$ & 0.168 & 0.194 & 281 & 0.176 & 0.209 & 185 \\
\hline Agricultural loans per capita (Rs.) & 0.038 & 0.093 & 260 & 0.055 & 0.109 & 174 \\
\hline \multicolumn{7}{|l|}{ NON-MIDDLEMAN PROPORTION } \\
\hline All middlemen & 0.416 & 0.429 & 327 & 0.333 & 0.425 & 194 \\
\hline Landlords & 0.451 & 0.433 & 327 & 0.380 & 0.440 & 194 \\
\hline \multicolumn{7}{|l|}{ MIDDLEMAN DETERMINANTS } \\
\hline Thomas Munro & 0.099 & 0.299 & 334 & 0.169 & 0.376 & 195 \\
\hline Lord Elphinstone & 0.057 & 0.232 & 334 & 0.097 & 0.297 & 195 \\
\hline Mutiny of 1857 & 0.461 & 0.499 & 334 & 0.456 & 0.499 & 195 \\
\hline pre-existing landlord class & 0.201 & 0.401 & 334 & 0.277 & 0.449 & 195 \\
\hline Years under colonial rule & 89.95 & 81.10 & 334 & 141.08 & 34.25 & 195 \\
\hline \multicolumn{7}{|l|}{ SETTLEMENT CRITERIA } \\
\hline Caste privileges & 0.538 & 0.499 & 316 & 0.550 & 0.499 & 191 \\
\hline Old rent rolls & 0.177 & 0.382 & 316 & 0.288 & 0.454 & 191 \\
\hline Permanent Settlement & 0.243 & 0.429 & 334 & 0.415 & 0.494 & 191 \\
\hline Topography & 0.155 & 0.363 & 316 & 0.157 & 0.365 & 191 \\
\hline Crop type & 0.136 & 0.343 & 316 & 0.136 & 0.344 & 191 \\
\hline Soil survey & 0.617 & 0.487 & 316 & 0.576 & 0.496 & 191 \\
\hline
\end{tabular}




\section{4 \\ Estimation strategy}

\subsection{1}

\section{Overview}

We use the same linear approach employed in Banerjee and Iyer (2005) to estimate the impacts of the institutional variations on agricultural outcomes. However, we extend their landlord analysis on three dimensions we study institutions in native-ruled territories in addition to those in British India, we look at the impact of middlemen on both the colonial and the post-Independence period, and we study not only landlords but all middlemen. In addition, we look at the parallel variation of the settlement criteria, which allows us to outline the multi-channel mechanism by which the institution of land revenue has impacts in the colonial and post-Independence periods. Finally, we study the political and historical determinants of the middleman variation, which allows us to control for these determinants as possible confounding factors. Figure 1.1 outlines how our estimation strategy builds on Banerjee and Iyer (2005) and the parallel channels we study to estimate the long-run impacts of the land revenue system.

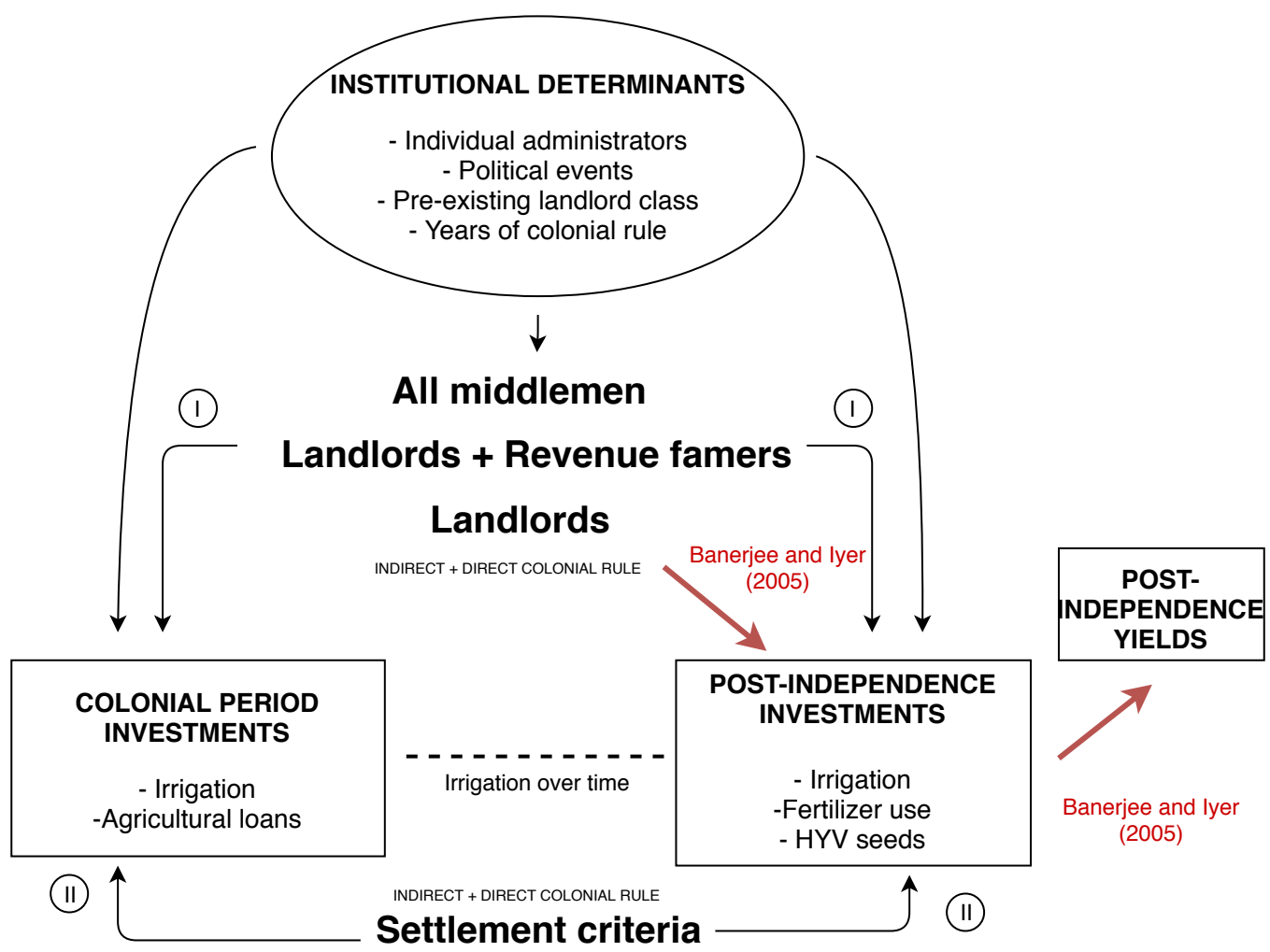

Figure 1.1: Estimation strategy, Impact of land revenue institution 


\subsection{2 \\ Middlemen}

We compare agricultural investment between middleman and non-middleman areas by running regressions of the form:

$$
y_{i t}=\text { constant }+\alpha_{t}+\beta N M_{i}+X_{i t} \gamma+\epsilon_{i t}
$$

where $y_{i t}$ is our outcome variable of interest (agricultural investments in the colonial and post-Independence periods) in district $i$ and year $t, \alpha_{t}$ is a year fixed effect ${ }^{11}, N M_{i}$ is the historical measure of the non-middleman control by area ${ }^{12}, X_{i t}$ is a set of control variables and $\epsilon_{i t}$ is an unobserved error term. Our coefficient of interest, $\beta$, captures the average difference between a non-middleman district and a middleman district in the outcome variable of interest. For each dependent variable, we include two specifications using definitions of middlemen of varying broadness. The narrower definition considers "landlords", i.e. those entities who lease out land and collect rents for themselves and revenue for the state ${ }^{13}$. The broader definition comprises "all middlemen" which in addition to landlords includes village headmen receiving a commission for collecting revenue on behalf of the state. Thus, for each outcome variable of interest, we have two regressions using different definitions of middleman and subsequently, distinct calculations of $N M_{i}$. Our dependent variables in the colonial period are irrigation and agricultural loans per capita, and in the contemporary period, irrigation, fertilizer use and use of high-yielding varieties (HYV) seeds of various crops.

Our set of control variables $X_{i t}$ includes key geographic characteristics latitude, altitude, soil type, mean annual rainfall ${ }^{14}$, and a dummy indicating whether the district is a coastal district - as well as the length of time under British rule. This latter control is included because areas targeted early

\footnotetext{
${ }^{11}$ In our colonial period regressions, the year fixed effect is excluded as the data is a single year cross section.

${ }^{12}$ In many districts a small proportion (under 1 percent in all cases) of the area does not pay land revenue to the state. Some of these are government administered estates, but more commonly, they are feudal grants, and the individual holding the grant has the exclusive right to extract revenue from the cultivators. We have included these latter areas in our analysis as landlord areas. However, our results are robust to excluding these lands from the analysis.

${ }^{13}$ In our definition of landlords, we also include revenue farmers. Revenue farming was a system prevalent in some parts of India, particularly those under the Maratha Empire, in which rents from entire villages were auctioned off to the highest bidder for a given amount of time. These revenue farmers were responsible for ensuring the state received the fixed revenue. Beyond this rate, they were free to extract as much rent as possible from the cultivators. Revenue farmers did not hold permanent ownership of the lands from which they extracted rents. However, since landlords in pre-colonial India also did not have permanent legal rights before the British, for all practical purposes the system of revenue farming was similar to landlordism in other parts of the country.

${ }^{14}$ Calculated as the average of annual rainfall from 2008-2014.
} 
on by the colonizers might be inherently different from areas that only fell under British rule later, or areas which never fell under colonial rule at all. Banerjee and Iyer (2005) use the date of conquest, equivalent to length of time under British rule, to control for these unobservable differences. However, since our sample also includes regions that were never directly colonized, our specification uses an indicator for the number of years under colonial administration, which is set to 0 for native territories.

Since the measure of the historical land revenue system is fixed for district $i$ over time, we do not include district fixed effects in Equation 1-1. However, in our post-Independence regressions, we adjust standard errors for within-district correlations due to our use of repeated observations from each district over time. State fixed effects are excluded because within-state variation in non-landlord proportions are much lower than cross-state variation. Furthermore, because modern states were formed almost five decades after the date of measurement of our non-landlord proportion, and we are concerned with the extent to which historical factors can explain the variation in the performance of post-Independence states, it does not make sense to include state effects.

We also repeat the regressions represented by Equation 1-1 using a binary indicator instead of a continuous measure of non-middleman control. We call this the "Majority dummy" and assign a value of 1 to any district where the non-middleman proportion is greater than half, thus capturing the dominant system of a given district, even if the district in question has multiple systems of revenue administration.

In classifying systems as individual or middleman based, we use the same coding used in Banerjee and Iyer (2005). As in Banerjee and Iyer (2005), we distinguish between fundamentally different types of village-based systems, classifying them as landlord or non-landlord as seems appropriate. However, we differ in our treatment of a specific type of village-based system called bhaiyachara, found in the province of Oudh. The two main systems in this region are pattidari (joint responsibility based on ancestry) or bhaiyachara (joint responsibility based on actual possession). Banerjee and Iyer (2005) categorize the former as a landlord system but hold that the latter category is very much like the individual based ryotwari system practiced elsewhere. However, we believe that while land revenue responsibility in bhaiyachara villages were divided up between different families, this does not equate to land revenue being paid by cultivators. This is illustrated in Bates (2013), where an account from Mathura district states: 
other words, the village lands were divided up between different families, who paid the land revenue charge jointly. This conflicted with British attempts to distinguish individual peasant holdings in the villages and to estimate the land revenue charge on each of them.

This source suggests that joint responsibility for revenue payment is not the same as individual peasant holdings as in the ryotwari system. Bhaiyachara means simply that multiple individuals or families had land rights in the village and that the rights of these individuals did not have their source in a hereditary grant. It does not imply, however, that land dealings were made with peasant cultivators, thus making this sytem quite distinct from the ryotwari system. In fact, pattidari and bhaiyachara are treated as very similar from the point of view of administrators, both in our source as well as in previous regulations and records (Bhanu 1979). Since the two categories differ only in the source of the right of the landowner, we do not think it is accurate to categorize one as a landlord system and the other as a non-landlord system. Both should be classified as landlord systems if our concern is not primarily with the origin of the land right, but rather with the existence of a non-cultivating party that receives rents, thus fulfilling the definition of a middleman.

As the bhaiyachara system is found only in the province of Oudh in our source, this difference in our definition only impacts a limited number of districts in the modern state of Uttar Pradesh. However, in order to assuage any concerns that our results are biased because of this classification, we include in the Appendix Table A.2, which reports results excluding Uttar Pradesh from the sample. These results are just as significant as our primary results and show impacts of a considerably greater magnitude for some inputs.

\section{4 .3}

\section{Settlement criteria}

Apart from the presence of middlemen, we study the impact of the settlement criteria, i.e. the criteria used to determine the amount of land revenue to be assessed from each estate. We group the various historical criteria into three categories: subjective, objective, and soil survey ${ }^{15}$. To estimate the impact of these different types of historical criteria on contemporary agricultural investments, we run a regression of the form:

$$
y_{i t}=\text { constant }+\alpha_{t}+S C_{i} \beta+X_{i t} \gamma+\epsilon_{i t}
$$

\footnotetext{
${ }^{15}$ The subjective criteria include: old rent rolls, caste privileges, and Permanent Settlement. The objective criteria include crop type and topography.
} 
where $y_{i t}$ is our the outcome variable of interest in district $i$ and year $t, \alpha_{t}$ is a year fixed effect ${ }^{16}$, and $S C_{i}$ is a set of three dummy variables that indicates whether the historical settlement criteria used in district $i$ included, respectively, subjective criteria, objective criteria and soil survey. The controls $X_{i t}$ are the same as in Equations 1, namely, geographic controls and the number of years under colonial rule. Our coefficients of interest, $\beta_{1}, \ldots, \beta_{5}$ capture the average difference between an area where a given type of criteria was in use and one where it was not.

\subsection{4}

\section{Determinants of institutional variation}

Since the choice of which system to implement was not random, the source of the institutional variation gives rise to concerns of endogeneity. Differences in the political environment that led to variation in the land revenue system could be precisely the same reasons that explain why the historical land revenue system matters for agricultural investments. To alleviate these concerns, we test several historical factors as predictors of a region's non-middleman proportion, and then include them in our base specification to isolate the independent effect of the institution.

We focus on the factors outlined in Banerjee and Iyer (2005) as the likely determinants of institutional choice. These include: a) Individual administrators, specifically Thomas Munro and Lord Elphinstone, both of whom promoted the ryotwari system in the provinces they governed; b) Political events, particularly the Mutiny of 1857, after which landlords were appeased by the British in areas affected by the Mutiny; c) Date of conquest, as areas colonized later were more likely to be free of middlemen due to existing precedents, changing historical preferences of policymakers, and the ability to take on the higher administrative costs of a cultivator based system; and d) A pre-existing landlord class, which would naturally render a region more likely to have a middleman based system during the colonial period.

Since these factors are not explicitly tested in Banerjee and Iyer (2005), we first examine the explanatory power of these factors using the following set of regressions:

$$
N M_{i}=\text { constant }+D_{i} \beta+\epsilon_{i}
$$

where $N M_{i}$ is the non-middleman proportion in district $i$ and $D_{i}$ is one or all of the aforementioned set of factors that we would like to test as determinants of institutional choice. The coding of these factors is

\footnotetext{
${ }^{16}$ This year fixed effect is excluded for our colonial period regressions, which use a single year cross-section.
} 
done as follows. For Thomas Munro, we assign a dummy variable to all districts in the Madras presidency which were under British control during the years $1819-1827$, the years of Thomas Munro's governorship ${ }^{17}$. Similarly, for Lord Elphinstone, we assign a dummy variable to all districts in the Bombay Presidency under British control at the time of Lord Elphinstone's governorship from $1853-1860^{18}$. For the Mutiny of 1857 we assign a dummy variable to each district affected by the Mutiny. Further, to check whether this effect is sensitive to support for the British by the native ruler, we assign two other dummy variables: the dummy "pro British" is assigned to districts where the native ruler actively assisted the British in quelling the revolt, and "against British" is assigned to the remaining districts affected by the Mutiny, where widespread action against the British met no resistance from, and in many cases was supported by, native rulers. Instead of date of conquest, we include years under colonial rule as our sample contains districts that were never conquered. For pre-existing landlord class we assign a dummy variable to all districts where the landlord system existed before the colonial period.

We first test each factor separately, and also test them jointly using Equation 1-3. In the joint specification, we do not include the "against British" and "pro British" dummies for districts affected by the Mutiny of 1857 . We then include these factors into our base specification, using the following:

$$
y_{i t}=\text { constant }+\alpha_{t}+\beta N M_{i}+D_{i} \delta+X_{i t} \gamma+\epsilon_{i t}
$$

where the additional set of controls, denoted by $D_{i}$, contains the historical factors we tested as determinants of non-landlord proportion using Equation 1-3. This includes dummies for Thomas Munro, Lord Elphinstone, the Mutiny of 1857 and pre-existing landlord class. Years of colonial rule is already included in our base set of controls. All other variables are defined as in Equation 1-1. In this specification $\beta$ captures the independent effect of the land revenue system as separate from the impacts of the political and historical factors that contributed to that choice of system.

\footnotetext{
${ }^{17} 33$ districts of the Madras Presidency had been administered under Thomas Munro, whereas 6 were brought under British administration after his governorship.

1819 districts of the province had been administered under Lord Elphinstone while 10 were brought under British control after his governorship.
} 


\section{5 Results}

\subsection{1}

\section{Impact of middlemen}

We find considerable differences in agricultural investments during the post-Independence period between areas with and without middlemen, as reported in Tables 1.3 and 1.4. Each cell represents a separate regression in the aforementioned tables. We see that in the post-Independence area (Table 1.3), areas that historically had a greater proportion of middlemen use significantly less fertilizer per acre and a significantly smaller percentage of HYV seeds in various crops. These results are not restricted to landlords. They hold, and even strengthen marginally, when we include other types of middlemen. This shows that the negative impacts of rent-seeking intermediaries is not restricted to cases where intermediaries own land.

Non-middleman areas have 56-percent greater fertilizer usage, as well as 45-percent more rice, 57-percent more wheat, and 46-percent more of other cereals under HYV. The magnitudes of the middleman effect decreases to 53-percent, 39-percent, and 46-percent for fertilizer, HYV rice, and HYV wheat respectively, when we restrict the definition of middlemen to include only landlords. In the case of other cereals, however, it increases to 51-percent.

Results of a comparable significance and magnitude are seen both in the full sample as well as in the British districts. In addition, the results are robust to using the binary indicator of non-middleman control. Regressions using the dummy variable for non-middleman districts show results of a comparable significance and magnitude to those using the continuous measure of non-middleman control. 
Table 1.3: Impact of middlemen on agricultural investments 1957-86

\begin{tabular}{|c|c|c|c|c|c|c|}
\hline \multirow[b]{2}{*}{$\begin{array}{l}\text { TYPE OF } \\
\text { MIDDLEMAN }\end{array}$} & \multicolumn{3}{|c|}{ FULL SAMPLE } & \multicolumn{3}{|c|}{ BRITISH DISTRICTS ONLY } \\
\hline & $\begin{array}{c}\text { Mean of } \\
\text { dependent } \\
\text { variable }\end{array}$ & $\begin{array}{l}\text { Coefficient } \\
\text { on non- } \\
\text { middleman } \\
\text { proportion } \\
\quad(1)\end{array}$ & $\begin{array}{c}\text { Coefficient } \\
\text { on Majority } \\
\text { dummy } \\
(2)\end{array}$ & $\begin{array}{c}\text { Mean of } \\
\text { dependent } \\
\text { variable }\end{array}$ & $\begin{array}{l}\text { Coefficient } \\
\text { on non- } \\
\text { middleman } \\
\text { proportion } \\
\quad(3)\end{array}$ & $\begin{array}{c}\text { Coefficient } \\
\text { on Majority } \\
\text { dummy } \\
(4)\end{array}$ \\
\hline \multicolumn{7}{|l|}{ Irrigation (\% area) } \\
\hline All middlemen & 0.243 & $\begin{array}{c}0.0327 \\
(0.0441)\end{array}$ & $\begin{array}{c}0.0451 \\
(0.0315)\end{array}$ & 0.292 & $\begin{array}{c}0.0148 \\
(0.0640)\end{array}$ & $\begin{array}{c}0.0380 \\
(0.0480)\end{array}$ \\
\hline Landlords & & $\begin{array}{c}0.0272 \\
(0.0395)\end{array}$ & $\begin{array}{c}0.0385 \\
(0.0292)\end{array}$ & & $\begin{array}{l}-0.00268 \\
(0.0551)\end{array}$ & $\begin{array}{c}0.0232 \\
(0.0439)\end{array}$ \\
\hline Observations & & 8576 & 8576 & & 5248 & 5248 \\
\hline \multicolumn{7}{|l|}{ Fertilizer use (kg/ha) } \\
\hline All middlemen & 20.07 & $\begin{array}{c}11.23^{* * *} \\
(4.075)\end{array}$ & $\begin{array}{c}9.627 * * * \\
(3.132)\end{array}$ & 23.97 & $\begin{array}{l}11.05 * * \\
(5.343)\end{array}$ & $\begin{array}{c}11.30 * * * \\
(4.096)\end{array}$ \\
\hline Landlords & & $\begin{array}{c}10.55^{* * *} \\
(3.679)\end{array}$ & $\begin{array}{c}9.143^{* * *} \\
(2.874)\end{array}$ & & $\begin{array}{l}11.14^{* *} \\
(4.719)\end{array}$ & $\begin{array}{c}11.43^{* * *} \\
(3.797)\end{array}$ \\
\hline Observations & & 8576 & 8576 & & 5248 & 5248 \\
\hline \multicolumn{7}{|l|}{ Rice (\% HYV) } \\
\hline All middlemen & 0.218 & $\begin{array}{c}0.0990^{* * *} \\
(0.0373)\end{array}$ & $\begin{array}{c}0.0868^{* * *} \\
(0.0261)\end{array}$ & 0.219 & $\begin{array}{c}0.168^{* * * *} \\
(0.0453)\end{array}$ & $\begin{array}{c}0.105^{* * *} \\
(0.0335)\end{array}$ \\
\hline Landlords & & $\begin{array}{c}0.0854^{* *} \\
(0.0337)\end{array}$ & $\begin{array}{c}0.0786^{* * *} \\
(0.0242)\end{array}$ & & $\begin{array}{c}0.144^{* * *} \\
(0.0418)\end{array}$ & $\begin{array}{c}0.0955^{* * *} \\
(0.0308)\end{array}$ \\
\hline Observations & & 8151 & 8151 & & 5238 & 5238 \\
\hline \multicolumn{7}{|l|}{ Wheat (\% HYV) } \\
\hline All middlemen & 0.500 & $\begin{array}{l}0.283^{* * *} \\
(0.0763)\end{array}$ & $\begin{array}{c}0.216^{* * *} \\
(0.0595)\end{array}$ & 0.470 & $\begin{array}{l}0.210^{* *} \\
(0.0877)\end{array}$ & $\begin{array}{l}0.201^{* * *} \\
(0.0638)\end{array}$ \\
\hline Landlords & & $\begin{array}{l}0.230 * * * \\
(0.0708)\end{array}$ & $\begin{array}{c}0.179 * * * \\
(0.0543)\end{array}$ & & $\begin{array}{c}0.123 \\
(0.0814)\end{array}$ & $\begin{array}{l}0.132^{* *} \\
(0.0623)\end{array}$ \\
\hline Observations & & 7674 & 7674 & & 4573 & 4573 \\
\hline \multicolumn{7}{|l|}{ Other cereals (\% HYV) } \\
\hline All middlemen & 0.174 & $\begin{array}{c}0.0797^{* *} \\
(0.0328)\end{array}$ & $\begin{array}{c}0.0400 \\
(0.0521)\end{array}$ & 0.192 & $\begin{array}{l}0.109 * * \\
(0.0532)\end{array}$ & $\begin{array}{c}0.0719 \\
(0.0928)\end{array}$ \\
\hline Landlords & & $\begin{array}{c}0.0896^{* * *} \\
(0.0300)\end{array}$ & $\begin{array}{c}0.0497 \\
(0.0462)\end{array}$ & & $\begin{array}{l}0.115^{* *} \\
(0.0484)\end{array}$ & $\begin{array}{c}0.0806 \\
(0.0822)\end{array}$ \\
\hline Observations & & 8396 & 8396 & & 5092 & 5092 \\
\hline Year fixed effects & & YES & YES & & YES & YES \\
\hline Colonial rule control & & YES & YES & & YES & YES \\
\hline Geographical controls & & YES & YES & & YES & YES \\
\hline
\end{tabular}


Table 1.4: Impact of middlemen on agricultural investments in 1904

\begin{tabular}{|c|c|c|c|c|c|c|}
\hline \multirow[b]{2}{*}{$\begin{array}{l}\text { TYPE OF } \\
\text { MIDDLEMAN }\end{array}$} & \multicolumn{3}{|c|}{ FULL SAMPLE } & \multicolumn{3}{|c|}{ BRITISH DISTRICTS ONLY } \\
\hline & $\begin{array}{l}\text { Mean of } \\
\text { dependent } \\
\text { variable }\end{array}$ & $\begin{array}{l}\text { Coefficient } \\
\text { on non- } \\
\text { middleman } \\
\text { proportion } \\
\quad(1)\end{array}$ & $\begin{array}{c}\text { Coefficient } \\
\text { on Majority } \\
\text { dummy } \\
(2)\end{array}$ & $\begin{array}{l}\text { Mean of } \\
\text { dependent } \\
\text { variable }\end{array}$ & $\begin{array}{l}\text { Coefficient } \\
\text { on non- } \\
\text { middleman } \\
\text { proportion } \\
\quad(3)\end{array}$ & $\begin{array}{c}\text { Coefficient } \\
\text { on Majority } \\
\text { dummy } \\
\text { (4) }\end{array}$ \\
\hline \multicolumn{7}{|l|}{ Irrigation (\% area) } \\
\hline All middlemen & 0.168 & $\begin{array}{c}0.000452 \\
(0.0284)\end{array}$ & $\begin{array}{r}-0.00647 \\
(0.0260)\end{array}$ & 0.176 & $\begin{array}{c}0.0232 \\
(0.0408)\end{array}$ & $\begin{array}{c}0.0489 \\
(0.0410)\end{array}$ \\
\hline Landlords & & $\begin{array}{l}-0.00851 \\
(0.0271)\end{array}$ & $\begin{array}{l}-0.0125 \\
(0.0248)\end{array}$ & & $\begin{array}{c}0.0101 \\
(0.0414)\end{array}$ & $\begin{array}{c}0.0375 \\
(0.0409)\end{array}$ \\
\hline Observations & & 281 & 281 & & 185 & 185 \\
\hline \multicolumn{7}{|l|}{$\begin{array}{l}\text { Agricultural loans per } \\
\text { capita (Rs.) }\end{array}$} \\
\hline All middlemen & 0.0384 & $\begin{array}{c}0.0294 \\
(0.0180)\end{array}$ & $\begin{array}{c}0.0134 \\
(0.0129)\end{array}$ & 0.0552 & $\begin{array}{c}0.0449 \\
(0.0280)\end{array}$ & $\begin{array}{c}0.0263 \\
(0.0235)\end{array}$ \\
\hline Landlords & & $\begin{array}{c}0.0285 \\
(0.0177)\end{array}$ & $\begin{array}{c}0.0129 \\
(0.0127)\end{array}$ & & $\begin{array}{c}0.0455 \\
(0.0281)\end{array}$ & $\begin{array}{c}0.0261 \\
(0.0232)\end{array}$ \\
\hline Observations & & 260 & 260 & & 174 & 174 \\
\hline Colonial rule control & & YES & YES & & YES & YES \\
\hline Geographical controls & & YES & YES & & YES & YES \\
\hline
\end{tabular}

Unlike the results from the contemporary period, we do not see impacts of colonial middlemen on agricultural investment in the historical period (Table 1.4), suggesting that the impact of this specific variation only manifested after the colonial period.

\subsection{2}

\section{Impact of settlement criteria}

Tables 1.5 and 1.6 show that the settlement criteria used to determine the amount of land revenue assessed significantly impacted investments in both the historical and contemporary period. Each column of Tables 1.5 and 1.6 represents one regression, and the reported coefficients on the various types of settlement criteria captures the impact of using that type of criteria.

We find that in the colonial period, areas using subjective criteria have 21-percent greater proportion of area under irrigation than areas not using these subjective criteria. However, such areas also suffer a significant disadvantage in agricultural loans, with 84-percent lower agricultural loans per capita. In our discussion section, we explore some potential reasons behind 
these seemingly contradictory patterns in areas using subjective criteria. Further significant results in the colonial period are seen for areas using objective criteria, which have a 46-percent lower proportion of irrigated area. This disadvantage also holds when the sample is restricted to British India.

In the post-Independence period, soil survey is the only type of criteria that appears to have a significant impact across various inputs, with a 16-percent advantage in irrigation, a 28-percent advantage in HYV rice and a 43-percent advantage in other HYV cereals. Objective criteria have largely negative impacts in this period as well as the colonial period, with a 21-percent, 22-percent, and 20-percent disadvantage in irrigation, fertilizer use, and HYV wheat, respectively. Apart from the significant effects described above, coefficients on soil survey for all our dependent variables are positive, and are negative for both subjective and objective criteria, showing very consistent patterns in the relationship between the different types of criteria and various inputs. Results restricted to British India are of slightly lower significance but follow these same general patterns. 


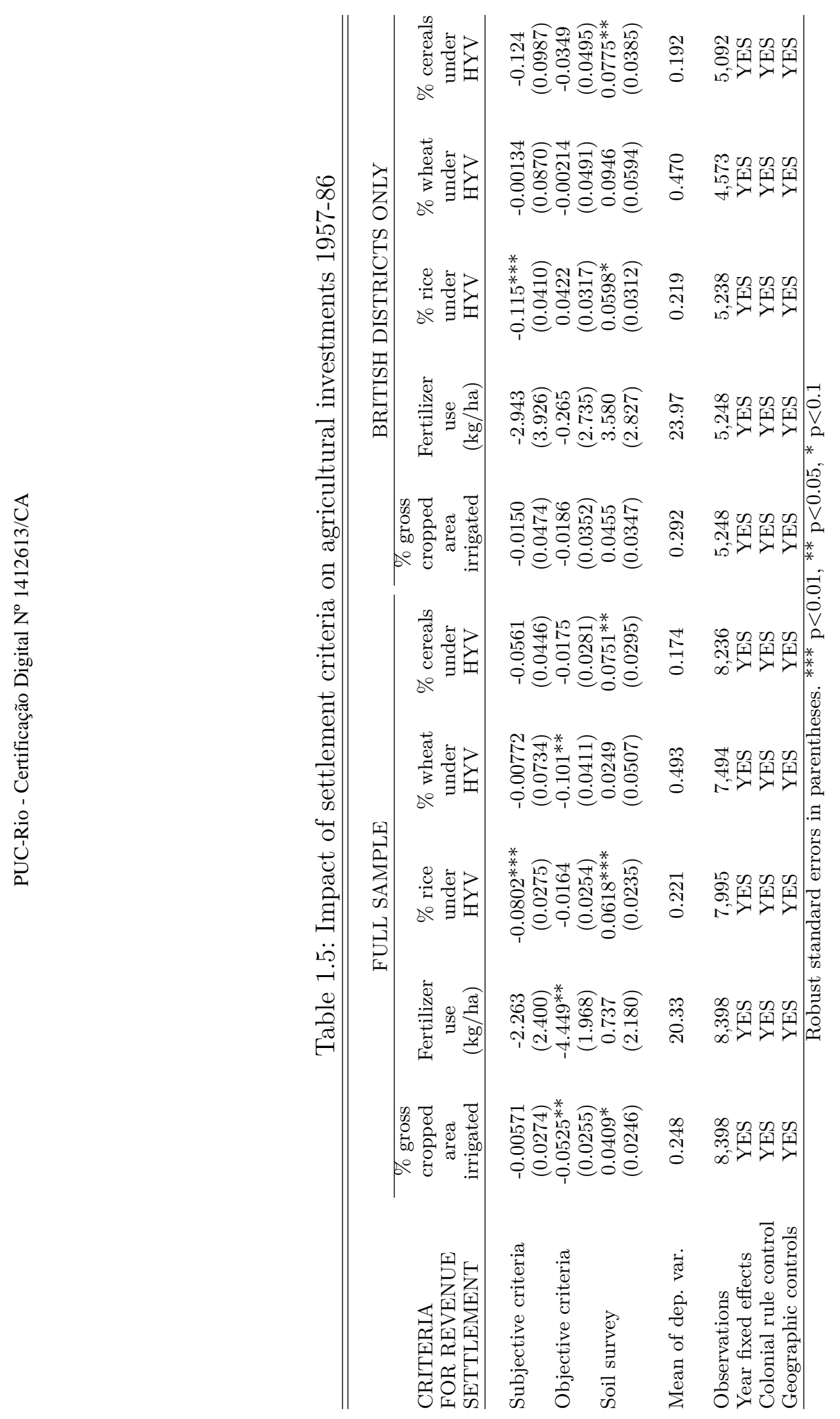


Table 1.6: Impact of settlement criteria on agricultural investments 1904

\begin{tabular}{|c|c|c|c|c|}
\hline \multirow[b]{2}{*}{$\begin{array}{l}\text { CRITERIA } \\
\text { FOR REVENUE } \\
\text { SETTLEMENT } \\
\end{array}$} & \multicolumn{2}{|c|}{ FULL SAMPLE } & \multicolumn{2}{|c|}{ BRITISH DISTRICTS ONLY } \\
\hline & $\begin{array}{c}\text { Irrigation } \\
\% \text { cultivated } \\
\text { area }\end{array}$ & $\begin{array}{l}\text { Agricultural } \\
\text { loans per } \\
\text { capita }\end{array}$ & $\begin{array}{c}\text { Irrigation } \\
\% \text { cultivated } \\
\text { area }\end{array}$ & $\begin{array}{l}\text { Agricultural } \\
\text { loans per } \\
\text { capita }\end{array}$ \\
\hline Subjective criteria & $\begin{array}{c}0.0362^{*} \\
(0.0211)\end{array}$ & $\begin{array}{c}-0.0328^{* *} \\
(0.0163)\end{array}$ & $\begin{array}{c}0.0230 \\
(0.0323)\end{array}$ & $\begin{array}{c}-0.0488 \\
(0.0295)\end{array}$ \\
\hline Objective criteria & $\begin{array}{c}-0.0774^{* * *} \\
(0.0215)\end{array}$ & $\begin{array}{c}-0.00952 \\
(0.00917)\end{array}$ & $\begin{array}{c}-0.0817^{* * *} \\
(0.0295)\end{array}$ & $\begin{array}{c}-0.000861 \\
(0.0147)\end{array}$ \\
\hline Soil survey & $\begin{array}{c}0.0130 \\
(0.0262)\end{array}$ & $\begin{array}{l}-0.00809 \\
(0.00868)\end{array}$ & $\begin{array}{c}0.0380 \\
(0.0330)\end{array}$ & $\begin{array}{c}0.0155 \\
(0.0156)\end{array}$ \\
\hline Mean of dep. var. & 0.170 & 0.0391 & 0.176 & 0.0552 \\
\hline Observations & 276 & 255 & 183 & 172 \\
\hline Colonial rule control & YES & YES & YES & YES \\
\hline Geographic controls & YES & YES & YES & YES \\
\hline
\end{tabular}

\subsection{3}

\section{Explaining institutional choice}

We find that the factors outlined in Banerjee and Iyer (2005) as likely determinants of institutional choice significantly affect the proportion of area under the control of middlemen. This holds both when the factors are tested separately (Table 1.7, Panel A) and when tested together (Table 1.7, Panel B). All the factors impact non-middleman proportion in the expected direction.

Individual administrators have a significant positive impact on non-landlord proportion, attesting to the reforming tendencies of these administrators. Districts administered by Lord Elphinstone as governor of Bombay Presidency had a 50-percent higher proportion of areas not under middlemen. A less clear effect is seen for Thomas Munro who governed Madras Presidency and was actually the first to introduce the cultivator based ryotwari system in India. We only find a significant positive impact for this administrator in the restricted sample limited to British areas. However, this may say less about the administrator and more about the relative difficulties of changing the landlord system in different regions. The greater variety of middlemen in the Bombay Presidency, in particular a lower proportion of hereditary landlords relative to revenue farmers ${ }^{19}$ may be why we see stronger effects for Lord Elphinstone than for Munro. Further, as the first to implement the ryotwari system, Munro may have had more formidable administrative and political barriers at hand.

The Mutiny of 1857, which is highlighted by Banerjee and Iyer (2005) as

\footnotetext{
${ }^{19}$ Revenue farming was particularly rife in that region under the rule of the pre-colonial Maratha kingdom and it may have been easier to do away with landowners holding temporary rights than to remove the hereditary landlords dominating other regions.
} 
Table 1.7: Factors impacting non-middleman proportion

\begin{tabular}{|c|c|c|c|c|}
\hline & \multicolumn{2}{|c|}{ Full sample } & \multicolumn{2}{|c|}{ British districts only } \\
\hline & $\begin{array}{l}\text { Non-middleman } \\
\text { proportion } \\
(1)\end{array}$ & $\begin{array}{l}\text { Non-landlord } \\
\text { proportion } \\
(2)\end{array}$ & $\begin{array}{l}\text { Non-middleman } \\
\text { proportion } \\
(3)\end{array}$ & $\begin{array}{c}\text { Non-landlord } \\
\text { proportion } \\
(4)\end{array}$ \\
\hline \multicolumn{5}{|l|}{ A: Tested separately } \\
\hline \multicolumn{5}{|l|}{ INDIVIDUALS } \\
\hline Thomas Munro & $\begin{array}{c}0.0261 \\
(0.0936)\end{array}$ & $\begin{array}{c}0.0280 \\
(0.0928)\end{array}$ & $\begin{array}{c}0.233^{* *} \\
(0.102)\end{array}$ & $\begin{array}{c}0.212^{* *} \\
(0.102)\end{array}$ \\
\hline Lord Elphinstone & $\begin{array}{l}0.209^{* *} \\
(0.0819)\end{array}$ & $\begin{array}{l}0.200^{* *} \\
(0.0822)\end{array}$ & $\begin{array}{l}0.310^{* * *} \\
(0.0884)\end{array}$ & $\begin{array}{l}0.312^{* * *} \\
(0.0870)\end{array}$ \\
\hline \multicolumn{5}{|l|}{ POLITICAL EVENTS } \\
\hline Mutiny of 1857 & $\begin{array}{r}-0.137^{* *} \\
(0.0573)\end{array}$ & $\begin{array}{r}-0.148^{* *} \\
(0.0574)\end{array}$ & $\begin{array}{l}-0.0788 \\
(0.0647)\end{array}$ & $\begin{array}{l}-0.0715 \\
(0.0641)\end{array}$ \\
\hline Against British & $\begin{array}{c}-0.203^{* * *} \\
(0.0536)\end{array}$ & $\begin{array}{c}-0.172^{* * * *} \\
(0.0542)\end{array}$ & $\begin{array}{l}-0.110^{*} \\
(0.0639)\end{array}$ & $\begin{array}{l}-0.0931 \\
(0.0628)\end{array}$ \\
\hline Pro British & $\begin{array}{c}0.0435 \\
(0.0599)\end{array}$ & $\begin{array}{c}0.0209 \\
(0.0599)\end{array}$ & $\begin{array}{c}0.102 \\
(0.145)\end{array}$ & $\begin{array}{c}0.176 \\
(0.157)\end{array}$ \\
\hline $\begin{array}{l}\text { PRE-EXISTING } \\
\text { LANDLORD CLASS }\end{array}$ & $\begin{array}{c}-0.425^{* * *} \\
(0.0403)\end{array}$ & $\begin{array}{c}-0.359 * * * \\
(0.0552)\end{array}$ & $\begin{array}{c}-0.281^{* * *} \\
(0.0529)\end{array}$ & $\begin{array}{c}-0.284^{* * *} \\
(0.0545)\end{array}$ \\
\hline $\begin{array}{l}\text { YEARS OF } \\
\text { COLONIAL RULE }\end{array}$ & $\begin{array}{c}-0.00119^{* * *} \\
(0.000375)\end{array}$ & $\begin{array}{c}-0.000916^{* * *} \\
(0.000338)\end{array}$ & $\begin{array}{c}-0.00282^{* * *} \\
(0.000774)\end{array}$ & $\begin{array}{c}-0.00244^{* * *} \\
(0.000735)\end{array}$ \\
\hline \multicolumn{5}{|l|}{ B: Tested together } \\
\hline Thomas Munro & $\begin{array}{c}0.164 \\
(0.101)\end{array}$ & $\begin{array}{c}0.138 \\
(0.0984)\end{array}$ & $\begin{array}{c}0.507 * * * \\
(0.0976)\end{array}$ & $\begin{array}{c}0.475^{* * *} \\
(0.0995)\end{array}$ \\
\hline Lord Elphinstone & $\begin{array}{c}0.335^{* * * *} \\
(0.0898)\end{array}$ & $\begin{array}{c}0.300^{* * *} \\
(0.0871)\end{array}$ & $\begin{array}{c}0.512^{* * * *} \\
(0.107)\end{array}$ & $\begin{array}{c}0.506^{* * *} \\
(0.105)\end{array}$ \\
\hline Mutiny of 1857 & $\begin{array}{c}-0.132^{* * *} \\
(0.0492)\end{array}$ & $\begin{array}{c}-0.142^{* * *} \\
(0.0527)\end{array}$ & $\begin{array}{c}-0.00152 \\
(0.0595)\end{array}$ & $\begin{array}{l}0.00600 \\
(0.0586)\end{array}$ \\
\hline Pre-existing landlord class & $\begin{array}{c}-0.381^{* * *} \\
(0.0450)\end{array}$ & $\begin{array}{c}-0.324^{* * *} \\
(0.0603)\end{array}$ & $\begin{array}{c}-0.259^{* * *} \\
(0.0522)\end{array}$ & $\begin{array}{c}-0.264^{* * *} \\
(0.0545)\end{array}$ \\
\hline Years of colonial rule & $\begin{array}{c}-0.00126^{* * *} \\
(0.000432)\end{array}$ & $\begin{array}{l}-0.00100^{* *} \\
(0.000390)\end{array}$ & $\begin{array}{c}-0.00331^{* * *} \\
(0.000777)\end{array}$ & $\begin{array}{c}-0.00288^{* * *} \\
(0.000741)\end{array}$ \\
\hline
\end{tabular}

being a key political event that influenced British policies towards landlords, also significantly affects the presence of middlemen. Districts impacted by the Mutiny, and particularly districts that took an anti-British approach, had a significantly lower proportion of non-middleman or non-landlord controlled areas, suggesting that landlords were appeased in politically unstable areas after the Mutiny. Districts affected by the Mutiny had a 33-percent lower proportion of areas not controlled by any middlemen. The magnitude of this effect rises to 49-percent when we consider only those districts that took an anti-British stance during the Mutiny.

Pre-existing landlord systems are unsurprisingly very telling in explaining the non-landlord proportion during the colonial period. Areas with a pre-existing landlord class had a 102-percent lower proportion of non-middleman areas. The magnitude of this impact was 84-percent in British areas. 
The number of years under colonial rule also had a significant, negative effect on non-middleman proportion, thus confirming that areas that were colonized later were more likely to have middlemen. Though each additional year has a relatively small (less than 1-percent) effect, this impact adds up when we consider the longevity of colonial rule in many parts of the country.

\section{5 .4}

\section{Controlling for determinants of institutional choice}

We continue to find a positive, significant impact of non-middleman areas on agricultural investments in the post-Independence period after adding the factors tested in the previous section as controls to our base specification. For the most part, our results increase in magnitude and significance after including these additional controls.

For example, in Table 1.8 we see a significant difference in irrigation between middlemen and non-middleman areas which was not present in Table 1.3. This increased significance suggests that one or more of our additional controls was a confounding variable negatively impacting the relationship between irrigation and non-middleman proportion. With the additional set of controls, we find that non-middleman districts have 44-percent greater area under irrigation in the post-Independence period than middleman regions.

The magnitude of some of our results from the post-Independence period also increase once we control for the institutional determinants. For example, the impact of non-middleman control increases from 56-percent to 88-percent on fertilizer use and from 56-percent to 79-percent on HYV wheat.

Our results from the colonial period continue insignificant after the addition of the institutional determinants (Table 1.9). 
Table 1.8: Middlemen and agricultural investments 1957-86

\begin{tabular}{|c|c|c|c|c|c|c|}
\hline \multirow[b]{2}{*}{$\begin{array}{l}\text { TYPE OF } \\
\text { MIDDLEMAN }\end{array}$} & \multicolumn{3}{|c|}{ FULL SAMPLE } & \multicolumn{3}{|c|}{ BRITISH DISTRICTS ONLY } \\
\hline & $\begin{array}{c}\text { Mean of } \\
\text { dependent } \\
\text { variable }\end{array}$ & $\begin{array}{l}\text { Coefficient } \\
\text { on non- } \\
\text { middleman } \\
\text { proportion } \\
\text { (1) }\end{array}$ & $\begin{array}{c}\text { Coefficient } \\
\text { on Majority } \\
\text { dummy } \\
(2)\end{array}$ & $\begin{array}{c}\text { Mean of } \\
\text { dependent } \\
\text { variable }\end{array}$ & $\begin{array}{l}\text { Coefficient } \\
\text { on non- } \\
\text { middleman } \\
\text { proportion } \\
(3)\end{array}$ & $\begin{array}{c}\text { Coefficient } \\
\text { on Majority } \\
\text { dummy } \\
(4)\end{array}$ \\
\hline \multicolumn{7}{|l|}{ Irrigation (\% area) } \\
\hline All middlemen & 0.243 & $\begin{array}{l}0.109 * * \\
(0.0433)\end{array}$ & $\begin{array}{c}0.0872^{* * *} \\
(0.0307)\end{array}$ & 0.292 & $\begin{array}{c}0.0869 \\
(0.0608)\end{array}$ & $\begin{array}{c}0.0722 \\
(0.0460)\end{array}$ \\
\hline Landlords & & $\begin{array}{c}0.0854^{* *} \\
(0.0395)\end{array}$ & $\begin{array}{c}0.0718^{* *} \\
(0.0290)\end{array}$ & & $\begin{array}{c}0.0480 \\
(0.0529)\end{array}$ & $\begin{array}{c}0.0482 \\
(0.0419)\end{array}$ \\
\hline Observations & & 8576 & 8576 & & 5248 & 5248 \\
\hline \multicolumn{7}{|l|}{ Fertilizer use $(\mathrm{kg} / \mathrm{ha})$} \\
\hline All middlemen & 20.07 & $\begin{array}{c}17.76^{* * *} \\
(4.158)\end{array}$ & $\begin{array}{c}12.52^{* * *} \\
(3.258)\end{array}$ & 23.97 & $\begin{array}{c}18.68^{* * *} \\
(5.644)\end{array}$ & $\begin{array}{c}14.88^{* * *} \\
(4.515)\end{array}$ \\
\hline Landlords & & $\begin{array}{c}15.13^{* * *} \\
(3.851)\end{array}$ & $\begin{array}{c}11.17^{* * *} \\
(3.038)\end{array}$ & & $\begin{array}{c}17.64^{* * *} \\
(5.091)\end{array}$ & $\begin{array}{c}14.73^{* * *} \\
(4.178)\end{array}$ \\
\hline Observations & & 8576 & 8576 & & 5248 & 5248 \\
\hline \multicolumn{7}{|l|}{ Rice (\%HYV) } \\
\hline All middlemen & 0.218 & $\begin{array}{c}0.0881^{* *} \\
(0.0412)\end{array}$ & $\begin{array}{c}0.0743^{* * *} \\
(0.0275)\end{array}$ & 0.219 & $\begin{array}{c}0.170 * * * \\
(0.0464)\end{array}$ & $\begin{array}{c}0.0819 * * \\
(0.0337)\end{array}$ \\
\hline Landlords & & $\begin{array}{c}0.0819 * * \\
(0.0347)\end{array}$ & $\begin{array}{c}0.0715^{* * *} \\
(0.0244)\end{array}$ & & $\begin{array}{c}0.146^{* * *} \\
(0.0400)\end{array}$ & $\begin{array}{c}0.0777^{* *} \\
(0.0301)\end{array}$ \\
\hline Observations & & 8151 & 8151 & & 5238 & 5238 \\
\hline \multicolumn{7}{|l|}{ Wheat (\% HYV) } \\
\hline All middlemen & 0.500 & $\begin{array}{c}0.397^{* * *} \\
(0.0851)\end{array}$ & $\begin{array}{c}0.262^{* * *} \\
(0.0628)\end{array}$ & 0.470 & $\begin{array}{c}0.172^{* * *} \\
(0.0561)\end{array}$ & $\begin{array}{c}0.148^{* * *} \\
(0.0379)\end{array}$ \\
\hline Landlords & & $\begin{array}{c}0.297^{* * *} \\
(0.0775)\end{array}$ & $\begin{array}{c}0.203^{* * *} \\
(0.0574)\end{array}$ & & $\begin{array}{c}0.0778 \\
(0.0629)\end{array}$ & $\begin{array}{c}0.0770 \\
(0.0474)\end{array}$ \\
\hline Observations & & 7674 & 7674 & & 4573 & 4573 \\
\hline \multicolumn{7}{|l|}{ Other cereals (\% HYV) } \\
\hline All middlemen & 0.174 & $\begin{array}{l}-0.0117 \\
(0.0643)\end{array}$ & $\begin{array}{l}-0.0133 \\
(0.0643)\end{array}$ & 0.192 & $\begin{array}{l}-0.0231 \\
(0.114)\end{array}$ & $\begin{array}{c}-0.00935 \\
(0.126)\end{array}$ \\
\hline Landlords & & $\begin{array}{c}0.0159 \\
(0.0541)\end{array}$ & $\begin{array}{l}0.00482 \\
(0.0560)\end{array}$ & & $\begin{array}{c}0.0121 \\
(0.0968)\end{array}$ & $\begin{array}{l}0.0124 \\
(0.110)\end{array}$ \\
\hline Observations & & 8396 & 8396 & & 5092 & 5092 \\
\hline Year fixed effects & & YES & YES & & YES & YES \\
\hline Geographical controls & & YES & YES & & YES & YES \\
\hline Institution determinants ${ }^{a}$ & & YES & YES & & YES & YES \\
\hline
\end{tabular}


Table 1.9: Middlemen and agricultural investments in 1904

\begin{tabular}{|c|c|c|c|c|c|c|}
\hline \multirow[b]{2}{*}{$\begin{array}{l}\text { TYPE OF } \\
\text { MIDDLEMAN }\end{array}$} & \multicolumn{3}{|c|}{ FULL SAMPLE } & \multicolumn{3}{|c|}{ BRITISH DISTRICTS ONLY } \\
\hline & $\begin{array}{c}\text { Mean of } \\
\text { dependent } \\
\text { variable }\end{array}$ & $\begin{array}{l}\text { Coefficient } \\
\text { on non- } \\
\text { middleman } \\
\text { proportion } \\
\text { (1) }\end{array}$ & $\begin{array}{c}\text { Coefficient } \\
\text { on Majority } \\
\text { dummy } \\
(2)\end{array}$ & $\begin{array}{c}\text { Mean of } \\
\text { dependent } \\
\text { variable }\end{array}$ & $\begin{array}{l}\text { Coefficient } \\
\text { on non- } \\
\text { middleman } \\
\text { proportion } \\
(3)\end{array}$ & $\begin{array}{c}\text { Coefficient } \\
\text { on Majority } \\
\text { dummy } \\
(4)\end{array}$ \\
\hline \multicolumn{7}{|l|}{ Irrigation (\% area) } \\
\hline All middlemen & 0.168 & $\begin{array}{c}0.0231 \\
(0.0301)\end{array}$ & $\begin{array}{l}0.00962 \\
(0.0269)\end{array}$ & 0.176 & $\begin{array}{c}0.0147 \\
(0.0413)\end{array}$ & $\begin{array}{c}0.0472 \\
(0.0383)\end{array}$ \\
\hline Landlords & & $\begin{array}{l}0.00680 \\
(0.0273)\end{array}$ & $\begin{array}{c}-0.000271 \\
(0.0248)\end{array}$ & & $\begin{array}{r}-0.00173 \\
(0.0421)\end{array}$ & $\begin{array}{c}0.0337 \\
(0.0387)\end{array}$ \\
\hline Observations & & 281 & 281 & & 185 & 185 \\
\hline \multicolumn{7}{|l|}{$\begin{array}{l}\text { Agricultural loans per } \\
\text { capita (Rs.) }\end{array}$} \\
\hline All middlemen & 0.0384 & $\begin{array}{c}-0.00625 \\
(0.0123)\end{array}$ & $\begin{array}{l}-0.00748 \\
(0.00911)\end{array}$ & 0.0552 & $\begin{array}{l}-0.00709 \\
(0.0217)\end{array}$ & $\begin{array}{l}-0.0121 \\
(0.0176)\end{array}$ \\
\hline Landlords & & $\begin{array}{c}-0.000944 \\
(0.0121)\end{array}$ & $\begin{array}{l}-0.00402 \\
(0.00908)\end{array}$ & & $\begin{array}{l}-0.00376 \\
(0.0219)\end{array}$ & $\begin{array}{l}-0.00947 \\
(0.0177)\end{array}$ \\
\hline Observations & & 260 & 260 & & 174 & 174 \\
\hline Geographical controls & & YES & YES & & YES & YES \\
\hline Institution determinants ${ }^{a}$ & & YES & YES & & YES & YES \\
\hline
\end{tabular}

\section{6}

\section{Discussion}

\subsection{1}

Interpretation of results

Our results indicate significant differences in agricultural investment between regions varying in the land revenue institution. While the settlement criteria impacts agricultural investment in both the colonial and the post-Independence period, the presence of middlemen has impacts that only manifest after Independence. The emergence of new impacts through an additional channel after the abolition of the land revenue system attests not only to the persistence of institutional choice but also to the possibility that institutional variations can lead to disparities that increase rather than diminish with time. 


\subsection{2 \\ Impacts of settlement criteria}

The impacts of the settlement criteria begin in the colonial period, with an early irrigation advantage for regions using subjective criteria as the basis of land revenue settlement. Though these settlement criteria were often arbitrary and inequitable, favoring upper caste landlords over lower caste peasants, they were predictable. In a criterion like old rent rolls, there was little annual variation in the relative amounts paid by different cultivators. There was even less variation when using Permanent Settlement, as under this system the landlord was promised a revenue rate in perpetuity. Furthermore, Permanent Settlement revenue rates were usually quite low, leaving a bulk of the rents - often as high as eighty or ninety percent - with the landlords. The predictability of revenue rates under systems such as this thus provided the impetus for investment in productivity, such that the cultivator would be guaranteed to pocket the bulk of residual profits resulting from productivity gains.

The same reasoning explains the absence of an advantage for soil surveys in the colonial period. While in the post-Independence period soil surveys gain an advantage in several of the inputs we consider, including in irrigation, in the colonial period, soil surveys have an insignificant impact on irrigation. This may be because of differential rates for irrigated and unirrigated lands in some areas, leaving little scope for residual profits to accrue to investors. A farmer investing in irrigation would have to pay a higher rate of revenue if future surveys judged his land to be more productive, thus cancelling out the gains from investing in productivity. This explains why we would see a market lack of effect of soil surveys in the colonial period.

However, in the contemporary period, once the removal of agricultural land tax ensured that farmers in these regions did stand to receive the additional profits from any productivity gains, soil survey takes on an advantage in several inputs. The source of this advantage could lie in better information. as farmers in these regions would be better acquainted with the productivity potential of their lands. Additionally, the past soil surveys provided documentation to accord a legal basis for the secure rights of cultivators, who no longer had to fear losing the gains from increased productivity through a higher revenue rate. We believe these two factors better information and increased security of tenure - are behind the positive impact we see in the post-Independence period for areas historically settled using soil surveys.

Perhaps a little surprisingly, we see disadvantages in both colonial and 
post-Independence periods for objective criteria. This is likely driven by the criteria topography, which was most often used where mountainous regions bordered plains or valleys - - the hill-dwelling communities would be charged a lower revenue rate, whereas those inhabiting fertile valleys would be charged a higher rate. Even though we control for each district's geographical features, including altitude, we do not have a measure of the variance of geographical conditions within the district, which may be associated with this criteria and which may also serve as a long-run impediment to investment in agricultural productivity.

Finally, it is worth noting the seemingly contradictory pattern we see in colonial period agricultural loans in areas using subjective criteria. While these regions have a significant advantage in irrigation, they significantly lag behind in agricultural loans per capita. We believe that this may be partially explained by the fact that subjective criteria relied on preserving a long held status quo based on some subjective perception of revenue officers. Borrowing from the state to invest in productivity could have changed the state's expectations regarding productivity in these regions, which could have led to this pattern we see, where investors are investing, but not using available state funds. Furthermore, sometimes agricultural loans were used as a form of famine relief. In this capacity, areas with subjective criteria would be particularly unlikely to receive loans, as they already benefitted from low rates.

Overall, settlement criteria appear to matter in the colonial period insomuch as they determined the amount of residual profits from productivity gains, paradoxically yielding an advantage to criteria which imposed arbitrary rates that remained relatively constant over time. Meanwhile, scientific criteria that frequently adjusted revenue rate to the productivity of the soil discouraged investment by cancelling out the potential gains of investment. However we see these patterns change once land revenue is abolished and cultivators stand to reap the full benefits of investments in agricultural productivity. For reasons such as better information and more secure rights, the advantage in this period belongs squarely to areas formerly settled using soil surveys.

\subsection{3}

\section{Impacts of agricultural middlemen}

We find that the effects of the middleman channel only manifest after the colonial period. One reason for this delayed impact may lie in increased returns to investment due to the removal of all taxation on agricultural land. While the return to investment increased across the board upon Independence, it is possible that it was particularly marked for non-middleman regions. 
Table 1.10: Differences in colonial revenue burden

\begin{tabular}{lcccc}
\hline \hline & Mean & Standard deviation & Difference $^{a}$ & $\begin{array}{c}\text { Standard error } \\
\text { of difference }\end{array}$ \\
\hline Land revenue burden per capita & & & & \\
in 1901 & 0.619 & 6.896 & 0.599 & 0.911 \\
in 1891 & 0.0131 & 0.00935 & $0.00520^{* * *}$ & 0.00119 \\
in 1881 & $1.39 \mathrm{e}-05$ & $9.93 \mathrm{e}-06$ & $6.19 \mathrm{e}-06^{* * *}$ & $1.30 \mathrm{e}-06$ \\
\hline Total revenue burden per capita & & & \\
in 1901 & 0.0245 & 0.0188 & $0.00484^{*}$ & 0.00241 \\
in 1891 & 0.211 & 0.0138 & $0.00669^{* * *}$ & 0.00168 \\
in 1881 & 0.0196 & 0.0131 & $0.00702^{* * *}$ & 0.00175 \\
\hline $\begin{array}{l}a \\
\text { Difference represents the average difference between non-middleman and middleman districts, }\end{array}$ \\
computed as the regression coefficient on the non-landlord proportion
\end{tabular}

As Table 1.10 shows, in the colonial period, non-middleman regions paid significantly more revenue per capita than regions with middlemen, thus the removal of revenue would have been especially beneficial in the non-middleman regions. Apart from the relatively lower benefit from the removal of state revenue, cultivators in many middleman regions continued to suffer from rent extraction under landlords, thus the return to investment would not have risen as dramatically for cultivators in these regions.

However, if a differential increase in the return to investment alone explained the results, we would see the divergence begin at Independence, when land revenue was abolished. Banerjee and Iyer (2005) find that the landlord impacts in the post-Independence period really emerge after 1965. The reason for the timing of this divergence might have to do with two policies in post-Independence India, namely land reform and the Green Revolution.

Ironically, it may have been land reform, which intended to eliminate the inequalities associated with the landlord system, that created the basic conditions for the divergence between middlemen and non-middleman regions to emerge. Land reform in India took the form of a considerable body of legislation, the largest in the world to have been passed in such a short period of time in any country (Thorner 1976). The 1949 Constitution left the topic of land reforms to individual states, which resulted in considerable heterogeneity in the passing and implementation of legislation across the country in the decades after Independence (Besley and Burgess 2000; Ghatak and Roy 2007). As pointed out by Banerjee and Iyer (2005), states with a higher proportion of landlords before Independence tended to place a greater emphasis on land reform by enacting land reform legislation. The heterogeneity of land reforms in the post-Independence period thus had its roots in the presence of agricultural middlemen during the colonial period.

Even within states that implemented a high level of reform, there was considerable heterogeneity in the implementation of reform. In a few states 
with socialist leanings, considerable success was achieved in reducing the power of landlords and redistributing land to the rural landless. In most other landlord dominated states, however, landowners continued to wield political power and influence. Though legislation was passed, it was not robustly executed due to lack of political will (Planning Commission 1973). In some such states, fraudulent land transfers allowed landholders to circumvent land ceiling laws and continue rent-seeking through informal arrangements (Guha 2007). In places where tenancy reform was implemented, land inequality paradoxically increased, suggesting that landlords were engaging in anticipatory eviction (Ghatak and Roy 2007), thereby defeating the purpose of the legislation. Thus, land reform efforts succeeded in some places and failed to achieve results in others.

Based on the legislation and implementation of land reform, states can be classified under three main categories: those with a low level of reform; those with a high level of reform where reform failed; and those with a high level of reform that was successful. Both categories of high reform states had a considerable proportion of middlemen in the past, thus necessitating reform. We argue that regardless of the success or failure of land reform efforts, formerly middleman dominated, high reform states had a distinct disadvantage vis-a-vis non-middleman, low reform states when it came to agricultural investments in the post-Independence period. This disadvantage played out in both public policy priorities and private investment incentives, as shown by Figure 1.2. 


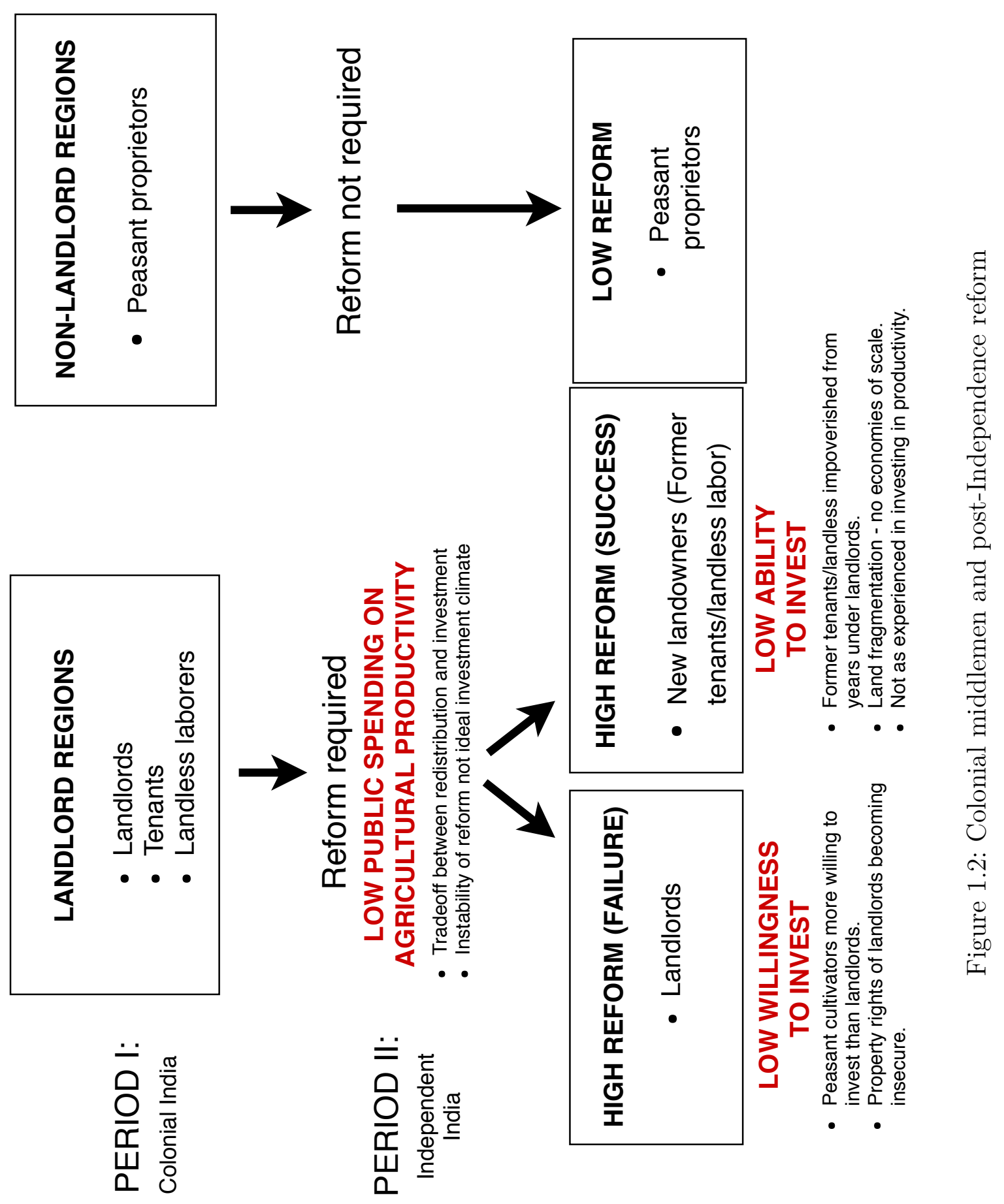


States which were historically dominated by middlemen prioritized redistributive land reform at the cost of public investment in agricultural productivity, whereas the historically non-middleman states were able to prioritize public investment in productivity. Figure 1.3 shows that high-reform states $^{20}$ spent less public money on capital investments in agriculture than low-reform states. Banerjee and Iyer (2005) argue that the distinct public spending priorities in landlord vs. non-landlord states can be attributed to a difference in the nature of collective action between these states. Masses in landlord areas may have perceived their interests as opposed to that of the local elite, while those in non-landlord areas would have been more interested in working with the elite. Thus, the political environment in landlord areas is one marked by class conflict, whereas in non-landlord regions, a more cooperative environment, conducive to expenditure in beneficial public goods, would have been found. While we believe that the class dynamics described above probably played a potent role in determining political priorities, particularly given the longevity of landlord influence in some of the regions being studied, there are also other reasons why landlord regions would prioritize redistribution over public investment in agricultural productivity.

In theory, redistribution and investment in productivity should be complementary policies, as public investment in agricultural infrastructure, technology and extension services would make redistributed land more valuable (Banerjee 2000). However, in practice, these two policies might behave like substitutes. A widespread push to improve agricultural productivity in a developing world setting is costly. Apart from the cost of research and investment in public goods, an institutional framework is required to deliver the benefits of the technology to small-scale, undereducated farmers. Land reforms also consist of a costly process, requiring considerable legislative, administrative and physical resources, thus directly impacting the resources available for public investment in the agriculture sector.

Furthermore, the process of land reform, regardless of whether it fails or succeeds, creates a considerable amount of uncertainty in the overall

\footnotetext{
${ }^{20}$ In classifying states as high or low reform, we used Besley and Burgess's (2000) classification system, which considers states that have passed three or more land reform legislations (of any type) during the period 1958-1992 as high reform states. Under this classification the following states are considered "Low reform": Andhra Pradesh, Assam, Haryana, Jammu and Kashmir, Madhya Pradesh, Maharashtra, Punjab, and Rajasthan. The following states are "High reform" states according to this classification scheme: Bihar, Gujarat, Karnataka, Kerala, Orissa, Tamil Nadu, Uttar Pradesh, and West Bengal. We further classified the latter category into states where land reform was successful and those where it was not. Since only Kerala and Bengal are widely considered to be success stories of land reform (Ghatak and Roy 2007), the category of "high reform (success)" states is made up of these two states, whereas all remaining states with more than three land reform legislations between 1958-1992 are classified as "high reform (failure)".
} 


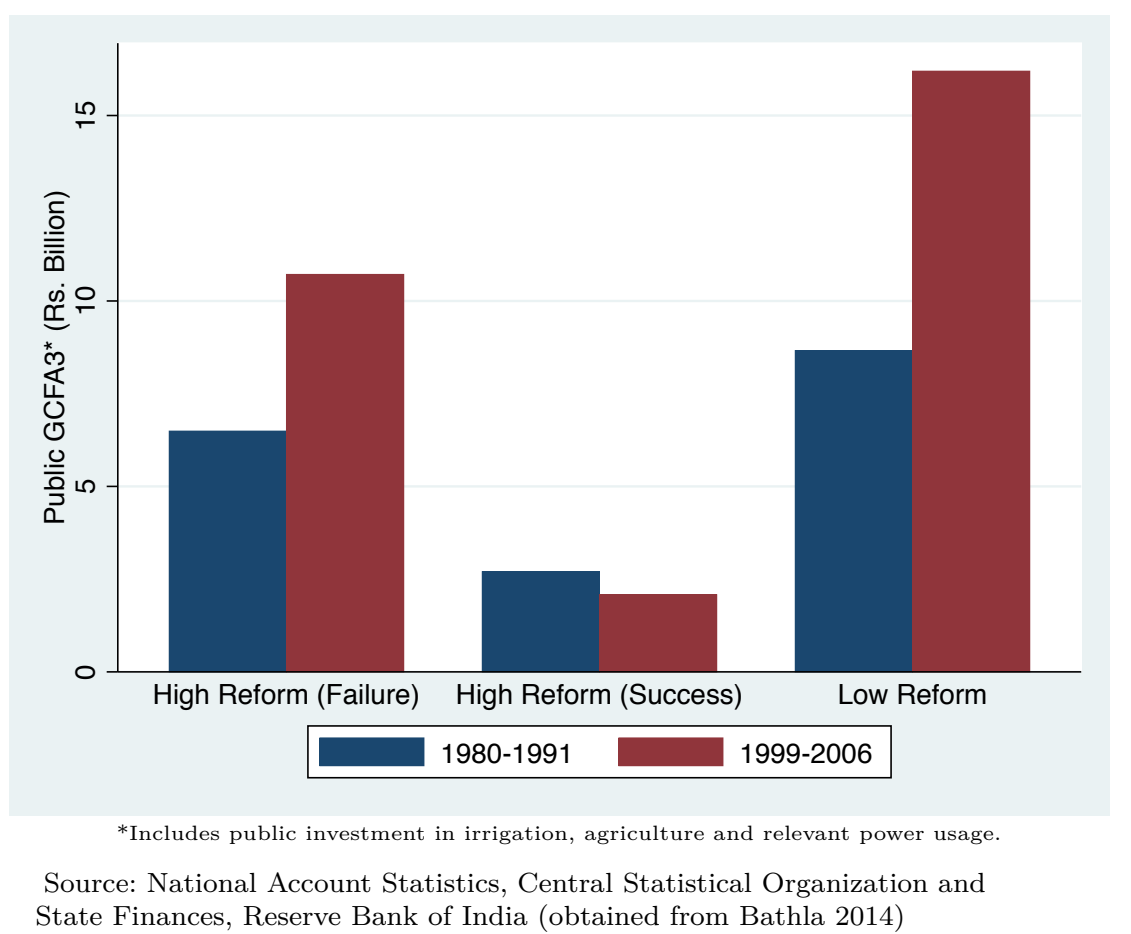

Figure 1.3: Public gross fixed capital formation in agriculture

economic environment. This is perhaps especially true in a place like India where the justice system is slow and where legal disputes over land can go on for decades. In the meanwhile, there is much scope for intimidation and informal arrangements in the land market, which remains in flux till reforms are definitively completed. Therefore, regions where redistribution is underway do not make ideal candidates for public investment.

In such settings, public investments come with considerable uncertainty whereas redistribution is a topic that easily raises passions and thus garners votes from political constituents. For these reasons, it is not surprising that regions with a legacy of landlords and land inequality would focus their efforts first on redistribution and only secondarily on creating public assets in the agriculture sector. This is the case partly because it makes logical sense to implement the two policies in this order if they cannot be implemented simultaneously, and partly because short-sighted politicians prefer to involve themselves in the political hot-topic of redistribution (or lack thereof, in the case of politicians who represent the interests of landowners). Focusing efforts on redistribution appears to be a more successful election strategy rather than spending resources and effort on uncontroversial but expensive capital investments which take years to reap benefits, and come with considerable uncertainty. Thus it is unsurprising that we should see a divergence emerge between states dominated by middlemen and those under individual cultivators, with a redistributive agenda dominating public 
investments into productivity in the former category.

Apart from differences in public priorities, land reform also created the conditions for a divergence in the private investment structures of middleman and non-middleman regions. In states where land reforms failed to achieve redistribution, agricultural investment decisions were made primarily by the landlords who dominated the agricultural sector. Compared to these landlords, farmers in low reform, non-middleman states, who tilled the land with their own and family labor had much greater incentives to put in effort and invest in productivity, the theoretical case for which is shown in Banerjee (2007). As further pointed out by Banerjee (2000), people hold on to ownership of land for reasons other than making money, particularly in rural societies where land can serve as a source of political power and social prestige. This certainly holds for India, where the little mobility offered by a rigid caste system is associated with land ownership. This being the case, one would expect that the productivity of the land is not the primary concern of the large landowner, who is therefore, less likely to invest in it than a farmer who makes his living off the land. Landlords' interest in long-term improvement would have been even further reduced due to the dilution of their property rights by land reforms. Where landlords managed to hold on to land through fraudulent or informal means, their inability to appeal to the court systems compounded the uncertainty of their landholdings, making them less likely to invest in their lands.

Meanwhile, in formerly landlord-dominated states where land reform was successful in its redistributive agenda, control of land passed into the hands of a rural underclass impoverished by decades under rent-seeking landlords. Compared to farmer-cultivators in the low reform states, who had been tilling their own land for generations, these new landowners had neither the means to invest in their lands nor the experience of the colonial period to help them navigate the bureaucratic government system to access agricultural loans and other resources. Furthermore, the scale of redistributed land was often more appropriate for subsistence farming, leaving their owners with few options for capital improvement. For example, Kerala, which was one of the leading states in land reform implementation, saw agriculture becoming a relatively low-profit venture over time due to the extreme fragmentation of land (Krishnakumar 2004).

Figures 1.4 and 1.5 show evidence for these patterns in private investments using state-level data. As can be seen from these figures, private investment in agriculture was greatest in states with a low level of land reform. Similarly, as Figure 1.6 shows using district-level data aggregated by states, this pattern is reflected in the utilization of agricultural credit by rural households 


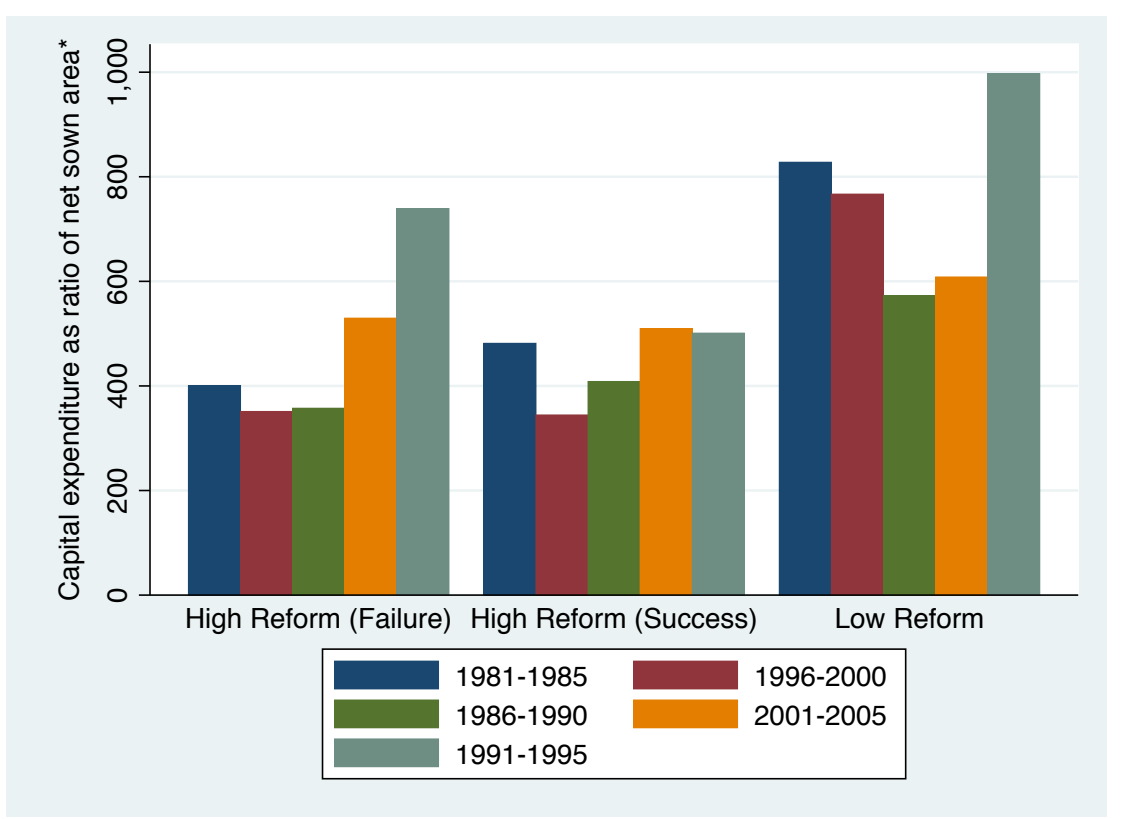

Source: Reserve Bank of India (obtained from Singh 2014)

Figure 1.4: Average capital expenditure as a ratio of net sown area

as recently as 2011. Both categories of high reform states, those where reform was successful and those where it was not, lag behind low reform states in these various indicators of private agricultural investment, with the pattern holding for decades after land reform was first initiated.

Overall, where land reforms failed there was a lower willingness to invest, and where they succeeded, a lower ability to do so. This pattern of investment is compatible with the theory presented in Banerjee (2000), which outlines how incentive effects cause decreasing returns to scale while technological factors cause increasing returns to scale. The advantage thus went to farmers in the low reform regions where the state had historically dealt directly with individuals, be these peasant proprietors or tenants with long-term occupancy rights. Compared to landlords, they had stronger long-term incentives to invest in their land. And compared to formerly landless cultivators receiving recently redistributed land, they had economical plots of land and the experience of dealing with the government to access agricultural resources. Therefore, due to a higher willingness and ability to invest in land, farmers in formerly non-middleman, low-reform states were the ones that were best placed to enjoy the additional returns to investment and increased government resources available after Independence. Table 1.11 shows that the interaction between low reform and non-landlord areas has positive, significant impacts on fertilizer use, irrigation, and area under HYV wheat cultivation, thus suggesting that the policy of reform interacted with the institutional variation from the previous period to create the conditions leading to a divergence between different areas 


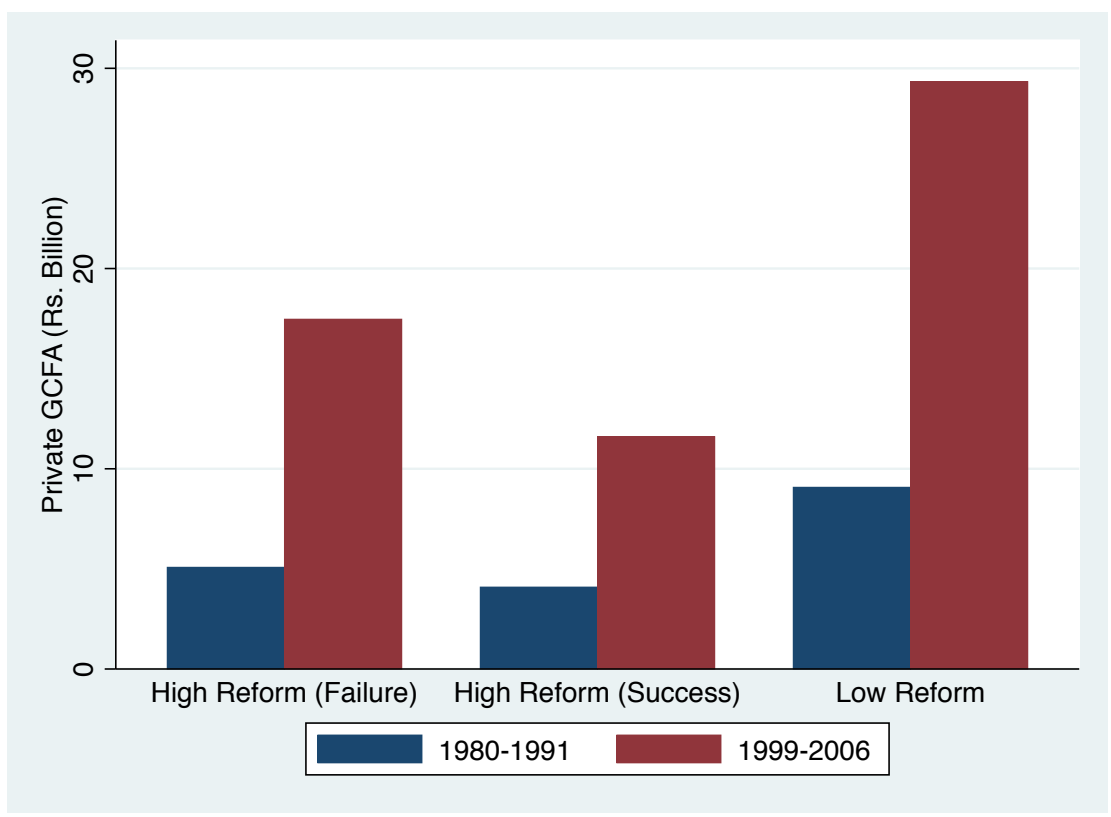

Source: National Account Statistics, Central Statistical Organization and State Finances, Reserve Bank of India (obtained from Bathla 2014)

Figure 1.5: Private gross fixed capital formation in agriculture

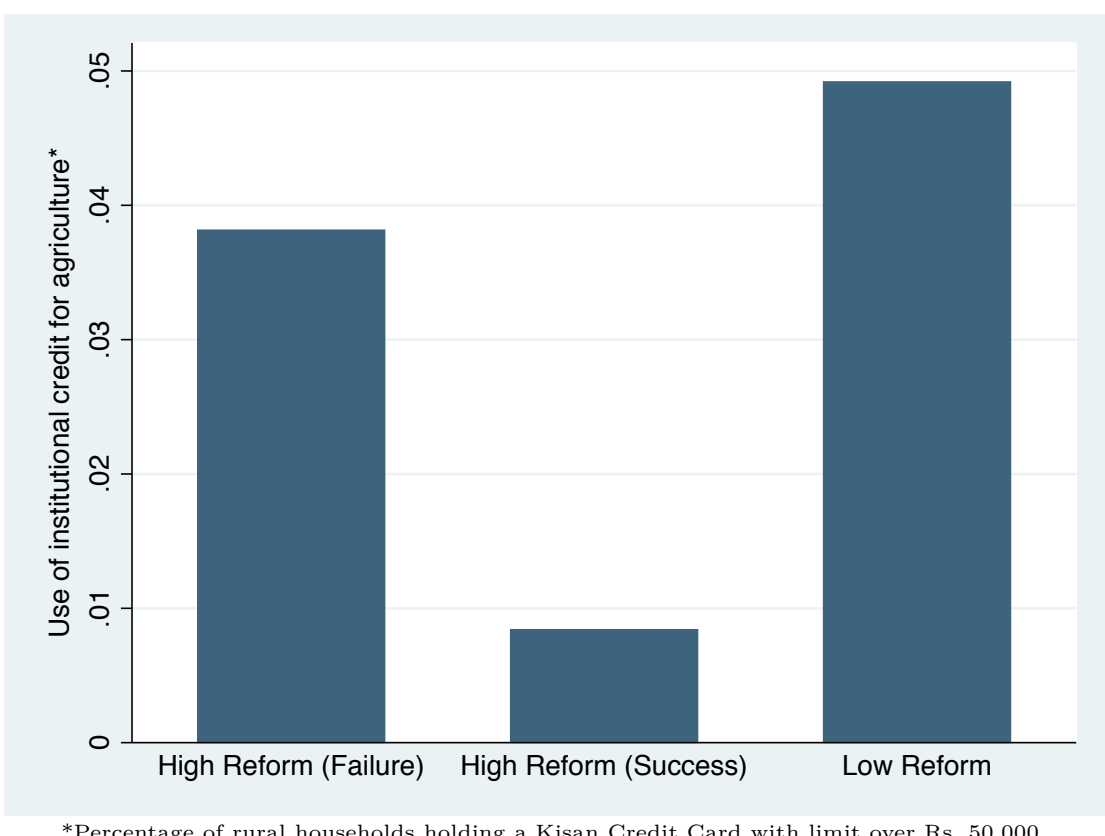

Source: Socio Economic Caste Census, 2011

Figure 1.6: Agricultural credit utilization in 2011 
in the post-Independence period.

Thus, for the reasons outlined above and in Figure 1.2, the public priorities and private incentives prevalent in formerly non-middleman and middleman dominated regions led to diverging patterns of investment in agriculture. These disparities were further widened by the concentrated impetus towards adoption of new agricultural technology, which we discuss in the next sub-section.

\subsection{4}

\section{New technology and widening divergence}

In the 1960s a serious famine combined with US policies limiting food aid to India led to an increased urgency towards the goal of higher agricultural productivity and self-sufficiency in food grains. This created the impetus for the Green Revolution in India, which was introduced nationally but was widely adopted only in a few, limited pockets of the country. Apart from a push to overhaul agricultural bureaucracy and improve credit distribution and extension services, the central government launched programs directed towards the diffusion of HYV seeds in India. A massive public information campaign targeting radio, press, and cinema was launched to spread knowledge about the benefits of HYV seeds. Land extension officers and agricultural scientists carried out an extensive seed demonstration campaign, developing model farms to show farmers the benefits of the new seeds. Early adopters of HYV seeds were even guaranteed compensation if the seeds did not lead to a bumper crop as promised (Sandhu 2014; Parayil 1992).

Despite this national push, only a few regions widely adopted the technology in its early phases. In particular, farmers in the states of Punjab and Haryana in the northwestern plains of India enthusiastically embraced the new technology. In a matter of two decades, agriculture in these states was transformed to a modern, profitable, and market-oriented enterprise, playing a big role in helping the nation reach self-sufficiency in food grains. The natural question then is, why these regions? What about them made them so receptive to the new technology?

Some scholars attribute the adoption of technology by these states to scale. States like Punjab had a large proportion of relatively larger farms which facilitated access to credit and were better suited towards mechanization (Krishnaji 1975; Sandhu 2014). Meanwhile, small scale farmers in the eastern regions of India did not have enough capital for the irrigation that was quite essential to the success of many new HYV varieties (Fujita 2009). Other explanations for why certain areas were better suited to adopt the new form of 
Table 1.11: Land reforms and agricultural investments 1957-86

\begin{tabular}{|c|c|c|c|c|}
\hline & \multicolumn{2}{|c|}{ Full sample } & \multicolumn{2}{|c|}{ British districts only } \\
\hline & $\begin{array}{l}\text { Coefficient } \\
\text { on non- } \\
\text { middleman } \\
\text { proportion } \\
(1)\end{array}$ & $\begin{array}{l}\text { Coefficient } \\
\text { on Majority } \\
\text { dummy } \\
(2)\end{array}$ & $\begin{array}{l}\text { Coefficient } \\
\text { on non- } \\
\text { landlord } \\
\text { proportion } \\
(3) \\
\end{array}$ & $\begin{array}{c}\text { Coefficient } \\
\text { on Majority } \\
\text { dummy } \\
(4)\end{array}$ \\
\hline \multicolumn{5}{|l|}{ Irrigation (\% cropped area) } \\
\hline Non-landlord & $\begin{array}{c}-0.0618 \\
(0.0458)\end{array}$ & $\begin{array}{c}-0.0306 \\
(0.0384)\end{array}$ & $\begin{array}{c}-0.0929 \\
(0.0644)\end{array}$ & $\begin{array}{l}-0.0265 \\
(0.0555)\end{array}$ \\
\hline Low reform & $\begin{array}{c}-0.129 * * * \\
(0.0353)\end{array}$ & $\begin{array}{c}-0.108^{* * *} \\
(0.0321)\end{array}$ & $\begin{array}{c}-0.154^{* * *} \\
(0.0494)\end{array}$ & $\begin{array}{c}-0.125^{* * *} \\
(0.0455)\end{array}$ \\
\hline Non-landlord $\times$ Low reform & $\begin{array}{c}0.142^{* *} \\
(0.0579)\end{array}$ & $\begin{array}{c}0.0935^{* *} \\
(0.0461)\end{array}$ & $\begin{array}{l}0.172^{* *} \\
(0.0855)\end{array}$ & $\begin{array}{c}0.0905 \\
(0.0740)\end{array}$ \\
\hline \multicolumn{5}{|l|}{ Fertilizer usage $(\mathrm{kg} / \mathrm{Ha})$} \\
\hline Non-landlord & $\begin{array}{c}4.183 \\
(4.625)\end{array}$ & $\begin{array}{c}4.473 \\
(3.830)\end{array}$ & $\begin{array}{c}8.518 \\
(6.432)\end{array}$ & $\begin{array}{l}9.167^{*} \\
(5.425)\end{array}$ \\
\hline Low reform & $\begin{array}{c}-10.97^{* * *} \\
(2.811)\end{array}$ & & $\begin{array}{c}-10.76^{* * *} \\
(3.947)\end{array}$ & $\begin{array}{c}-9.580^{* * *} \\
(3.573)\end{array}$ \\
\hline Non-landlord $\times$ Low reform & $\begin{array}{c}9.804^{*} \\
(5.484)\end{array}$ & $\begin{array}{c}5.975 \\
(4.464)\end{array}$ & $\begin{array}{c}5.982 \\
(7.301)\end{array}$ & $\begin{array}{c}4.196 \\
(6.266)\end{array}$ \\
\hline \multicolumn{5}{|c|}{ Rice under HYV (\% cropped area) } \\
\hline Non-landlord & $\begin{array}{l}0.0800^{*} \\
(0.0427)\end{array}$ & $\begin{array}{c}0.0875^{* *} \\
(0.0358)\end{array}$ & $\begin{array}{c}0.0950 \\
(0.0582)\end{array}$ & $\begin{array}{l}0.0915^{*} \\
(0.0496)\end{array}$ \\
\hline Low reform & $\begin{array}{c}0.0899^{* *} \\
(0.0372)\end{array}$ & $\begin{array}{c}0.103^{* * *} * \\
(0.0357)\end{array}$ & $\begin{array}{c}0.118^{* *} \\
(0.0466)\end{array}$ & $\begin{array}{c}0.145^{* * *} \\
(0.0515)\end{array}$ \\
\hline Non-landlord $\times$ Low reform & $\begin{array}{c}0.0278 \\
(0.0543)\end{array}$ & $\begin{array}{l}0.00381 \\
(0.0478)\end{array}$ & $\begin{array}{c}0.0619 \\
(0.0670)\end{array}$ & $\begin{array}{l}0.00355 \\
(0.0676)\end{array}$ \\
\hline \multicolumn{5}{|c|}{ Wheat under $H Y V$ (\% cropped area) } \\
\hline Non-landlord & $\begin{array}{c}0.0297 \\
(0.113)\end{array}$ & $\begin{array}{c}-0.0388 \\
(0.0936)\end{array}$ & $\begin{array}{c}-0.274^{* * *} \\
(0.0915)\end{array}$ & $\begin{array}{c}-0.188^{* *} \\
(0.0884)\end{array}$ \\
\hline Low reform & $\begin{array}{c}-0.279^{* * *} * \\
(0.0690)\end{array}$ & $\begin{array}{c}-0.275^{* * *} \\
(0.0650)\end{array}$ & $\begin{array}{c}-0.116^{* *} \\
(0.0523)\end{array}$ & $\begin{array}{l}-0.0827 \\
(0.0504)\end{array}$ \\
\hline Non-landlord $\times$ Low reform & $\begin{array}{c}0.320^{*} \\
(0.184)\end{array}$ & $\begin{array}{c}0.309^{* *} \\
(0.145)\end{array}$ & $\begin{array}{c}0.651^{* * *} \\
(0.207)\end{array}$ & $\begin{array}{c}0.553^{* * *} \\
(0.176)\end{array}$ \\
\hline \multicolumn{5}{|c|}{ Other Cereals under HYV (\% cropped area) } \\
\hline Non-landlord & $\begin{array}{c}0.150^{* * *} \\
(0.0512)\end{array}$ & $\begin{array}{l}0.113^{* *} \\
(0.0451)\end{array}$ & $\begin{array}{c}0.0653 \\
(0.105)\end{array}$ & $\begin{array}{c}0.0544 \\
(0.0849)\end{array}$ \\
\hline Low reform & $\begin{array}{l}0.145^{* *} \\
(0.0624)\end{array}$ & $\begin{array}{l}0.144^{* *} \\
(0.0678)\end{array}$ & $\begin{array}{c}0.145^{*} \\
(0.0755)\end{array}$ & $\begin{array}{c}0.154 \\
(0.0945)\end{array}$ \\
\hline Non-landlord $\times$ Low reform & $\begin{array}{c}-0.0845 \\
(0.0700)\end{array}$ & $\begin{array}{c}-0.0785 \\
(0.0774)\end{array}$ & $\begin{array}{l}0.0540 \\
(0.147)\end{array}$ & $\begin{array}{l}0.0401 \\
(0.161)\end{array}$ \\
\hline Year fixed effects & YES & YES & YES & YES \\
\hline Colonial rule control & YES & YES & YES & YES \\
\hline Geographical controls & YES & YES & YES & YES \\
\hline
\end{tabular}


agriculture focus on social and human factors. Chakravarti (1973) attributes "awareness of (the) new system and a willingness to get involved in it" as an important factor in the transition to higher productivity agriculture while Bhaduri (1973) argues that the "semi-feudal mode of production" in eastern India was behind the slow adoption of the new technology in that region, in sharp contrast with north India. Other authors indirectly support this view by suggesting that self-cultivation was an important part of this modernized mode of agriculture (Bhalla 1995). This is echoed in Parayil (1992) who describes the situation in successful states as one where "peasant cultivators became farmers for whom agriculture was a calling beyond subsistence".

When we consider both scale and willingness to invest as factors encouraging adoption of technology, it appears that the colonial land tenure system is a strong explanatory factor behind the differential rates of technology adoption. Punjab and Haryana fall in the category of historically non-middleman, low reform states. As such, they had the ideal conditions for investing in agriculture. Part of their advantage over the middleman dominated, high reform states had to do with scale. In comparison to places where land reform was successful and fragmented parcels of land passed into the hands of an impoverished rural class, farmers in Punjab and Haryana enjoyed the advantages of being relatively larger. However, if we were seeing a purely scale effect, then areas that continued under landlords, who controlled entire villages at times, should have had a clear advantage. The failure of large landlords to adopt the Green Revolution suggests that scale alone cannot explain why certain regions successfully transitioned to the new technology where others did not. Apart from scale, which affords the ability to invest in land, a willingness to invest, stemming from self-cultivation, was an important factor in choosing to adopt new technology.

As we described in the previous sub-section, farmers in non-middleman areas had a considerable advantage over their peers in middleman areas, both when it came to state-level public policy that prioritized productivity, as well as in the ability and willingness to take on private investment. The pattern of which regions embraced and benefitted most from the Green Revolution is fully in line with the mechanism and pattern we highlight in the previous sub-section. While the disparities between previously middleman dominated, high-reform states and individual dominated, low-reform states may have existed even without the Green Revolution, it seems that the transition to the new technology helped to exacerbate the regional divergence that was already in progress. 


\subsection{5}

\section{Green Revolution and crop choice}

We find significant differences between middleman and non-middleman regions in the case of rice and wheat HYVs but not for other cereals. These results make sense due to the prevalence of rice and wheat in Indian diets, and because HYV varieties in other cereals did not make such spectacular increases in their yield in this period (Farmer 1981). For these reasons, wheat and rice were the major beneficiaries of the Green Revolution, sharing a major portion of the irrigation potential created and receiving the maximum benefit from government policies such as price support (Challa et al., 2004; Chakravarti 1973).Thus, it is unsurprising that we see weaker results for other cereals than for rice and wheat.

Though HYV usage for both rice and wheat is significantly different between middlemen and non-middleman areas, the effect is of almost double the magnitude in wheat as in rice, with non-middleman areas having 40-percent more of the rice crop and 79-percent of the wheat crop under HYV cultivation (Table 1.8). Again, this is explained by the nature of the Green Revolution in India. Though both crops were introduced around the same time by same government agencies (Munshi 2004), wheat HYVs enjoyed several advantages over rice HYVs in the early phases of the Green Revolution.

Many scholars consider wheat the true success of the Green Revolution as wheat varieties imported from Mexico had more favorable effects on production than their rice counterparts from the Philippines (Farmer 1981; Chakravarti 1973; Krishnaji 1975). Apart from giving much higher returns than traditional technology, early wheat HYVs provided more stable yields in different settings (Munshi 2004; Ninan and Chandrashekhar 1993). The early imported wheat varieties were well-suited to climactic conditions in northwest India (Fujita 2009), and the local variants that were later developed could be used in multiple zones of the country (Munshi 2004). In contrast, the early rice HYVs performed poorly under stress conditions like water logging, salinity and drought, and were susceptible to pests (Farmer 1981; Munshi 2004). Furthermore, rice is grown in India in areas with a wide variation in soil characteristics. The local variants of rice HYVs that were developed were adapted to local conditions and were sensitive to unobserved farm characteristics. Munshi (2004) finds that this led to significant differences in the process of social learning for farmers of wheat and rice, with far greater diffusion of HYV technology in the case of wheat.

Market factors also conferred a relative advantage on wheat. Though consumers had an initial distaste for HYV varieties of both wheat and rice - 
they preferred white or amber wheat to the reddish wheat produced by HYV seeds, and traditional long-grain rice to the chalky HYV rice - agricultural research seems to have alleviated this problem more successfully for wheat. Meanwhile rice farmers growing the new varieties continued to receive lower prices due to consumer preference for the indigenous varieties of rice (Parayil 1992; Chakravarti 1973).

For this combined host of reasons, HYV wheat was a relatively more popular choice to HYV rice in the early phases of the Green Revolution.This may be of some cause of concern for our analysis since the major success stories of the Green Revolution, Punjab and Haryana, were not only non-middleman regions but also fortuitously happened to be regions where the traditional crop of choice is wheat rather than rice. Thus our concern is whether our results are explained by the conditions created by the historical land revenue system or whether they can be attributed merely to the fact that the primary crop of the northwest region happened to be the one which experienced the greatest productivity growth under the new technology.

We believe that though the crop-specificity of the Green Revolution may have given wheat-growing Punjab and Haryana slight advantages in the early adoption of the HYV technology, our results cannot be attributed to this fact. Firstly, non-middleman regions were not only restricted to these two wheat growing northwest states. Table 1.12 shows that even if we exclude all the districts of Punjab and Haryana from the analysis, non-middleman districts still have significantly higher fertilizer use and proportion of the wheat crop under HYV. In fact, taking out these traditionally wheat-growing states causes the result for the rice crop to cease being significant, suggesting that the advantage for non-middleman states in HYV rice was driven by the two traditionally wheat-growing states. Thus the dominance of these two states was not limited to wheat, even though these regions traditionally grew and consumed wheat. Secondly, though rice HYV had a slow start relative to wheat, agricultural research ensured considerable productivity gains for rice during the second wave of the Green Revolution in the 1980s, the beginning of which is captured by our data. Even during this phase, Punjab and Haryana continued to lead the country in agricultural growth and productivity (Sawant and Achuthan 1995). This suggests that that though some regions might have had predominantly rice or wheat consumers, considerable national trade ensured that this did not limit production options to catering to local consumption patterns. As Chakravarti (1973) points out, wheat has been more successful than rice in some traditionally paddy regions just as rice has had greater success in some wheat districts. 230 out of 270 districts in our dataset had 
areas dedicated to both rice and wheat crops under HYV. Thus, we do not believe that our result is driven by the crop-specificity of the early phases of the Green Revolution but, rather, by the conditions and incentives created by the historical land tenure system.

\subsection{6}

\section{Relative importance of inputs over time}

Our results show that, controlling for geography and the determinants of institutional choice, there is a significant difference in the proportion of irrigated lands between middleman and non-middleman areas in our sample from 1957-86. We can see from the results in Table 1.13 that the interaction between the contemporary period and individual based regions is positive and significant in the case of irrigation, confirming that an irrigation advantage for non-middleman areas only emerges in the post-Independence area.

We believe this may be because the move towards HYV seeds also necessitated ensuring a stable water supply as HYVs were more sensitive to drought than traditional varieties (Farmer 1981). In addition, the costly choice of investing in HYV was made worthwhile only if timely and adequate water ensured their success (Chakravarti 1973). The greatest spurts in production and growth during the Green Revolution were in the irrigated sector, and the diffusion of irrigation was a prime factor in the rapid growth of agriculture in the 1980s (Challa et al., 2004; Fujita 2009). Thus, as the importance of irrigation grew, individual based areas were better able to invest in this crucial implement.

While irrigation was perhaps the most important input for preventing crop failure, fertilizers also served as an important complement to HYV technology (Krishnaji 1975; Chakravarti 1973). Due to its greater divisibility than irrigation, fertilizers were an input adopted by farmers of all sizes (Sandhu 2014). The fertilizer industry is highly subsidized in India, making this input more accessible than irrigation, which often requires a high upfront capital investment. Therefore, even though irrigation may be the more crucial input from the perspective of avoiding crop failure, fertilizer is a relatively more elastic input with broader adoption. The large significant and positive impact we see on fertilizer use in individual based regions is important shows that our results hold for inputs of a diverse nature, for which the decision-making process of whether to invest may be considerably different. 
Table 1.12: Agricultural investments 1857-86, excluding Punjab and Haryana

\begin{tabular}{|c|c|c|c|c|c|c|}
\hline \multirow[b]{2}{*}{$\begin{array}{l}\text { TYPE OF } \\
\text { MIDDLEMAN }\end{array}$} & \multicolumn{3}{|c|}{ FULL SAMPLE } & \multicolumn{3}{|c|}{ BRITISH DISTRICTS ONLY } \\
\hline & $\begin{array}{c}\text { Mean of } \\
\text { dependent } \\
\text { variable }\end{array}$ & $\begin{array}{l}\text { Coefficient } \\
\text { on non- } \\
\text { middleman } \\
\text { proportion } \\
(1)\end{array}$ & $\begin{array}{c}\text { Coefficient } \\
\text { on Majority } \\
\text { dummy } \\
(2)\end{array}$ & $\begin{array}{l}\text { Mean of } \\
\text { dependent } \\
\text { variable }\end{array}$ & $\begin{array}{l}\text { Coefficient } \\
\text { on non- } \\
\text { middleman } \\
\text { proportion } \\
(3)\end{array}$ & $\begin{array}{c}\text { Coefficient } \\
\text { on Majority } \\
\text { dummy } \\
(4)\end{array}$ \\
\hline \multicolumn{7}{|l|}{ Irrigation (\% area) } \\
\hline All middlemen & 0.221 & $\begin{array}{c}0.0147 \\
(0.0349)\end{array}$ & $\begin{array}{c}0.0285 \\
(0.0234)\end{array}$ & 0.269 & $\begin{array}{c}-0.0696 \\
(0.0480)\end{array}$ & $\begin{array}{l}-0.0194 \\
(0.0355)\end{array}$ \\
\hline Landlords & & $\begin{array}{l}0.00278 \\
(0.0323)\end{array}$ & $\begin{array}{c}0.0177 \\
(0.0228)\end{array}$ & & $\begin{array}{l}-0.0728^{*} \\
(0.0408)\end{array}$ & $\begin{array}{l}-0.0304 \\
(0.0332)\end{array}$ \\
\hline Observations & & 8064 & 8064 & & 4864 & 4864 \\
\hline \multicolumn{7}{|l|}{ Fertilizer use (ton/ha) } \\
\hline All middlemen & 18.41 & $\begin{array}{c}9.603^{* * *} \\
(3.151)\end{array}$ & $\begin{array}{c}6.520^{* * *} \\
(2.501)\end{array}$ & 22.07 & $\begin{array}{l}9.140^{* *} \\
(4.439)\end{array}$ & $\begin{array}{l}7.395^{* *} \\
(3.527)\end{array}$ \\
\hline Landlords & & $\begin{array}{c}7.950^{* *} \\
(3.606)\end{array}$ & $\begin{array}{l}5.690^{* *} \\
(2.689)\end{array}$ & & $\begin{array}{c}10.63^{* *} \\
(5.131)\end{array}$ & $\begin{array}{c}8.661^{* *} \\
(3.909)\end{array}$ \\
\hline Observations & & 8064 & 8064 & & 4864 & 4864 \\
\hline \multicolumn{7}{|l|}{ Rice (\% under $H Y V)$} \\
\hline All middlemen & 0.197 & $\begin{array}{l}0.00695 \\
(0.0395)\end{array}$ & $\begin{array}{l}0.0466^{*} \\
(0.0269)\end{array}$ & 0.195 & $\begin{array}{c}0.0648 \\
(0.0459)\end{array}$ & $\begin{array}{l}0.0520^{*} \\
(0.0301)\end{array}$ \\
\hline Landlords & & $\begin{array}{c}0.0149 \\
(0.0350)\end{array}$ & $\begin{array}{l}0.0460^{*} \\
(0.0248)\end{array}$ & & $\begin{array}{c}0.0649 \\
(0.0429)\end{array}$ & $\begin{array}{l}0.0546^{*} \\
(0.0300)\end{array}$ \\
\hline Observations & & 7666 & 7666 & & 4854 & 4854 \\
\hline \multicolumn{7}{|l|}{ Wheat (\% under $H Y V$ ) } \\
\hline All middlemen & 0.497 & $\begin{array}{c}0.373^{* * *} \\
(0.101)\end{array}$ & $\begin{array}{c}0.227 * * * \\
(0.0677)\end{array}$ & 0.463 & $\begin{array}{c}0.173^{*} \\
(0.0906)\end{array}$ & $\begin{array}{c}0.146^{* * *} \\
(0.0540)\end{array}$ \\
\hline Landlords & & $\begin{array}{c}0.255^{* * *} \\
(0.0874)\end{array}$ & $\begin{array}{c}0.163^{* * *} \\
(0.0609)\end{array}$ & & $\begin{array}{c}0.0397 \\
(0.0812)\end{array}$ & $\begin{array}{c}0.0518 \\
(0.0591)\end{array}$ \\
\hline Observations & & 7166 & 7166 & & 4189 & 4189 \\
\hline \multicolumn{7}{|l|}{ Other cereals (\% under $H Y V$ ) } \\
\hline All middlemen & 0.172 & $\begin{array}{l}-0.0414 \\
(0.0836)\end{array}$ & $\begin{array}{l}-0.0296 \\
(0.0765)\end{array}$ & 0.191 & $\begin{array}{l}-0.140 \\
(0.192)\end{array}$ & $\begin{array}{l}-0.0573 \\
(0.170)\end{array}$ \\
\hline Landlords & & $\begin{array}{l}0.000453 \\
(0.0676)\end{array}$ & $\begin{array}{l}-0.00533 \\
(0.0655)\end{array}$ & & $\begin{array}{r}-0.0510 \\
(0.139)\end{array}$ & $\begin{array}{l}-0.0183 \\
(0.140)\end{array}$ \\
\hline Observations. & & 7884 & 7884 & & 4708 & 4708 \\
\hline Year fixed effects & & YES & YES & & YES & YES \\
\hline Geographical controls & & YES & YES & & YES & YES \\
\hline Institution determinants $^{a}$ & & YES & YES & & YES & YES \\
\hline
\end{tabular}


Table 1.13: Irrigation over time

\begin{tabular}{|c|c|c|c|c|}
\hline & \multicolumn{2}{|c|}{ Full sample } & \multicolumn{2}{|c|}{ British districts only } \\
\hline & $\begin{array}{l}\text { Coefficient } \\
\text { on non- } \\
\text { middleman } \\
\text { proportion } \\
\quad(1)\end{array}$ & $\begin{array}{c}\text { Coefficient } \\
\text { on Majority } \\
\text { dummy } \\
(2)\end{array}$ & $\begin{array}{c}\text { Coefficient } \\
\text { on non- } \\
\text { landlord } \\
\text { proportion } \\
(3)\end{array}$ & $\begin{array}{c}\text { Coefficient } \\
\text { on Majority } \\
\text { dummy } \\
(4)\end{array}$ \\
\hline \multicolumn{5}{|l|}{ All middlemen } \\
\hline Non-middleman & $\begin{array}{c}0.0296 \\
(0.0401)\end{array}$ & $\begin{array}{c}0.0261 \\
(0.0326)\end{array}$ & $\begin{array}{c}0.0597 \\
(0.0478)\end{array}$ & $\begin{array}{l}0.0890^{*} \\
(0.0456)\end{array}$ \\
\hline Post-Independence & $\begin{array}{c}0.170^{* * *} * \\
(0.0195)\end{array}$ & $\begin{array}{c}0.166^{* * *} \\
(0.0195)\end{array}$ & $\begin{array}{c}0.215^{* * *} \\
(0.0215)\end{array}$ & $\begin{array}{c}0.222^{* * *} \\
(0.0202)\end{array}$ \\
\hline $\begin{array}{l}\text { Non-middleman } \times \\
\text { post-Independence }\end{array}$ & $\begin{array}{c}0.0150 \\
(0.0369)\end{array}$ & $\begin{array}{c}0.0245 \\
(0.0300)\end{array}$ & $\begin{array}{c}0.0234 \\
(0.0464)\end{array}$ & $\begin{array}{c}-6.34 \mathrm{e}-05 \\
(0.0396)\end{array}$ \\
\hline \multicolumn{5}{|l|}{ Landlords } \\
\hline Non-landlord & $\begin{array}{l}-0.0483 \\
(0.0361)\end{array}$ & $\begin{array}{l}-0.0302 \\
(0.0298)\end{array}$ & $\begin{array}{l}-0.0648 \\
(0.0488)\end{array}$ & $\begin{array}{c}-0.00924 \\
(0.0446)\end{array}$ \\
\hline Post-Independence & $\begin{array}{c}0.143^{* * *} \\
(0.0184)\end{array}$ & $\begin{array}{c}0.147^{* * *} \\
(0.0185)\end{array}$ & $\begin{array}{c}0.185^{* * *} \\
(0.0197)\end{array}$ & $\begin{array}{l}0.198^{* * *} \\
(0.0186)\end{array}$ \\
\hline $\begin{array}{l}\text { Non-landlord } \times \\
\text { post-Independence }\end{array}$ & $\begin{array}{c}0.0852^{* *} \\
(0.0375)\end{array}$ & $\begin{array}{c}0.0724^{* *} \\
(0.0311)\end{array}$ & $\begin{array}{l}0.115^{* *} \\
(0.0486)\end{array}$ & $\begin{array}{l}0.0719^{*} \\
(0.0424)\end{array}$ \\
\hline
\end{tabular}

\section{7}

\section{Conclusion}

Historically, the land revenue system was an institution that had implications far beyond how the land tax was determined and collected. It had political significance, welfare implications, and as our results show, long-lasting impacts on how individuals under those systems made, and continue to make, their economic decisions. In a country like India, where agriculture is the primary occupation of more than half the population, this lasting impact is of great importance in determining the success of one of the key sectors of the economy.

While the particular historical conditions and policies described in this paper might be specific to India, the broader lessons for agricultural organization are not. Apart from showing the importance of institutions in agricultural decision-making, this specific experiment shows the extreme persistence of institutional choices. It also shows a setting in which the long-run impacts of institutions magnify rather than diminish over time, along with a detailed mechanism for how an initial institutional choice may interact unpredictably with policies in the future to lead to divergent outcomes.

In its most broad application, however, this work aims to show the primacy of institutions as a determinant of economic outcomes. While this means that our present and historical institutional choices could hold much greater significance than policymakers may originally intend - and the existence of undesirable institutions attests to the fact that selfish 
or shortsighted decisions are more common than we would like - the institutional perspective is essentially an optimistic one, for it holds the promise that a society can overcome limitations imposed by nature and history by organizing itself in ways that are favorable to its growth and development. 


\section{The melting pot effect: The impact of religious and linguistic diversity on growth and poverty}

\section{1 \\ Introduction}

Cultural diversity is one of the most contentious topics of modern-day political life. In Western society, many welcome the new values and skills brought in by immigrants, yet there is often also a section of the population that feels that their interests are harmed by the influx of people from different cultures. In a non-Western setting, where the concept of nation-states has been introduced relatively more recently through borders imposed by Europeans, cultural diversity is an even more volatile topic. On one hand, cultural differences have led to many violent conflicts, even culminating in civil war in some cases. Yet on the other hand, there is always the promise that the rich cultural heritages of the various ethnic or tribal groups that came to be united as modern nation-states will contribute to thriving economies with a variety of skills, perspectives, and ideas.

India, which we study in this work, is an exemplar of both the challenges and opportunities presented by cultural diversity in a developing world setting. While it has seen many violent conflicts marked by religious and linguistic divisions, it is also a secular republic with more than twenty-eight official languages and citizens from every major world religion. But the question of whether its impressive cultural diversity has served it well or hampered its progress remains to this day a question fraught with tension and discord.

Economists have fared little better than the general public in reaching a consensus on whether the impact of cultural diversity is ultimately positive or negative for economic outcomes. In general, studies employing cross-country data on ethnic, linguistic, or religious diversity have found negative impacts on economic outcomes (Easterly and Levine, 1997; Alesina et al., 1999; Alesina et al, 2003; Montalvo and Reynal-Querol 2005a, 2005b) while studies focusing on birthplace or genetic diversity in one country, usually Western nations, have highlighted the positive impacts of diversity (Bellini et al., 2013; Ager and Bruckner, 2013a, 2013b; Ottaviano and Peri, 2006; Alesina et al., 2016). 
That all forms of cultural diversity cannot be equated is made clear by Alesina et al. (2016), who find that birthplace diversity is largely uncorrelated with ethnic, linguistic, and genetic diversity. Additionally, the particular setting in which cultural diversity is found appears to be crucial in determining its impacts. This implies that culture, which consists of several dimensions shaped by historical factors, does not operate on its own but, rather, in tandem with a given institutional setting, which itself may be influenced by the history of a given region.

In this work, we aim to measure the impact of two particular dimensions of cultural diversity - religion and language — on growth and poverty. We apply the same measures of diversity, i.e. religious and linguistic fractionalization, used by Alesina et al. (2003) to an empirical strategy inspired by Tabellini (2010). We build a case for the causal impact of culture on economic outcomes by employing an instrumental variables strategy that uses historical variables as instruments for religious and linguistic fractionalization. In order to separate the cultural impacts from the institutional settings in which they arise, we focus on district-level data, controlling for institutional differences at the state level.

We find that religious fractionalization has large and positive significant impacts on both growth and poverty and that these results are robust to various specifications. Linguistic fractionalization, on the other hand, does not have significant impacts on either growth or poverty. We rule out the possibility that the effects of religious heterogeneity stem from the presence or absence of the majority religion, Hinduism, and the caste system that is a major feature of the religion. One potential mechanism by which religious diversity positively impacts economic outcomes is through the institutional environment facilitated by the coexistence of various religious communities. We believe that in most democratic settings of religious diversity, secular institutions tend to gain importance, either due to competition in the religious institutional sphere or due to directed institutional change. However, the fact that religious fractionalization has impacts where linguistic fractionalization does not suggests that there may also be a value-based explanation in play. Religious diversity may lead to syncretic beliefs or to an increase in generalized values of tolerance and cooperation. Such values could be conducive to the overall economic advancement of society by providing a favorable environment for the functioning of institutions beneficial for growth.

Our results are significant for several reasons. Firstly, our instrumental variables strategy allows us to establish a stronger causal claim for the impacts of cultural heterogeneity than the correlations used in most of the literature. 
Secondly, our results provide a rare case in which clearly positive impacts are found for any form of diversity other than birthplace or genetic diversity. This induces us to go beyond the skill diversity mechanism to seek out institutional and value based explanations of how cultural diversity can impact economic outcomes. Lastly, and perhaps most importantly, the results presented here provide a rare example in which religious and linguistic diversity are studied at the sub-national level, particularly in a developing world setting. The positive results we find are made all the more remarkable because of this setting. The uniqueness of our results, however, does not render them with limited utility to policymakers in other nations. If anything, these results outline that even in a relatively underdeveloped country whose history has been marked by violence based on religious and linguistic differences, the bane of cultural heterogeneity can be a blessing.

The remainder of this paper is structured as follows. The literature on the impacts of cultural diversity is summarized in Section 2, followed by descriptions of our data and estimation strategy in Sections 3 and 4 . Our results are presented in Section 5. Section 6 discusses some potential mechanisms explaining our results. We end with concluding remarks in Section 7.

\section{2}

\section{Literature}

The theoretical case for both the positive and negative impacts of cultural diversity is made by Alesina and Ferrara (2005). While the positive impacts largely stem from a diverse working age population with a greater variety of skills, the negative impacts arise from the potential for social conflict and a reduction in the quality and quantity of public good provision. This under-provision of public goods comes about as a result of the inability of different groups to agree on public goods like infrastructure and education.

While the empirical literature provides ample evidence both in favor of and against cultural heterogeneity, it is interesting to note that positive impacts are largely attributed to birthplace diversity in Western settings, often favoring on a particular country or region. For example, Bellini et al. (2013) find that the share of foreigners in the total population positively impacts productivity in European regions. Ager and Bruckner (2013a, 2013b) find similar positive impacts for country of origin and genetic diversity in the United States. Furthermore, Ottavio and Peri $(2004,2006)$ find that an increase in the share of foreign born in US cities increases the productivity of natives as well. There are hardly any counterexamples of similar works studying sub-national diversity in a developing world setting. 
Meanwhile, in most cross-country settings, the results are overwhelmingly negative. However, it is possible that most of these results are being driven by countries in Africa. Notably, most of these negative results are found for definitions of diversity that use criteria other than birthplace diversity. For example, Montalvo and Reynal Querol (2005a, 2005b) find that ethnic diversity has a detrimental effect on output growth through the mechanism of increased social conflict and worse public good provision. Earlier works also find a correlation between diversity and unfavorable economic outcomes. While Easterly and Levine (1997) find that ethnolinguistic fractionalization is inversely related to growth, Alesina et al. (1999) find that ethnic fragmentation is inversely related to spending on productive public goods.

Of this latter category of cross-country studies, our work is perhaps most directly comparable with Alesina et al. (2003), which studies religious, linguistic, and ethnic fractionalization and focuses on discerning the impacts of different dimensions of diversity. That work finds in a cross-country setting that ethnic and linguistic fractionalization are correlated with negative economic outcomes and quality of government. Interestingly, religious fractionalization in Alesina et al. (2003) is significantly correlated with improved indicators of good governance. However, since governance tends to be better in more tolerant and free societies, the causal impact of religious diversity on governance is not firmly established. This paper hopes to build a stronger causal case for the impacts of diversity through the instrumental variables strategy made possible by our novel historical data. Establishing this causal connection also allows us to delve deeper into the mechanisms for why religious fractionalization in particular has the positive impacts that we find in this work.

The empirical literature described above often uses the fractionalization indicator as a measure of diversity. This indicator represents the probability that two individuals randomly selected from the population belong to different groups defined on the basis of various criteria such as religion, language, country of origin, ethnicity or ethnolinguistic differences. However, another alternative class of indices are polarization measures, which measure the normalized distance of a distribution of groups from a bimodal distribution. The main proponents of this latter class of indicators are Montalvo and Reynal-Querol (2002, 2005a, 2005b) argue that polarization measures are more appropriate to measure potential conflict. Though these measures may be adequate for measuring the probability of civil war, Alesina et al. (2003) hold that fractionalization, which better captures the scenario where many groups fight over public resources, may be better to study outcomes such as the quality of policy. Further, they argue that the fractionalization measure 
performs as a better predictor of outcome variables when the correlation between fractionalization and polarization is high. Even when the correlation between the two indices is low, Alesina et al. (2003) find that fractionalization provides marginally better results.

As our aim is primarily to estimate the impact of economic outcomes, rather than conflict per se, we believe that fractionalization is the appropriate measure for our study. Furthermore, the two indices are more correlated at relatively lower levels of diversity (Montalvo and Reyna-Querol 2005b) as is likely the case in our work. Not only does this mean that we are unlikely to get highly different results using the different results using the two indicators, but also that at these lower levels of correlation, fractionalization should perform better in predicting our outcome variables. Thus, following Alesina et al. (2003) we use religious and linguistic fractionalization in our primary specifications and include polarization as a robustness check.

\section{3 \\ Data}

\subsection{1}

\section{Data sources}

We use a combination of present and historical data at the district-level, using district boundaries from $2001^{1}$. While the historical data is obtained from the Imperial Gazetteer of India, a 22-volume administrative record published in 1909 by the British government of India, our contemporary data is collected from various Government of India sources. Further details on the various sources are included below. The main variables are summarized in Table 3.1.

Our outcome variables of interest are GDP per capita and the percentage of households above the poverty line. Our district-wise GDP data was reported by individual states for a range of years from 2001 to 2008. However, we used the data from 2005 since this year had the maximum number of observations. As this GDP data is from mid-decade, in order to calculate per capita GDP we calculated a projected population for the year 2005 using population data from the censuses conducted in 2001 and 2011. The data on district-wise percentage of households above the poverty line is from the 2008 Below Poverty Line survey by the government of India, using the guidelines of the Tendulkar

\footnotetext{
${ }^{1}$ Even though a census was conducted in 2011, we use 2001 data because of the availability of information on district-wise religions and mother tongues. Because of our use of 2001 district boundaries, we aggregate our GDP and poverty data, which date from 2005 and 2008, respectively, over post-2001 splits in districts.
} 
Committee to define the poverty line. We obtained this data through a public data aggregator ${ }^{2}$.

Our main regressors, religious and linguistic fractionalization, are calculated using data on religions and mother tongues (i.e. primary language spoken) from the 2001 Census, using the following formula:

$$
\begin{aligned}
& R F_{i}=1-\sum_{j=1}^{N} r_{i j}^{2} \\
& L F_{i}=1-\sum_{j=1}^{N} l_{i j}^{2}
\end{aligned}
$$

where $R F_{i}$ and $L F_{i}$ are religious and linguistic fractionalization in district $i, r_{i j}$ and $l_{i j}$ are the shares of groups $j(J=1 \ldots N)$ (by religion and mother tongue, respectively), in district $i^{3}$. This measure, fractionalization, reflects the probability that two randomly selected individuals from a population belong to different groups. It is used commonly in the literature, including in Alesina et al. (2003), which calculates it at the country level. Our measures for religious and linguistic fractionalization are described in greater detail in the next subsection.

Our instruments are historical variables derived from the Imperial Gazetteer of India (1909). This source contains detailed information about most of India, including British India and native-ruled princely states. Apart from information about the administration, economy and history of each region, these encyclopedic volumes also provide a rich source of demographic information from that period. For most regions, we have district level data on the strength of different religious groups, which allows us to construct a historical measure of religious fractionalization in each district in the year 1901, using the formula laid out in Equation 2-1.

Unfortunately, due to the vast variety of languages spoken in different regions of India, we do not have similarly detailed data on the proportion of speakers of every language, thus rendering us unable to calculate a historical equivalent for linguistic fractionalization. However, the Imperial Gazetteer of India reports the proportion of people speaking the most widely spoken languages in each district, which gives us some idea of the linguistic heterogeneity of a given district, even though is a far more blunt measure than fractionalization. Because this measure does not make as strong an

\footnotetext{
${ }^{2}$ Knoema

${ }^{3}$ For religious groups, we consider Hinduism, Islam, Christianity, Buddhism and Jainism. Some religions, such as Zoroastrianism and Judaism, are indistinguishable in the 2001 data as they have been coded collectively as 'Other'. Members of these religions and people not reporting a religion, comprising less than $1 \%$ of the population, have been left out of the analysis.
} 
Table 2.1: Summary statistics

\begin{tabular}{|c|c|c|c|c|}
\hline & Mean & $\begin{array}{l}\text { Standard } \\
\text { deviation }\end{array}$ & Districts & States \\
\hline \multicolumn{5}{|l|}{ Dependent variables } \\
\hline Log GDP per capita (2005) & 9.67 & 0.565 & 490 & 22 \\
\hline $\begin{array}{l}\text { Population } \% \text { above } \\
\text { poverty line }(2008)\end{array}$ & 67.12 & 18.335 & 567 & 31 \\
\hline \multicolumn{5}{|l|}{ Present cultural heterogeneity (2001) } \\
\hline Religious fractionalization & 0.246 & 0.1484 & 576 & 32 \\
\hline Linguistic fractionalization & 0.392 & 0.2360 & 576 & 32 \\
\hline $\begin{array}{l}\text { Colonial period urbanization } \\
\text { (buildings/area) }\end{array}$ & 0.262 & 2.744 & 576 & 32 \\
\hline \multicolumn{5}{|l|}{ Other controls (2001) } \\
\hline Literacy & 0.642 & 0.128 & 576 & 32 \\
\hline Population density & 861.28 & 2900.415 & 576 & 32 \\
\hline \multicolumn{5}{|l|}{ Historical instruments (1901) } \\
\hline Religious fractionalization & 0.239 & 0.1566 & 497 & 29 \\
\hline Linguistic minorities $^{a}$ & 0.189 & 0.2376 & 511 & 29 \\
\hline Literacy & 0.0479 & 0.0456 & 528 & 28 \\
\hline Population density & 1785.06 & 33375.01 & 576 & 32 \\
\hline $\begin{array}{l}\text { Proportion (by area) of individual- } \\
\text { based land revenue institutions }\end{array}$ & 0.429 & 0.437 & 507 & 29 \\
\hline
\end{tabular}

instrument as past fractionalization, for our IV regressions estimating the impact of linguistic fractionalization we used an alternative approach based on Tabellini (2010) that uses additional historical variables as instruments. This strategy required the historical equivalent of our other controls, namely, institutions, literacy, and population density. These were also obtained from the Imperial Gazetteer of India.

Our control variables are derived from both historical and contemporary sources. In all specifications, we control for past economic development. Ideally, we would have controlled for GDP or urbanization during the colonial period. However, since there is no preexisting district-level data on these indicators during this period, we construct a proxy for wealth using data on monuments made available by the Archaeological Survey of India. Specifically, we aim to gauge the number of "important" buildings — importance defined by the fact that the building in question is under the purview of the central or state government for preservation - per hundred square miles. The idea here is that regions that were wealthy, and often, urbanized, in that period also required a considerable physical infrastructure. For example, a commercial or administrative hub would require bureaucratic offices, courts, hospitals etc. Where these exist from the colonial period ${ }^{4}$, they are often preserved by

\footnotetext{
${ }^{4}$ We enumerate structures built during the colonial period, regardless of whether they were built by the colonizers or by a native ruler. For our purposes, the colonial period is
} 
the state or central government, unless they are deemed insignificant from a historical standpoint. Therefore, by measuring the extent of important historical buildings in a district, we are able to roughly capture the level of past economic development in that district.

In addition to this measure of past development and state effects to control for institutional differences between states, we also include literacy and population density to some specifications to check that our model is robust to the inclusion of these controls. This ensures that our results are not merely capturing the effects of human capital accumulation or of density rather than diversity per se. The data on literacy and population density in each district is obtained from the 2001 Census. Some of our robustness checks include controls for Scheduled caste population and crimes against Scheduled Castes. While the former is obtained from the census, the latter is obtained via the National Crime Records Bureau.

\subsection{2}

\section{Distribution of fractionalization}

Figures 2.1 and 2.2 show the distribution of religious and linguistic fractionalization and the correlation between the two indicators, respectively. These figures suggest that there is a considerable amount of noise in the relationship between the two dimensions of cultural diversity. Therefore, it would not be surprising if the two indicators have distinct impacts on the economic outcomes we study.

Certain aspects - both negative and positive - could stem from either religious or linguistic heterogeneity or, in fact, from any kind of diversity where groups are clearly delineated. While the presence of multiple groups could be expected to lead to social conflict and conflicting preferences for public goods, cultural heterogeneity may also have productivity impacts by adding diversity to the skills and experiences represented in the workforce.

Apart from these common impacts that either type of fractionalization could have, religious and linguistic differences may have unique effects. For example, in addition to the creation of social conflict, linguistic diversity may create difficulties in communication between different groups of people, thus hampering the evolution of common institutions. The potential effects of religious diversity are more complex. The power of religion to define values and lifestyles may make religion a particularly potent barrier between people. Conflicts based on religious identity could have a greater potential to become politically heated or even violent. On the other hand, living amongst people 
Figure 2.1: Distribution of religious and linguistic fractionalization
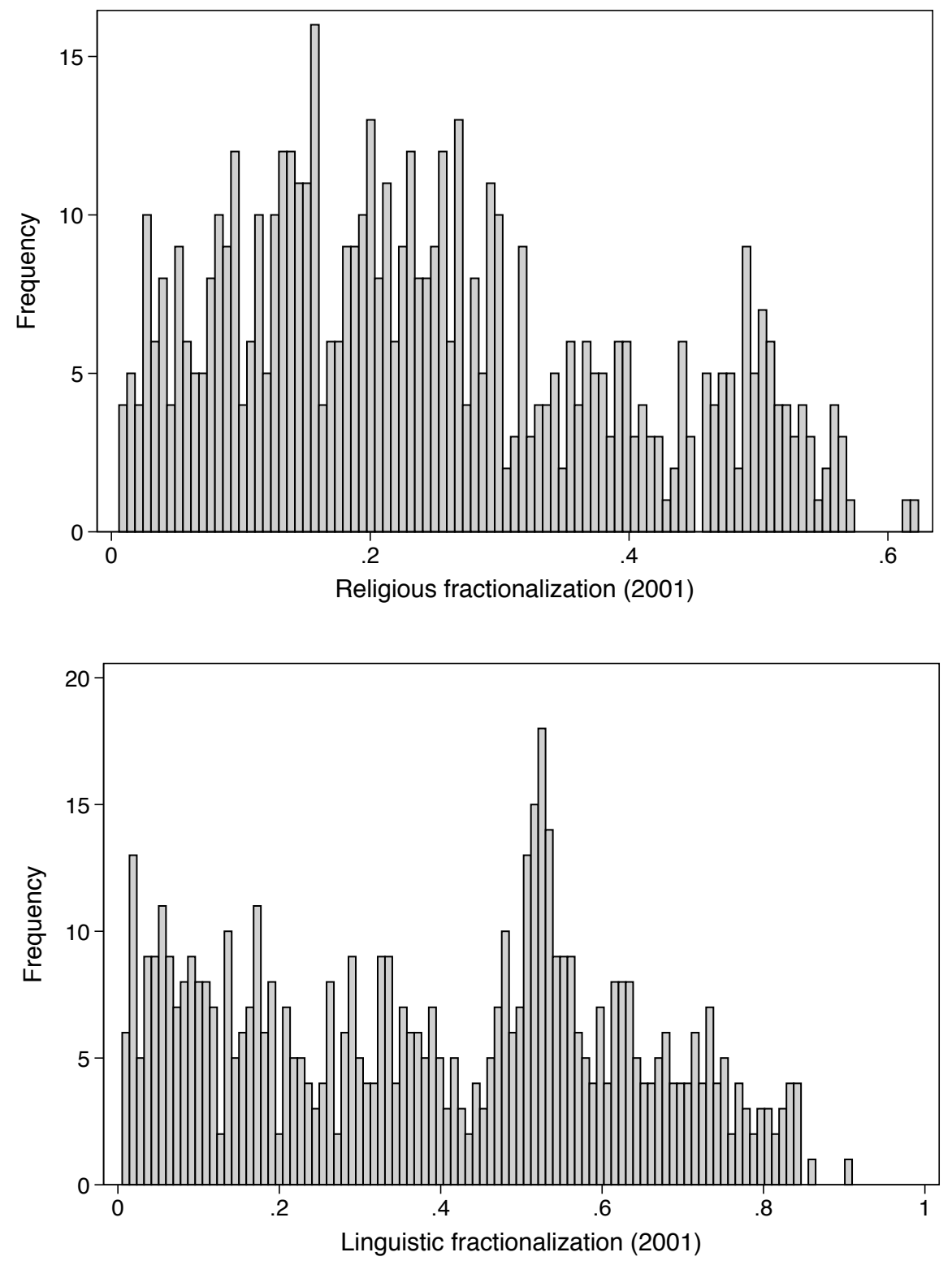

with different beliefs and practices may lead to the evolution of mutual tolerance or even syncretic beliefs that combine aspects from different religious traditions. Additionally, the existence of religious diversity may render secular institutions more necessary for the coexistence of the various faiths. This may be beneficial for the institutional environment at large.

While it is difficult to predict whether the impact of religious and linguistic fractionalization will be largely negative or positive, an initial look at their distributions and the correlation between them suggests that we are likely to see these distinct dimensions of cultural heterogeneity having effects exclusive to that form of cultural diversity. 
Figure 2.2: Religious and linguistic fractionalization correlation

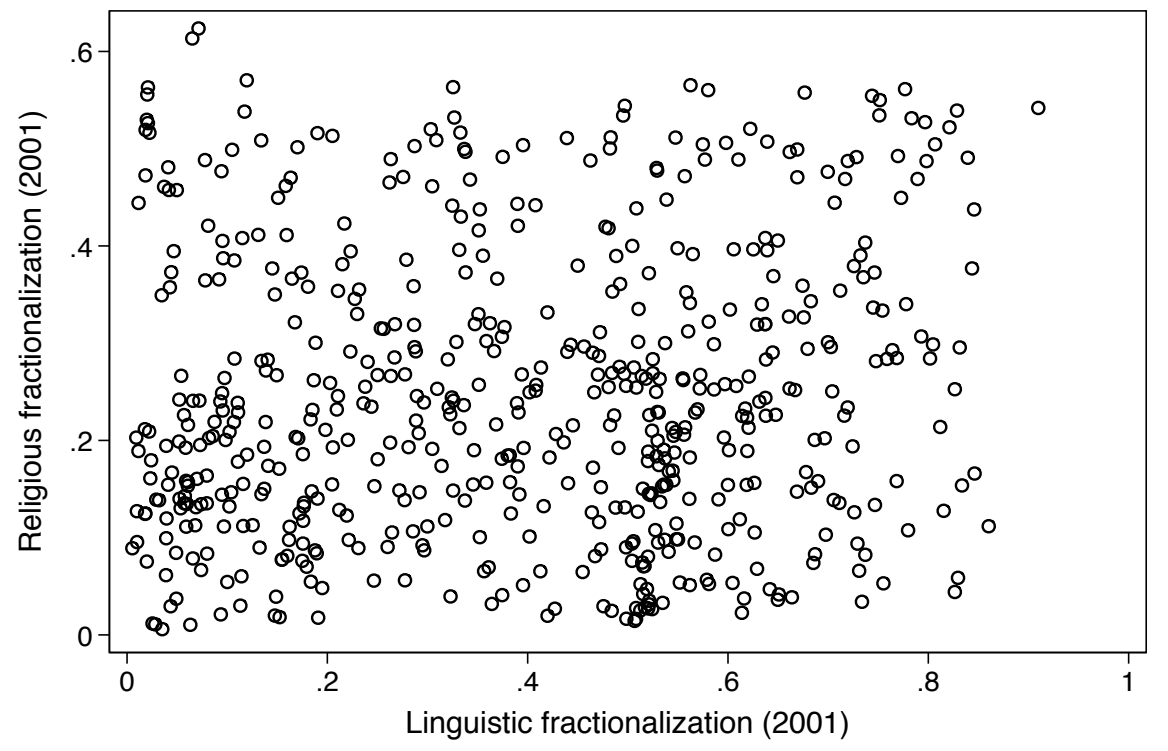

\subsection{3}

\section{Religious fractionalization over time}

Table 2.2 shows the evolution of religious diversity in different regions over the hundred year period from 1901 to 2001. While in some states - such as Uttar Pradesh and Uttarakhand in the North, and Andhra Pradesh and Tamil Nadu in the South - diversity appears to remain at similar levels as that in the past, in most places, there appears to be a reduction in religious diversity. In all states, a unit increase in religious fractionalization in 1901 is correlated with a less than unit increase in the same index in 2001. Figure 2.3 similarly shows that though there is a clear correlation between religious fractionalization in the past and present, overall, the degree of religious heterogeneity appears to decrease marginally over time. As border states (highlighted in Table 2.2 appear to have a correlation of smaller magnitude between religious diversity in both periods relative to other states in their geographic grouping, this may suggest that the lowering of diversity has to do with the formation of the Muslim-majority states of Pakistan and East Pakistan in 1947.

\subsection{4}

\section{Diversity and growth}

Linear estimates of the impact of religious and linguistic fractionalization on economic outcomes (Tables 2.3-2.5) suggest that cultural diversity has a positive effect on growth and poverty. These results are very different from those in Alesina (2003) which finds negative, though insignificant, impacts of religious and linguistic fractionalization on growth in a cross-country sample. 
Table 2.2: Religious fractionalization 1901-2001

\begin{tabular}{|c|c|c|}
\hline States & $\begin{array}{c}\text { Correlation between } \\
\text { religious diversity } \\
\text { in } 1901 \text { and } 2001^{a} \\
\end{array}$ & $\begin{array}{c}\text { No. of } \\
\text { districts }\end{array}$ \\
\hline \multicolumn{3}{|l|}{ SOUTH } \\
\hline Andhra Pradesh & $0.912^{* * *}$ & 17 \\
\hline Karnataka & $0.582^{* * *}$ & 22 \\
\hline Kerala & 0.0182 & 14 \\
\hline Tamil Nadu & $0.944^{* * *}$ & 30 \\
\hline \multicolumn{3}{|l|}{ EAST } \\
\hline Assam & $0.562^{* * *}$ & 19 \\
\hline Bihar & $0.891^{* * *}$ & 37 \\
\hline Meghalaya & 0.318 & 7 \\
\hline Odisha & 0.111 & 17 \\
\hline West Bengal & $0.678^{* * *}$ & 18 \\
\hline \multicolumn{3}{|l|}{ CENTRAL } \\
\hline Chhattisgarh & -0.229 & 8 \\
\hline Jharkhand & $0.845^{* * *}$ & 13 \\
\hline Madhya Pradesh & $0.744^{* * *}$ & 43 \\
\hline \multicolumn{3}{|l|}{ WEST } \\
\hline Gujarat & $0.472^{* * *}$ & 20 \\
\hline Maharashtra & $0.762^{* * *}$ & 27 \\
\hline Rajasthan & $0.564^{* * *}$ & 29 \\
\hline \multicolumn{3}{|l|}{ NORTH } \\
\hline Haryana & -0.0424 & 17 \\
\hline Himachal Pradesh & $0.205^{* * *}$ & 7 \\
\hline Jammu \& Kashmir & $0.808^{* * *}$ & 13 \\
\hline Punjab & -0.692 & 16 \\
\hline Uttarakhand & $0.968^{* * *}$ & 13 \\
\hline Uttar Pradesh & $0.967^{* * *}$ & 65 \\
\hline
\end{tabular}

Figure 2.3: Religious fractionalization over time

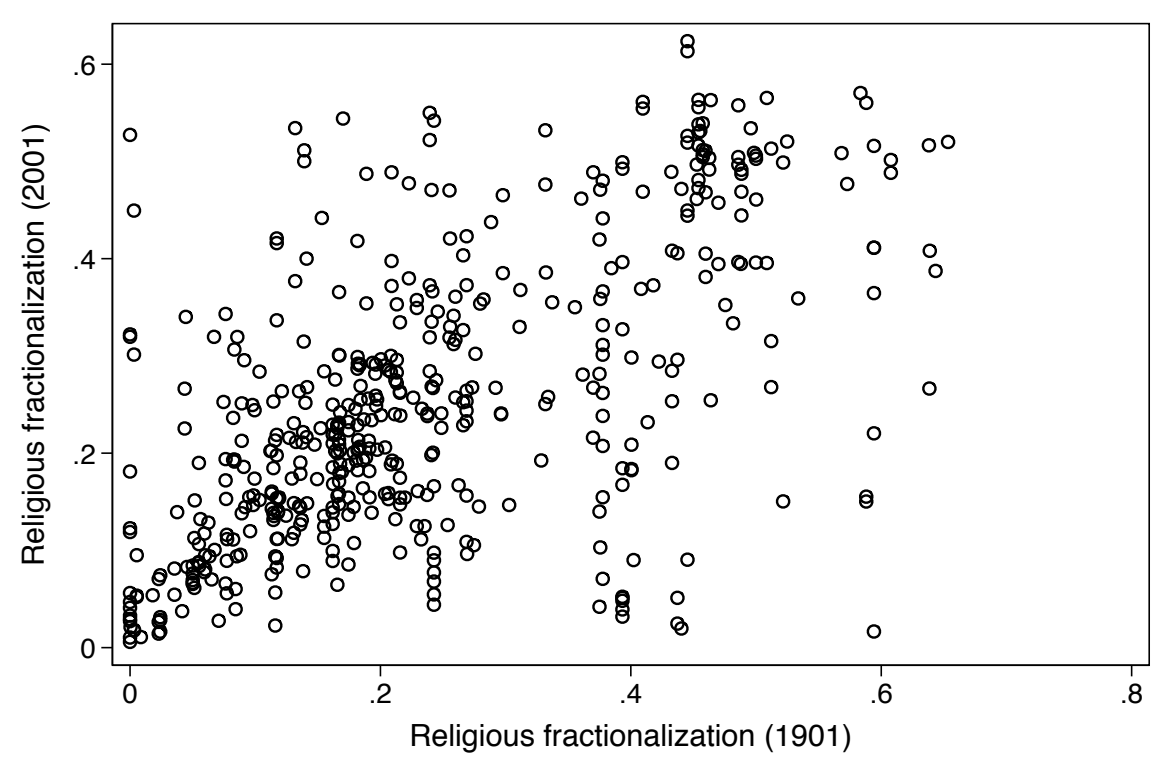


Table 2.3: Religious fractionalization and economic outcomes, OLS

\begin{tabular}{|c|c|c|c|c|}
\hline & $(1)$ & $(2)$ & $(3)$ & $(4)$ \\
\hline \multicolumn{5}{|l|}{ A: Log GDP per capita (2005) } \\
\hline Religious fractionalization (2001) & $\begin{array}{c}0.416 \\
(0.359)\end{array}$ & $\begin{array}{c}0.410^{*} \\
(0.228)\end{array}$ & $\begin{array}{c}0.522^{* *} \\
(0.220)\end{array}$ & $\begin{array}{c}0.527^{* *} \\
(0.224)\end{array}$ \\
\hline Colonial period urbanization & $\begin{array}{r}0.0554^{* * *} \\
(0.00646)\end{array}$ & $\begin{array}{c}0.0499 * * * \\
(0.00443)\end{array}$ & $\begin{array}{r}0.0434^{* * *} \\
(0.00555)\end{array}$ & $\begin{array}{c}0.0449 * * * \\
(0.00516)\end{array}$ \\
\hline Literacy (2001) & & & $\begin{array}{c}1.460^{* * *} \\
(0.228)\end{array}$ & $\begin{array}{c}1.468^{* * *} \\
(0.235)\end{array}$ \\
\hline Population density (2001) & & & & $\begin{array}{l}-2.74 \mathrm{e}-06 \\
(7.79 \mathrm{e}-06)\end{array}$ \\
\hline State fixed effects & $\mathrm{NO}$ & YES & YES & YES \\
\hline Observations & 490 & 490 & 490 & 490 \\
\hline \multicolumn{5}{|c|}{$\begin{array}{l}\text { B: \% of households above poverty line (2008) } \\
\quad(\text { Mean = 67.12) }\end{array}$} \\
\hline Religious fractionalization (2001) & $\begin{array}{c}32.84^{* * *} \\
(11.68)\end{array}$ & $\begin{array}{c}15.71^{* *} \\
(5.977)\end{array}$ & $\begin{array}{c}17.11^{* *} \\
(6.685)\end{array}$ & $\begin{array}{c}16.70^{* *} \\
(6.697)\end{array}$ \\
\hline Colonial period urbanization & $\begin{array}{c}0.609^{* * *} \\
(0.147)\end{array}$ & $\begin{array}{c}0.632^{* * * *} \\
(0.148)\end{array}$ & $\begin{array}{c}0.457^{* * *} \\
(0.106)\end{array}$ & $\begin{array}{c}0.381 \\
(0.263)\end{array}$ \\
\hline Literacy (2001) & & & $\begin{array}{c}40.27 * * * \\
(5.174)\end{array}$ & $\begin{array}{c}39.82^{* * *} \\
(5.162)\end{array}$ \\
\hline Population density (2001) & & & & $\begin{array}{c}0.000141 \\
(0.000411)\end{array}$ \\
\hline State fixed effects & NO & YES & YES & YES \\
\hline Observations & 567 & 567 & 567 & 567 \\
\hline
\end{tabular}

Table 2.4: Linguistic fractionalization and economic outcomes, OLS

\begin{tabular}{|c|c|c|c|c|}
\hline & (1) & $(2)$ & (3) & $(4)$ \\
\hline \multicolumn{5}{|l|}{ A: Log GDP per capita (2005) } \\
\hline Linguistic fractionalization (2001) & $\begin{array}{l}-0.276 \\
(0.370)\end{array}$ & $\begin{array}{c}-0.00135 \\
(0.0927)\end{array}$ & $\begin{array}{c}0.163^{*} \\
(0.0844)\end{array}$ & $\begin{array}{c}0.163^{*} \\
(0.0847)\end{array}$ \\
\hline Colonial period urbanization & $\begin{array}{c}0.0601^{* * *} \\
(0.00678)\end{array}$ & $\begin{array}{c}0.0515^{* * *} \\
(0.00491)\end{array}$ & $\begin{array}{l}0.0440 * * * \\
(0.00616)\end{array}$ & $\begin{array}{c}0.0438 * * * \\
(0.00578)\end{array}$ \\
\hline Literacy (2001) & & & $\begin{array}{c}1.464^{* * *} \\
(0.199)\end{array}$ & $\begin{array}{c}1.463^{* * *} \\
(0.201)\end{array}$ \\
\hline Population density (2001) & & & & $\begin{array}{l}3.99 \mathrm{e}-07 \\
(6.73 \mathrm{e}-06)\end{array}$ \\
\hline State fixed effects & $\mathrm{NO}$ & YES & YES & YES \\
\hline Observations & 490 & 490 & 490 & 490 \\
\hline \multicolumn{5}{|c|}{$\begin{array}{l}\text { B: \% of households above poverty line (2008) } \\
\quad(\text { Mean =67.12) }\end{array}$} \\
\hline Linguistic fractionalization (2001) & $\begin{array}{l}-3.616 \\
(7.919)\end{array}$ & $\begin{array}{l}-4.305 \\
(2.589)\end{array}$ & $\begin{array}{l}-0.949 \\
(2.993)\end{array}$ & $\begin{array}{l}-1.367 \\
(3.126)\end{array}$ \\
\hline Colonial period urbanization & $\begin{array}{c}0.729 * * * \\
(0.142)\end{array}$ & $\begin{array}{c}0.730^{* * *} \\
(0.133)\end{array}$ & $\begin{array}{c}0.536^{* * *} \\
(0.0918)\end{array}$ & $\begin{array}{c}0.368 \\
(0.260)\end{array}$ \\
\hline Literacy (2001) & & & $\begin{array}{c}38.96^{* * *} \\
(5.655)\end{array}$ & $\begin{array}{c}37.89^{* * *} \\
(5.557)\end{array}$ \\
\hline Population density (2001) & & & & $\begin{array}{c}0.000313 \\
(0.000441)\end{array}$ \\
\hline State fixed effects & $\mathrm{NO}$ & YES & YES & YES \\
\hline Observations & 567 & 567 & 567 & 567 \\
\hline
\end{tabular}


Table 2.5: Impact of religious and linguistic fractionalization on economic outcomes, OLS

\begin{tabular}{|c|c|c|c|c|}
\hline & (1) & $(2)$ & $(3)$ & (4) \\
\hline \multicolumn{5}{|l|}{ A: Log GDP per capita (2005) } \\
\hline Religious fractionalization (2001) & $\begin{array}{c}0.523 \\
(0.347)\end{array}$ & $\begin{array}{c}0.437^{*} \\
(0.233)\end{array}$ & $\begin{array}{c}0.492^{* *} \\
(0.233)\end{array}$ & $\begin{array}{c}0.497^{* *} \\
(0.236)\end{array}$ \\
\hline Linguistic fractionalization (2001) & $\begin{array}{l}-0.247 \\
(0.373)\end{array}$ & $\begin{array}{l}-0.0717 \\
(0.0923)\end{array}$ & $\begin{array}{c}0.0870 \\
(0.0927)\end{array}$ & $\begin{array}{c}0.0902 \\
(0.0912)\end{array}$ \\
\hline Colonial period urbanization & & $\begin{array}{l}0.0504^{* * *} * \\
(0.00449)\end{array}$ & $\begin{array}{c}0.0427^{* * *} \\
(0.00575)\end{array}$ & $\begin{array}{c}0.0447^{* * *} \\
(0.00532)\end{array}$ \\
\hline Literacy (2001) & & & $\begin{array}{c}1.493^{* * *} \\
(0.208)\end{array}$ & $\begin{array}{c}1.505^{* * *} \\
(0.214)\end{array}$ \\
\hline Population density (2001) & & & & $\begin{array}{l}-3.73 \mathrm{e}-06 \\
(7.64 \mathrm{e}-06)\end{array}$ \\
\hline State fixed effects & $\mathrm{NO}$ & YES & YES & YES \\
\hline Observations & 490 & 490 & 490 & 490 \\
\hline \multicolumn{5}{|c|}{$\begin{array}{l}\text { B: \% of households above poverty line (2008) } \\
\quad(\text { Mean =67.12) }\end{array}$} \\
\hline Religious fractionalization (2001) & $\begin{array}{c}33.57^{* * *} \\
(11.98)\end{array}$ & $\begin{array}{c}18.80^{* *} \\
(6.867)\end{array}$ & $\begin{array}{c}18.76^{* *} \\
(7.376)\end{array}$ & $\begin{array}{c}18.33^{* *} \\
(7.332)\end{array}$ \\
\hline Linguistic fractionalization (2001) & $\begin{array}{l}-5.422 \\
(7.596)\end{array}$ & $\begin{array}{c}-7.456^{* *} \\
(3.154)\end{array}$ & $\begin{array}{l}-4.096 \\
(3.409)\end{array}$ & $\begin{array}{l}-4.249 \\
(3.502)\end{array}$ \\
\hline Colonial period urbanization & $\begin{array}{c}0.634^{* * *} \\
(0.142)\end{array}$ & $\begin{array}{c}0.685^{* * *} \\
(0.155)\end{array}$ & $\begin{array}{c}0.492^{* * *} \\
(0.109)\end{array}$ & $\begin{array}{c}0.402 \\
(0.272)\end{array}$ \\
\hline Literacy (2001) & & & $\begin{array}{c}38.93^{* * *} \\
(4.924)\end{array}$ & $\begin{array}{c}38.35^{* * *} \\
(4.976)\end{array}$ \\
\hline Population density (2001) & & & & $\begin{array}{c}0.000170 \\
(0.000433)\end{array}$ \\
\hline State fixed effects & NO & YES & YES & YES \\
\hline Observations & 567 & 567 & 567 & 567 \\
\hline
\end{tabular}

Our OLS results further suggest that we expect to see stronger results for religious fractionalization than for linguistic fractionalization. Not only are the magnitudes of the coefficients on religious fractionalization greater and more significant in our GDP per capita regressions, religious fractionalization appears to significantly impact poverty, while linguistic fractionalization does not. When we include both indicators in a specification, linguistic fractionalization ceases to have significant impacts on GDP per capita as well.

These initial results hint that there is a considerable link between religious diversity and economic outcomes.Taking a specific example from our sample, the district of Nandurbar in Maharashtra state has a religious fractionalization score of 0.16 , whereas its counterpart from the same state, Nashik, has a religious fractionalization score of about 0.26 , or 0.1 points higher than that of Nandurbar. While Nandurbar has an average per capita GDP of Rs.16735, the average per capita GDP of Nashik is Rs.33442, or almost 100-percent higher than that of Nandurbar. The percentage of households above the poverty line in Nandurbar is $45 \%$, while the same figure for Nashik is $67.4 \%$, i.e. Nashik has about a 50 -percent greater percentage of households living above the poverty line. 
Of course, the positive correlation we see in this example and in our OLS regressions may simply be reflecting the fact that wealthier areas are likely to be more cosmopolitan, characterized by values like tolerance and secularism, and thus attract greater heterogeneity. We attempt to exclude the impacts due to this channel by controlling for past economic development, as measured by past urbanization, in all our specifications. In addition, we control for literacy and population density in some specifications. This seems to make the coefficients on religious and linguistic fractionalization all the more significant. Nevertheless, reverse causation remains a potential problem, and we will deal with this endogeneity concern through the instrumental variables strategy outlined in the next section.

\section{4}

\section{Estimation strategy}

Our estimation strategy is based on the approach used in Tabellini (2010) where within-country variations at the regional level are used to control for institutional differences and isolate the role of culture. In this work, within-state variations, i.e. variation at the district level, is used to to explore the link between historical institutions, culture and economic development. Our goal is to estimate the causal effect of cultural diversity on growth and poverty using the following:

$$
Y=\alpha+\beta C+\gamma Y_{0}+\delta X+e
$$

where $\mathrm{Y}$ is our dependent variable ( $\log$ GDP per capita, percentage of households above poverty line), $\mathrm{C}$ is an indicator of cultural heterogeneity (religious or linguistic fractionalization), $Y_{0}$ is an indicator of past economic development (colonial period urbanization), $\mathrm{X}$ includes the controls specified below, and $e$ is an unobserved error term, which we cluster by state. Our coefficient of interest, $\beta$, estimates the additional gain in our outcome of interest from a unit increase in the respective fractionalization index.

To check that the effect of diversity on economic outcomes is stable to the inclusion of different controls, we introduce the following one by one in our specifications: First, we include state dummies to capture the institutional variation between states. Next, we add literacy to ensure that our results are not merely capturing the effects of human capital accumulation. Lastly, we control for population density to ensure that we are truly capturing the effects of diversity rather than density, which tends to be correlated with both cosmopolitanism and wealth.

However, the inclusion of these controls does not sufficiently ensure that 
our indicator of cultural heterogeneity is not correlated to our unobserved error term. Our results could be prey to reverse causation if wealthier regions attract more diverse populations. In order to deal with this concern, we use the model of culture proposed in Tabellini (2010):

$$
C=a+d C_{0}+b Y_{0}+c X+u
$$

where $C_{0}$ denotes cultural traits of earlier generations, and $u$ is an error term capturing all other determinants of culture.

According to Equation 2-4, current religious or linguistic heterogeneity is determined by past heterogeneity, which would thus serve as an appropriate instrument for the current measure of diversity. In the case of religious fractionalization, we are able to use religious fractionalization from the past as a suitable instrument for the present measure. However, in the case of linguistic fractionalization, we only have the proportion of people not speaking the majority language in the past, which, while correlated with current linguistic fractionalization, does not make for a very strong instrument. For this reason, we use additional instruments for current linguistic fractionalization using the stochastic process postulated by Tabellini (2010) for currently observed culture:

$$
C=\lambda_{1}+\lambda_{2} X_{0}+\lambda_{3} Y_{0}+\lambda_{4} X+v
$$

where $\lambda_{i}$ are parameters, $v$ is an unobserved error term (possibly correlated with $e$, the error term of equation 2-3) and the vector $X_{0}$ includes the historical counterparts of the variables in $\mathrm{X}$, namely education, political institutions and population density. The idea behind Equation 2-5 is that since we don't observe $C_{0}$ in the case of linguistic fractionalization, we can apply the logic of Equation 2-4, which suggests that the culture of earlier generations is shaped by past social interactions. Thus, present culture is correlated with the historical features of the political and economic environment.

We measure historical education using the literacy rate in 1901. Population density from the same year is used. Institutions are measured as the proportion (by area) of individual-based, as opposed to landlord-based, land revenue institutions in 1901. As we outline in detail in Paper 1, there are fundamental differences in the institutional environment in individual vs. landlord dominated regions. Thus, we believe that the proportion of individual-based systems helps capture the historical institutional differences between different districts. Using the instruments described above allows us to isolate the variation in linguistic heterogeneity that is exogenous, i.e. due to the historical variables, from the possibly endogenous variation due to the unobserved error term $v$. 
This estimation strategy rests on two basic premises. The first of these assumptions is that culture is transmitted slowly over time yet also reflects the current environment. In our scenario, this means that the linguistic composition in the present is determined by the linguistic composition in the past. Furthermore, the linguistic composition, in any period, is also correlated with institutions, literacy and population density in that period. This is plausible in our setting because the institutional environment of a place determines whether or not smaller linguistic groups are able to maintain their mother tongue or whether they are forced to assimilate with the majority. Literacy is also relevant to the linguistic composition, particularly in a place like India where vernacular education has always favored more widely spoken languages. Because education would only be accessible to large enough linguistic groups, it is possible to see how literacy may be correlated with linguistic heterogeneity. Lastly, population density would likely be correlated with linguistic heterogeneity because of the tendency of denser places to concentrate a greater variety of cultural groups.

The second assumption on which we base our estimation strategy is that the historical variables for literacy, institutions and population density are valid instruments, uncorrelated with the error term $e$ in Equation 2-3. The identifying assumption is that these past variables do not have direct effects on output other than through the mechanism of current linguistic composition (These reduced form tables can be found in Appendix B.1). This assumption is justified by the fact that our output regression includes present literacy, institutions, and population density in addition to past economic development. Thus we control for the primary channels by which the historical variables could ostensibly impact economic outcomes in the present. Due to the inclusion of these controls, we assume that the impact of past religious fractionalization on current GDP per capita and poverty occurs only through the channel of present religious fractionalization. In the case of linguistic fractionalization, the historical variables we use as instruments appear to have even less significant impacts on GDP per capita and poverty. The sole exception to this is past literacy, which has a positive, significant impact on GDP per capita even after controlling for present literacy. While we believe that the primary way in which past literacy impacts current economic outcomes is through present literacy and linguistic fractionalization, it is possible to foresee other channels through which literacy in the past may impact current productivity, for example, by changing the composition of the labor market over time. To assuage the concern that our exclusion restriction is violated, we include additional specifications that include the gender literacy gap and past sectoral 
composition as controls for labor market composition. These robustness checks dismiss the possibility that past literacy is an invalid instrument due to indirect impacts on productivity through the channel of labor market composition.

Our first stage estimates (Appendix B.2) show that we have strong instruments for religious and linguistic fractionalization. The only exception may be historical population density. However, since it is included in only one out of four IV specifications for linguistic fractionalization, we continue to include it as it seems theoretically plausible that the population density in the past should have some impact on the cultural diversity in the present. Additionally, when we run our IV specifications we test for instrument strength using the Montiel-Pflueger Effective F-statistic, according to which the inclusion of past population density does not decrease the strength of our set of instruments to an unacceptable level.

\section{5}

\section{Results}

\subsection{1}

\section{Instrumental variables}

Our IV results, presented in Tables 2.6-2.8, reveal a considerable impact of religious diversity on economic outcomes. Controlling for past economic development, state fixed effects, literacy, and population density, a unit increase in the religious fractionalization index, i.e. going from complete religious homogeneity (an index of 0 ) to complete religious heterogeneity (an index of 1), is significantly correlated with an average increase of 79-percent in GDP per capita and 55-percent in the percentage of households above the poverty line (Table 2.6, Column 4). Specifications including both types of fractionalization suggest an impact of only a marginally smaller magnitude - a unit increase in religious fractionalization is significantly correlated with a 73-percent increase in GDP per capita and a 53-percent increase in the percentage of households above the poverty line.

Our IV results turn out to be considerably larger in magnitude than our OLS estimates while maintaining similar levels of significance. As in the OLS estimates, religious fractionalization has a positive, significant impact on both growth and poverty that is robust to the inclusion of various different controls (Table 2.6). Linguistic fractionalization, on the other hand, has no significant impacts (Table 2.7). Religious heterogeneity also trumps linguistic heterogeneity in a horse race (Table 2.8). Thus regardless of whether religious diversity and linguistic diversity are studied separately or together, religious 
diversity appears to have much stronger impacts on both growth and poverty.

It is of some concern that we have a clearly superior instrument in the case of religious fractionalization. We are able to calculate the exact same measure from the past, which we are unable to do in the case of linguistic fractionalization. However, as the Montiel-Pflueger efficient F-statistics of our various IV specifications show, we have considerably strong instruments for both religious and linguistic fractionalization, with less than 5-percent bias relative to OLS in many, and less than 10-percent bias relative to OLS in most specifications. Thus it seems unlikely that the weak results for linguistic fractionalization can be attributed to faulty instruments.

Table 2.6: Religious fractionalization and economic outcomes, IV

\begin{tabular}{|c|c|c|c|c|}
\hline & $(1)$ & $(2)$ & $(3)$ & $(4)$ \\
\hline \multicolumn{5}{|l|}{ A: Log GDP per capita (2005) } \\
\hline Religious fractionalization (2001) & $\begin{array}{l}1.218^{*} \\
(0.716)\end{array}$ & $\begin{array}{l}0.573^{*} \\
(0.336)\end{array}$ & $\begin{array}{l}0.775^{* *} \\
(0.329)\end{array}$ & $\begin{array}{l}0.787^{* *} \\
(0.342)\end{array}$ \\
\hline Colonial period urbanization & $\begin{array}{c}0.0512^{* * *} \\
(0.00763)\end{array}$ & $\begin{array}{c}0.0472^{* * *} \\
(0.00331)\end{array}$ & $\begin{array}{c}0.0398^{* * *} \\
(0.00454)\end{array}$ & $\begin{array}{c}0.0424^{* * *} \\
(0.00440)\end{array}$ \\
\hline Literacy (2001) & & & $\begin{array}{c}1.656^{* * *} \\
(0.190)\end{array}$ & $\begin{array}{c}1.674^{* * *} \\
(0.205)\end{array}$ \\
\hline Population density (2001) & & & & $\begin{array}{l}-4.69 \mathrm{e}-06 \\
(8.49 \mathrm{e}-06)\end{array}$ \\
\hline State fixed effects & NO & YES & YES & YES \\
\hline Observations & 426 & 426 & 426 & 426 \\
\hline Montiel-Pflueger Effective F-statistic & $34.513^{* * *}$ & $115.932^{* * * *}$ & $118.918^{* * * *}$ & $116.799^{* * * *}$ \\
\hline \multicolumn{5}{|c|}{$\begin{array}{l}\text { B: \% of households above poverty line (2008) } \\
\quad(\text { Mean =67.12) }\end{array}$} \\
\hline Religious fractionalization (2001) & $\begin{array}{c}63.51^{* * *} \\
(22.62)\end{array}$ & $\begin{array}{l}32.86^{* *} \\
(13.46)\end{array}$ & $\begin{array}{c}36.97^{* * *} \\
(13.47)\end{array}$ & $\begin{array}{c}37.19^{* * *} \\
(13.80)\end{array}$ \\
\hline Colonial period urbanization & $\begin{array}{c}0.346 \\
(0.224)\end{array}$ & $\begin{array}{c}0.560^{* * *} \\
(0.179)\end{array}$ & $\begin{array}{r}0.378^{* *} \\
(0.153)\end{array}$ & $\begin{array}{c}0.424 \\
(0.275)\end{array}$ \\
\hline Literacy (2001) & & & $\begin{array}{c}41.92^{* * *} \\
(8.243)\end{array}$ & $\begin{array}{c}42.26^{* * *} \\
(8.580)\end{array}$ \\
\hline Population density (2001) & & & & $\begin{array}{l}-8.67 \mathrm{e}-05 \\
(0.000391)\end{array}$ \\
\hline State fixed effects & NO & YES & YES & YES \\
\hline Observations & 488 & 488 & 488 & 488 \\
\hline Montiel-Pflueger Effective F-statistic & $40.695 * * * *$ & $114.756^{* * * *}$ & $121.720 * * * *$ & $117.595^{* * * *}$ \\
\hline
\end{tabular}

Robust standard errors in parentheses. ${ }^{* * *} \mathrm{p}<0.01,{ }^{*} * \mathrm{p}<0.05,{ }^{*} \mathrm{p}<0.1$.

Montiel-Pflueger Effective F-statistic maximum relative bias (confidence level $\alpha=5 \%$ ):

$* * * * 5 \%, * * * 10 \%, * * 20 \%, * 30 \%$. 
Table 2.7: Linguistic fractionalization and economic outcomes, IV

\begin{tabular}{|c|c|c|c|c|}
\hline & (1) & $(2)$ & $(3)$ & (4) \\
\hline \multicolumn{5}{|l|}{ A: Log GDP per capita (2005) } \\
\hline Linguistic fractionalization (2001) & $\begin{array}{c}0.254 \\
(0.697)\end{array}$ & $\begin{array}{l}0.0556 \\
(0.281)\end{array}$ & $\begin{array}{c}0.422 \\
(0.292)\end{array}$ & $\begin{array}{c}0.444 \\
(0.285)\end{array}$ \\
\hline Colonial period urbanization & $\begin{array}{c}0.0468^{* * *} \\
(0.0105)\end{array}$ & $\begin{array}{c}0.296^{* * *} \\
(0.0297)\end{array}$ & $\begin{array}{c}0.225^{* * *} \\
(0.0464)\end{array}$ & $\begin{array}{c}0.227^{* * *} \\
(0.0483)\end{array}$ \\
\hline Literacy (2001) & & & $\begin{array}{c}1.614^{* * *} \\
(0.218)\end{array}$ & $\begin{array}{c}1.627^{* * *} \\
(0.230)\end{array}$ \\
\hline Population density (2001) & & & & $\begin{array}{l}-1.56 \mathrm{e}-06 \\
(5.52 \mathrm{e}-06)\end{array}$ \\
\hline State fixed effects & $\mathrm{NO}$ & YES & YES & YES \\
\hline Observations & 443 & 410 & 392 & 392 \\
\hline Montiel-Pflueger Effective F-statistic & 8.326 & $27.030^{* * * *}$ & $22.625^{* * *}$ & $12.203^{* *}$ \\
\hline \multicolumn{5}{|c|}{$\begin{array}{l}\text { B: \% of households above poverty line (2008) } \\
\quad(\text { Mean }=67.12)\end{array}$} \\
\hline Linguistic fractionalization (2001) & $\begin{array}{l}-13.46 \\
(23.22)\end{array}$ & $\begin{array}{l}-6.138 \\
(6.661)\end{array}$ & $\begin{array}{l}-6.744 \\
(7.860)\end{array}$ & $\begin{array}{l}-5.937 \\
(7.388)\end{array}$ \\
\hline Colonial period urbanization & $\begin{array}{c}1.344^{* * *} \\
(0.330)\end{array}$ & $\begin{array}{c}5.327^{* * *} \\
(1.349)\end{array}$ & $\begin{array}{c}3.684^{* * *} \\
(1.081)\end{array}$ & $\begin{array}{c}3.438^{* * *} \\
(1.038)\end{array}$ \\
\hline Literacy (2001) & & & $\begin{array}{c}35.55^{* * *} \\
(7.614)\end{array}$ & $\begin{array}{c}34.74^{* * *} \\
(7.520)\end{array}$ \\
\hline Population density (2001) & & & & $\begin{array}{c}0.000311 \\
(0.000441)\end{array}$ \\
\hline State fixed effects & NO & YES & YES & YES \\
\hline Observations & 502 & 466 & 448 & 448 \\
\hline Montiel-Pflueger Effective F-statistic & 8.614 & $29.053^{* * * *}$ & $23.190^{* * *}$ & $12.051^{* *}$ \\
\hline
\end{tabular}

Robust standard errors in parentheses. ${ }^{* * *} \mathrm{p}<0.01,{ }^{* *} \mathrm{p}<0.05,{ }^{*} \mathrm{p}<0.1$.

Montiel-Pflueger Effective F-statistic maximum relative bias (confidence level $\alpha=5 \%$ ):

$* * * * 5 \%, * * * 10 \%, * * 20 \%, * 30 \%$. 
Table 2.8: Impact of religious and linguistic fractionalization on economic outcomes, IV

\begin{tabular}{|c|c|c|c|c|}
\hline & (1) & $(2)$ & (3) & $(4)$ \\
\hline \multicolumn{5}{|l|}{ A: Log GDP per capita (2005) } \\
\hline \multirow[t]{2}{*}{ Religious fractionalization (2001) } & $1.249^{*}$ & 0.503 & $0.730^{*}$ & $0.726^{* *}$ \\
\hline & $(0.733)$ & $(0.401)$ & $(0.378)$ & $(0.360)$ \\
\hline \multirow[t]{2}{*}{ Linguistic fractionalization (2001) } & -0.0148 & 0.0609 & 0.314 & 0.348 \\
\hline & $(0.833)$ & $(0.257)$ & $(0.236)$ & $(0.232)$ \\
\hline \multirow[t]{2}{*}{ Colonial period urbanization } & $0.0427 * * *$ & $0.277^{* * *}$ & $0.199 * * *$ & $0.206^{* * *}$ \\
\hline & $(0.0105)$ & $(0.0266)$ & $(0.0523)$ & $(0.0507)$ \\
\hline \multirow[t]{2}{*}{ Literacy (2001) } & & & $1.756^{* * *}$ & $1.798^{* * *}$ \\
\hline & & & $(0.234)$ & $(0.251)$ \\
\hline \multirow[t]{2}{*}{ Population density (2001) } & & & & $-8.34 \mathrm{e}-06$ \\
\hline & & & & $(7.66 \mathrm{e}-06)$ \\
\hline State fixed effects & $\mathrm{NO}$ & YES & YES & YES \\
\hline Observations & 395 & 364 & 348 & 348 \\
\hline Kleibergen-Paap rk Wald F-statistic & 3.254 & $25.059^{* * * *}$ & $25.746^{* * * *}$ & $22.033^{* * * *}$ \\
\hline \multicolumn{5}{|c|}{$\begin{array}{l}\text { B: \% of households above poverty line (2008) } \\
\quad(\text { Mean }=67.12)\end{array}$} \\
\hline \multirow[t]{2}{*}{ Religious fractionalization (2001) } & $50.64^{* *}$ & $28.68^{*}$ & $36.45^{* *}$ & $35.69^{* *}$ \\
\hline & $(24.22)$ & $(16.38)$ & $(17.27)$ & $(16.82)$ \\
\hline \multirow[t]{2}{*}{ Linguistic fractionalization (2001) } & -25.88 & -3.970 & -8.004 & -6.667 \\
\hline & $(25.42)$ & $(7.809)$ & $(8.248)$ & $(7.932)$ \\
\hline \multirow[t]{2}{*}{ Colonial period urbanization } & $1.083^{* * *}$ & $4.912^{* * *}$ & $2.863^{* * *}$ & $2.925^{* * *}$ \\
\hline & $(0.236)$ & $(0.939)$ & $(0.605)$ & $(0.617)$ \\
\hline \multirow[t]{2}{*}{ Literacy (2001) } & & & $42.23^{* * *}$ & $42.85^{* * *}$ \\
\hline & & & $(9.666)$ & $(10.31)$ \\
\hline \multirow[t]{2}{*}{ Population density (2001) } & & & & $-6.94 \mathrm{e}-05$ \\
\hline & & & & $(0.000420)$ \\
\hline State fixed effects & $\mathrm{NO}$ & YES & YES & YES \\
\hline Observations & 447 & 414 & 398 & 398 \\
\hline Kleibergen-Paap rk Wald F-statistic & 3.470 & $26.336^{* * * *}$ & $23.999^{* * * *}$ & $20.800^{* * * *}$ \\
\hline
\end{tabular}

Robust standard errors in parentheses. ${ }^{* * *} \mathrm{p}<0.01,{ }^{* *} \mathrm{p}<0.05,{ }^{*} \mathrm{p}<0.1$.

Kleibergen-Paap rk Wald F-statistic maximal IV size (confidence level $\alpha=5 \%$ ):

$* * * * 10 \%, * * * 15 \%, * *_{2} 0 \%,{ }^{*} 25 \%$. 


\subsection{2 \\ Robustness checks}

\subsubsection{1}

\section{The impact of the caste system}

There are two categories of explanations as to why religious diversity should have impacts on economic outcomes. The first has to do with the presence of many religious groups in one place. The positive effects resulting from the presence of multiple religious groups may come from a more diverse pool of of skills and ways of thinking, or they may have to do the values cultivated in places where people different beliefs live side by side, for example, tolerance and syncretism. They might also arise via the institutional environment of places where many religious groups coexist. For example, unlike places with homogenous religious populations, where religious norms can play a considerable role in controlling devious behavior, places with numerous religions may be inclined towards stronger secular institutions in order to define norms in society.

The second category of explanations focuses on the attributes of a particular religion rather than diversity per se. For example, if we assume that Hinduism, which is the majority religion in our sample, has negative impacts on economic outcomes, then the presence of other religious groups, which naturally would mean a smaller proportion of Hindus, would have positive impacts on growth and poverty. Similarly, if the minority groups in our sample are wealthier as a whole, this would also yield a positive impact of religious diversity on economic outcomes. In either case, the impact stems less from diversity and more from the absence or presence of particular religions.

We do not believe it is likely that our results are stemming from the presence of rich minority religions. In general, Muslims, who make up the largest minority group and thus drive much of our diversity indicators, fare much worse on poverty indicators (John and Mutakar, 2005. Panagariya and More, 2013). However, the possibility that the majority religion may have attributes that negatively impact economic growth is more difficult to discard since there is a considerable body of academic work suggesting that Hinduism may hamper growth. Max Weber, in his comparison of major world religions, argued that the effect of Hinduism on South Asian economic progress was "essentially negative" (Weber 2000, 2013). More recently, economists have shown how particular aspects of the Hindu religion, particularly the caste system, has undesirable economic consequences. Apart from leading to non-Pareto optimal outcomes and a skewed income distribution (Akerlof 1976), 
the caste system may also serve as an impediment to trade (Anderson 2011), add additional transition costs to the labor market (Ito 2009), and lead to a possible dynamic inefficiency in schooling choices (Munshi and Rosenzweig 2006). Empirical studies have also found evidence that Hinduism and the caste system engender a focus on casual labor, while Muslim and Christian populations are more likely to be entrepreneurial (Audretsch 2009). For all these reasons, Hinduism could ostensibly have a dampening effect on the economy. In this case increased heterogeneity would positively impact growth and poverty indicators only because of the relatively smaller presence of Hindus in the population.

In this section we attempt to show that our results are not due to the absence or presence of the majority religion by controlling for Hinduism and the caste system in our IV specifications. Specifically, we control for the proportion of Hindus and scheduled castes $^{5}$ in the population. We also run specifications which include the crime rate against scheduled castes, as this may indicate the degree to which the discriminatory aspects of the caste system are embedded in a particular district. In addition, Appendix B.3 includes specifications controlling for the proportion of each religion, separately and together.

Overall, the results shown in Table 2.9 suggest that our results are due to diversity driven explanations and not merely due to the presence or absence of Hinduism. The coefficient on religious fractionalization continues to be significant and positive even after controlling for Hinduism and our various measures of the caste system. These results also show positive coefficients on the percentage of Hindus, thus ruling out the negative impact of Hinduism on overall economic outcomes for the district. We also find, counterintuitively, that the scheduled caste percentage is positively correlated with the percentage of households above the poverty line. This is likely indicative of the high inequality prevalent in areas with large numbers of scheduled castes. Crimes against Scheduled Caste are negatively correlated with the percentage of households above the poverty line but positively correlated with GDP per capita. This suggests that caste antipathy is likely to be more prevalent in districts characterized by inequality, i.e. those that have a high GDP per capita but a low percentage of households above the poverty line.

\footnotetext{
${ }^{5}$ Scheduled caste is the officially designated term for historically disadvantaged castes, i.e. those once considered 'untouchable' by orthodox Hindu scriptures and practice.
} 
Table 2.9: Religious fractionalization and economic outcomes, IV estimates with additional controls for Hinduism and caste

\begin{tabular}{|c|c|c|c|c|}
\hline & (1) & $(2)$ & (3) & (4) \\
\hline \multicolumn{5}{|l|}{ A: Log GDP per capita (2005) } \\
\hline Religious fractionalization (2001) & $\begin{array}{c}1.012^{*} \\
(0.523)\end{array}$ & $\begin{array}{c}0.787^{* *} \\
(0.341)\end{array}$ & $\begin{array}{c}0.803^{* *} \\
(0.339)\end{array}$ & $\begin{array}{c}0.805^{* *} \\
(0.342)\end{array}$ \\
\hline Hindu \% (2001) & $\begin{array}{c}0.232 \\
(0.360)\end{array}$ & & & \\
\hline $\mathrm{SC} \%$ & & $\begin{array}{l}-1.42 \mathrm{e}-05 \\
(3.32 \mathrm{e}-05)\end{array}$ & $\begin{array}{c}2.35 \mathrm{e}-05 \\
(3.91 \mathrm{e}-05)\end{array}$ & $\begin{array}{c}2.38 \mathrm{e}-05 \\
(3.96 \mathrm{e}-05)\end{array}$ \\
\hline Crime rate against SCs (2001) & & & $\begin{array}{c}5.983^{* * *} \\
(0.458)\end{array}$ & $\begin{array}{c}5.897^{* * *} \\
(0.474)\end{array}$ \\
\hline $\mathrm{SC} \% \times$ Crime rate against SCs & & & & $\begin{array}{c}56.76 \\
(254.0)\end{array}$ \\
\hline Colonial period urbanization & $\begin{array}{c}0.0424^{* * *} \\
(0.00441)\end{array}$ & $\begin{array}{c}0.0424^{* * *} \\
(0.00440)\end{array}$ & $\begin{array}{c}0.0422^{* * *} \\
(0.00436)\end{array}$ & $\begin{array}{c}0.0421^{* * *} \\
(0.00436)\end{array}$ \\
\hline Literacy (2001) & $\begin{array}{c}1.633^{* * *} \\
(0.183)\end{array}$ & $\begin{array}{c}1.675^{* * *} \\
(0.205)\end{array}$ & $\begin{array}{c}1.681^{* * *} \\
(0.211)\end{array}$ & $\begin{array}{c}1.680^{* * *} \\
(0.210)\end{array}$ \\
\hline Population density (2001) & $\begin{array}{c}-4.95 \mathrm{e}-06 \\
(8.67 \mathrm{e}-06)\end{array}$ & $\begin{array}{c}-4.70 \mathrm{e}-06 \\
(8.48 \mathrm{e}-06)\end{array}$ & $\begin{array}{l}-4.53 \mathrm{e}-06 \\
(8.39 \mathrm{e}-06)\end{array}$ & $\begin{array}{l}-4.45 \mathrm{e}-06 \\
(8.34 \mathrm{e}-06)\end{array}$ \\
\hline State fixed effects & YES & YES & YES & YES \\
\hline Observations & 426 & 426 & 424 & 424 \\
\hline Montiel-Pflueger Effective F-statistic & 8.775 & $116.793^{* * * *}$ & $114.651^{* * * *}$ & $112.471^{* * * *}$ \\
\hline \multicolumn{5}{|c|}{$\begin{array}{l}\text { B: \% of households above poverty line (2008) } \\
\quad(\text { Mean }=67.12)\end{array}$} \\
\hline Religious fractionalization (2001) & $\begin{array}{l}43.53^{* *} \\
(19.02)\end{array}$ & $\begin{array}{c}37.16^{* * *} \\
(13.79)\end{array}$ & $\begin{array}{c}37.15^{* * *} \\
(13.84)\end{array}$ & $\begin{array}{c}37.55^{* * *} \\
(13.96)\end{array}$ \\
\hline Hindu \% (2001) & $\begin{array}{c}6.853 \\
(11.42)\end{array}$ & & & \\
\hline $\mathrm{SC} \%(2001)$ & & $\begin{array}{c}0.00889^{* * *} \\
(0.00129)\end{array}$ & $\begin{array}{c}0.00968^{* * *} \\
(0.00155)\end{array}$ & $\begin{array}{c}0.00974^{* * *} \\
(0.00157)\end{array}$ \\
\hline Crime rate against SCs (2001) & & & $\begin{array}{l}-17.71 \\
(17.63)\end{array}$ & $\begin{array}{c}-38.50^{* *} \\
(18.60)\end{array}$ \\
\hline SC \% times Crime rage against SCs & & & & $\begin{array}{c}13,659^{* *} \\
(6,334)\end{array}$ \\
\hline Colonial period urbanization & $\begin{array}{c}0.426 \\
(0.278)\end{array}$ & $\begin{array}{c}0.424 \\
(0.276)\end{array}$ & $\begin{array}{c}0.423 \\
(0.275)\end{array}$ & $\begin{array}{c}0.418 \\
(0.275)\end{array}$ \\
\hline Literacy (2001) & $\begin{array}{c}40.18^{* * *} \\
(8.246)\end{array}$ & $\begin{array}{c}42.03^{* * *} \\
(8.613)\end{array}$ & $\begin{array}{c}42.41^{* * *} \\
(8.631)\end{array}$ & $\begin{array}{c}42.17^{* * *} \\
(8.724)\end{array}$ \\
\hline Population density (2001) & $\begin{array}{l}-8.76 \mathrm{e}-05 \\
(0.000395)\end{array}$ & $\begin{array}{l}-8.36 \mathrm{e}-05 \\
(0.000392)\end{array}$ & $\begin{array}{c}-8.46 \mathrm{e}-05 \\
(0.000391)\end{array}$ & $\begin{array}{c}-7.66 \mathrm{e}-05 \\
(0.000394)\end{array}$ \\
\hline State fixed effects & YES & YES & YES & YES \\
\hline Observations & 488 & 488 & 485 & 485 \\
\hline Montiel-Pflueger Effective F-statistic & $18.203^{* *}$ & $117.429 * * * *$ & $115.513^{* * * *}$ & $113.040^{* * * *}$ \\
\hline
\end{tabular}

Robust standard errors in parentheses. ${ }^{* * *} \mathrm{p}<0.01,{ }^{* *} \mathrm{p}<0.05,{ }^{*} \mathrm{p}<0.1$.

Montiel-Pflueger Effective F-statistic maximum relative bias (confidence level $\alpha=5 \%$ ):

$* * * * 5 \%, * * * 10 \%, * * 20 \%, * 30 \%$. 


\subsubsection{2}

\section{Religious polarization}

Another concern stemming from the presence of a dominant majority religion is that perhaps our results overemphasize the positive side of cultural heterogeneity while downplaying the negative aspects because social conflict is artificially suppressed due to the sheer size of the majority group, which makes up about eighty percent of the population in the country as a whole. In order to better capture the competition between different religious groups, here we use an alternative indicator, polarization, measured as follows:

$$
R P_{i}=1-\sum_{j=1}^{N}\left(\frac{1 / 2-r_{i j}}{1 / 2}\right)^{2} r_{i j}
$$

where $R P_{i}$ is religious polarization in district $i$ and $r_{i j}$ is the share of religious group $j(J=1 \ldots N)$ in district $i$. This measure captures how far the distribution of the religious groups is from the bipolar distribution, and is maximized when there are two groups of equal size. Compared to fractionalization, this indicator better captures the potential for social conflict that is inherent with diversity (Montalvo and Reynal-Querol, 2005b). Our results in Table 2.10 show, however, that even when we use polarization in place of fractionalization, religious diversity continues to have significant, positive impacts on both growth and poverty. Thus, even factoring in the potential for conflict, it appears that the benefits of religious diversity outweigh the drawbacks.

\subsubsection{3}

\section{Controlling for additional impacts of past literacy}

Our reduced form estimates in Section 3 show that past literacy has a direct impact on current GDP per capita even after controlling for present literacy. This raises the concern that our instrument may be violating the exclusion restriction. Though we argue that past literacy impacts current economic outcomes only through present literacy and the linguistic composition of a region, another plausible channel through which past literacy could impact current economic outcomes may be by changing the long term composition of the labor market. In this section we explore this possibility by controlling for the gender gap in literacy as well as past sectoral composition, i.e. the percentage of the population engaged in the agricultural sector. We find that the inclusion of these controls yields essentially the same results as we found for linguistic fractionalization in our primary IV specification, with positive, insignificant impacts on GDP per capita and negative, insignificant impacts on the percentage of households above the poverty line (Table 2.11) . 
Table 2.10: Religious polarization and economic outcomes, IV

\begin{tabular}{|c|c|c|c|c|}
\hline & $(1)$ & $(2)$ & $(3)$ & $(4)$ \\
\hline \multicolumn{5}{|l|}{ A: Log GDP per capita (2005) } \\
\hline Religious polarization (2001) & $\begin{array}{c}0.472 \\
(0.381)\end{array}$ & $\begin{array}{c}0.265 \\
(0.182)\end{array}$ & $\begin{array}{c}0.437^{* *} \\
(0.176)\end{array}$ & $\begin{array}{c}0.406^{* *} \\
(0.176)\end{array}$ \\
\hline Colonial period urbanization & $\begin{array}{l}0.109^{* *} \\
(0.0487)\end{array}$ & $\begin{array}{c}0.0786^{* *} \\
(0.0397)\end{array}$ & $\begin{array}{c}0.0523 \\
(0.0363)\end{array}$ & $\begin{array}{c}0.0303 \\
(0.0275)\end{array}$ \\
\hline Literacy (2001) & & & $\begin{array}{c}1.738^{* * *} \\
(0.202)\end{array}$ & $\begin{array}{c}1.636^{* * *} \\
(0.205)\end{array}$ \\
\hline Population density (2001) & & & & $\begin{array}{l}2.41 \mathrm{e}-05^{*} \\
(1.36 \mathrm{e}-05)\end{array}$ \\
\hline State fixed effects & $\mathrm{NO}$ & YES & YES & YES \\
\hline Observations & 426 & 426 & 426 & 426 \\
\hline Montiel-Pflueger Effective F-statistic & $42.992^{* * * *}$ & $92.109 * * * *$ & $96.407^{* * * *}$ & $97.328^{* * * *}$ \\
\hline \multicolumn{5}{|c|}{$\begin{array}{l}\text { B: \% of households above poverty line (2008) } \\
\quad(\text { Mean }=67.12)\end{array}$} \\
\hline Religious polarization (2001) & $\begin{array}{c}34.67^{* * *} \\
(12.98)\end{array}$ & $\begin{array}{c}16.43^{* *} \\
(6.962)\end{array}$ & $\begin{array}{c}19.83^{* * *} \\
(7.177)\end{array}$ & $\begin{array}{c}19.73^{* * *} \\
(7.287)\end{array}$ \\
\hline Colonial period urbanization & $\begin{array}{c}-0.0576 \\
(0.920)\end{array}$ & $\begin{array}{c}1.392^{* * *} \\
(0.488)\end{array}$ & $\begin{array}{c}0.870^{* *} \\
(0.379)\end{array}$ & $\begin{array}{c}0.827^{* *} \\
(0.400)\end{array}$ \\
\hline Literacy (2001) & & & $\begin{array}{c}42.75^{* * *} \\
(8.440)\end{array}$ & $\begin{array}{c}42.47^{* * *} \\
(8.787)\end{array}$ \\
\hline Population density (2001) & & & & $\begin{array}{c}6.22 \mathrm{e}-05 \\
(0.000351)\end{array}$ \\
\hline State fixed effects & NO & YES & YES & YES \\
\hline Observations & 488 & 488 & 488 & 488 \\
\hline Montiel-Pflueger Effective F-statistic & $42.548^{* * * *}$ & $100.176^{* * * *}$ & $108.157^{* * * *}$ & $105.566^{* * * *}$ \\
\hline
\end{tabular}

\section{6}

\section{Discussion}

Our results indicate that considerable differences in growth and development outcomes can be attributed to religious fractionalization, which has significant, positive impacts on both GDP per capita and the percentage of households above the poverty line.

A preliminary concern to claiming primacy for religious fractionalization over linguistic fractionalization is our stronger instrument for religious fractionalization. This begets the possibility that we find stronger impacts for religious fractionalization only because we are not able to properly estimate the impact of linguistic fractionalization. However, we find that for the most part, our effective F-statistics for linguistic fractionalization fall within the realm of an acceptable level of IV bias. Furthermore, our OLS estimates confirm that religious fractionalization has larger and more significant impacts than linguistic fractionalization on growth and poverty. Thus there there is little to suggest that poor instruments are obfuscating a significant relationship between linguistic fractionalization and economic outcomes. 
Table 2.11: Linguistic fractionalization and economic outcomes, IV estimates with additional controls

\begin{tabular}{|c|c|c|c|c|}
\hline & $(1)$ & $(2)$ & $(3)$ & $(4)$ \\
\hline \multicolumn{5}{|l|}{ A: Log GDP per capita (2005) } \\
\hline Linguistic fractionalization (2001) & $\begin{array}{c}0.370 \\
(0.310)\end{array}$ & $\begin{array}{c}0.406 \\
(0.305)\end{array}$ & $\begin{array}{c}0.497 \\
(0.327)\end{array}$ & $\begin{array}{c}0.528 \\
(0.328)\end{array}$ \\
\hline Colonial period urbanization & $\begin{array}{c}0.183^{* * *} \\
(0.0589)\end{array}$ & $\begin{array}{c}0.188^{* * *} \\
(0.0610)\end{array}$ & $\begin{array}{l}0.178^{* *} \\
(0.0725)\end{array}$ & $\begin{array}{l}0.182^{* *} \\
(0.0720)\end{array}$ \\
\hline Literacy (2001) & $\begin{array}{l}1.270^{* * *} \\
(0.252)\end{array}$ & $\begin{array}{c}1.300^{* * *} \\
(0.258)\end{array}$ & $\begin{array}{c}1.331^{* * *} \\
(0.309)\end{array}$ & $\begin{array}{c}1.372^{* * *} \\
(0.317)\end{array}$ \\
\hline Gender gap in literacy (2001) & $\begin{array}{c}-1.614^{* * *} \\
(0.388)\end{array}$ & $\begin{array}{c}-1.629 * * * \\
(0.375)\end{array}$ & $\begin{array}{l}-1.599 * * * \\
(0.415)\end{array}$ & $\begin{array}{c}-1.638^{* * *} \\
(0.411)\end{array}$ \\
\hline Agricultural \% of population (1901) & & & $\begin{array}{l}-0.272 \\
(0.295)\end{array}$ & $\begin{array}{l}-0.287 \\
(0.299)\end{array}$ \\
\hline Population density (2001) & & $\begin{array}{l}-6.69 \mathrm{e}-06 \\
(5.76 \mathrm{e}-06)\end{array}$ & & $\begin{array}{l}-1.57 \mathrm{e}-05 \\
(1.22 \mathrm{e}-05)\end{array}$ \\
\hline State fixed effects & YES & YES & YES & YES \\
\hline Observations & 392 & 392 & 353 & 353 \\
\hline Montiel-Pflueger Effective F-statistic & $22.430 * * *$ & $12.014^{* *}$ & $24.385^{* * *}$ & $11.470^{*}$ \\
\hline \multicolumn{5}{|c|}{$\begin{array}{l}\text { B: \% of households above poverty line (2008) } \\
\quad(\text { Mean = 67.12) }\end{array}$} \\
\hline Linguistic fractionalization (2001) & $\begin{array}{l}-8.983 \\
(8.509)\end{array}$ & $\begin{array}{c}-7.616 \\
(8.110)\end{array}$ & $\begin{array}{l}-4.200 \\
(9.442)\end{array}$ & $\begin{array}{l}-2.986 \\
(9.440)\end{array}$ \\
\hline Colonial period urbanization & $\begin{array}{c}2.473^{* * *} \\
(0.782)\end{array}$ & $\begin{array}{c}2.363^{* * *} \\
(0.712)\end{array}$ & $\begin{array}{l}2.024^{* *} \\
(0.841)\end{array}$ & $\begin{array}{l}2.034^{* *} \\
(0.821)\end{array}$ \\
\hline Literacy (2001) & $\begin{array}{c}24.73^{* * *} \\
(7.130)\end{array}$ & $\begin{array}{c}24.92^{* * *} \\
(7.054)\end{array}$ & $\begin{array}{c}26.13^{* * *} \\
(9.032)\end{array}$ & $\begin{array}{c}26.28^{* * *} \\
(8.999)\end{array}$ \\
\hline Gender gap in literacy (2001) & $\begin{array}{c}-48.01^{* * *} \\
(11.32)\end{array}$ & $\begin{array}{l}-45.88^{* * * *} \\
(11.78)\end{array}$ & $\begin{array}{c}-45.16^{* * *} \\
(11.84)\end{array}$ & $\begin{array}{l}-42.92^{* * *} \\
(12.38)\end{array}$ \\
\hline Agricultural \% of population (2001) & & & $\begin{array}{r}-19.62^{*} \\
(10.03)\end{array}$ & $\begin{array}{c}-19.51^{*} \\
(10.05)\end{array}$ \\
\hline Population density (2001) & & $\begin{array}{c}0.000200 \\
(0.000425)\end{array}$ & & $\begin{array}{c}0.000226 \\
(0.000569)\end{array}$ \\
\hline State fixed effects & YES & YES & YES & YES \\
\hline Observations & 448 & 448 & 404 & 404 \\
\hline Montiel-Pflueger Effective F-statistic & $23.150^{* * *}$ & $11.841^{* *}$ & $23.504^{* * *}$ & $11.386^{* *}$ \\
\hline
\end{tabular}

Our results appear to contradict the takeaway from Alesina (2003) that ethnic and linguistic fractionalization, more so than religious fractionalization, are likely to be important determinants of economic outcomes. Firstly, it is certainly empirically possible for us to get different results as our study is at the sub-national rather than cross-country like like Alesina (2003). Secondly, the negative correlations presented in that work between various outcomes and dimensions of fractionalization are largely insignificant. The results that are most significant in Alesina (2003) are the correlations between fractionalization and quality of government, and in these, religious fractionalization appears to have a positive impact whereas ethnic and linguistic fractionalization have negative impacts. Thirdly, as pointed out in Alesina (2003) the patterns of cross-correlation between various indices make these horse races very difficult 
to resolve. Our results are complementary insofar as they shed light on different aspects of the same complex relationship between different dimensions of fractionalization and their impact on economic outcomes.

That said, the differences in our results may be explained by the lower mean value of religious fractionalization in India than in the sample from Alesina (2003) (Table 2.12), which may be attributed to the sub-national nature of our study. The literature on diversity and the endogenous formation of jurisdictions suggests that the optimal size and number of jurisdictions emerges from a tradeoff between the benefits and costs of heterogeneity (Alesina and Ferrara 2005, Alesina and Spolaore 1997, 2003). This is more likely to be possible in our sample since cultural factors may be taken into consideration relatively easily while making the administrative decision to split districts, whereas it is much more difficult to define country borders on such principles. Furthermore, though the number of religious and linguistic groups in India is large, the size of the minority groups is relatively small. This is particularly true because of the historical incident of Partition, whereby the region formerly known as India was divided into India and Pakistan (and Bangladesh, which was then known as East Pakistan). Partition led to a mass exodus of Muslims and an influx of Hindus into present-day India. Though this process involved much violent conflict, the end result was that particular regions - in this case, the nations of India, Pakistan, and Bangladesh - came to be dominated by one religion or the other. Despite the massive violence and conflict that marked Partition, paradoxically, it may also have served as a suppressor of the future potential for conflict, as communal strife would be less likely if groups are unevenly matched. Though our results cannot be attributed solely to the impact of Partition (see Appendix B.4 for specifications in which we drop the regions most affected by Partition and continue to find significant, positive impacts of religious fractionalization), it may well be the case that religious diversity is more likely to be beneficial when conflict is minimized because of uneven group strengths. In our sample, we see that religious diversity decreased, rather than increased, over the period 1901-2001. We also find, in OLS specifications, that religious fractionalization in the past appeared to have insignificant impacts on literacy and public goods provision (See Appendix B.5), suggesting that perhaps the positive impacts of religious diversity only manifested at slightly lower average levels of diversity.

However, no matter how diminished, the potential for conflict is always a real threat in a situation with diversity, as evidence by the many incidences of communal violence in India even after Partition. Why then, despite this elevated likelihood of conflict, which in the case of India has often borne fruit 
Table 2.12: Comparison of fractionalization indices

\begin{tabular}{lccccc}
\hline \hline & \multicolumn{2}{c}{$\begin{array}{c}\text { Cross-country sample from } \\
\text { Alesina et al. (2003) }\end{array}$} & & \multicolumn{2}{c}{ Indian districts } \\
\cline { 2 - 3 } \cline { 5 - 6 } Variable & Obs. & Sample mean & & Obs. & Sample mean \\
\hline Religious fractionalization & 198 & 0.439 & & 576 & 0.246 \\
Linguistic fractionalization & 185 & 0.385 & & 576 & 0.392 \\
\hline
\end{tabular}

in a very violent form, should the fact of different religions living side by side be beneficial for economic outcomes? We propose three mechanisms by which religious heterogeneity may impact growth and poverty. The first of these is the diversity of skills argument that is often emphasized in empirical studies using birthplace diversity as the measure of cultural heterogeneity. The second possibility is that of a value-based mechanism whereby religious diversity may have positive impacts through inter-cultural exchanges leading to changes in the values prevalent in a region. Lastly, we propose the possibility of differences in institutional environment that come about as a result of cultural diversity.

The skills argument, which may be more easily applicable to relatively recent immigrant groups, has interesting implications in the case of India. On one hand, the various religious groups represented in the population have historically been in the country for centuries and assimilated into the general populace, so it seems unlikely that any particular group would have unique skills distinct from the rest of the population. On the other hand, in a place like India, where the traditional social hierarchy of the caste system organized people into economic specializations by virtue of their birth, perhaps it is not so ludicrous to imagine a scenario where different religious groups and subgroups would indeed maintain a monopoly over certain trades and the skills associated with that trade. Additionally, some groups may also have historically dominated particular industries, professions, or skills under the patronage of pre-colonial native rulers.

Thus, due to the longevity of the socioeconomic hierarchies existing in various regions of India, it is plausible to imagine initial skill discrepancies between different religious groups persisting over a long period of time. Perhaps historical evidence of this is found in the dominance of certain religions over certain professions. For example, members of the Jain community are known for their skill in business and trade. The small Jewish population of India, similarly, was at the forefront of commerce even during the colonial period. While these are small communities, and relatively easier to fit into a profession and its related skill profile, it is much harder to classify larger 
communities like Hindus and Muslims, within which a much greater diversity of skill profiles is likely to be found. However, even these larger groups or subgroups within these religions - could cultivate a traditional skill set in specific regional settings. There may even be situations in which multiple religious communities specialize in different steps of the production process of a single product. For example, in the Benares region, which is famed for its traditional gold and silver embroidered silk fabrics, the weavers are usually Muslim while the embroiderers are Hindu. In cases like this, where different skills become the traditional domain of particular communities, religious heterogeneity could certainly increase productivity by diversifying the skill pool and aiding specialization. Increased productivity and, subsequently, increased prosperity may also explain the positive results we see for poverty.

Another plausible mechanism by which diversity could lead to improved economic outcomes is through values. At the beginning of the twentieth century, Max Weber published the book The Protestant Ethic and the Spirit of Capitalism, which had as its main thesis that certain religious groups held values that were inherently conducive to productivity and the accumulation of wealth (Weber 2013). More recent empirical works have argued in a similar vein, linking productivity to religious beliefs (Arslan 2001, Barro and McCleary 2003). These works raise the possibility that certain values, beliefs, and worldviews may be more conducive to growth than others. This value-centered mechanism implies that something about the mix of values present in religiously diverse regions renders them more productive than areas that are otherwise similar but characterized by religious homogeneity.

There are three ways that the value mechanism could manifest. First, it is possible that the preexisting values of the particular religions represented in the mix happen to be the ones that are most conducive to productivity. We are inclined to rule out this particular explanation since we already showed that our results are likely not due to the absence or presence of any one religion, and therefore, to the values represented by that religion. The other two ways that the value mechanism could manifest require cultural interchange. One form that this could take is that specific values of two or more religions interact to lead to a syncretic belief system that is conducive to positive economic outcomes. For example, the combination of Hinduism's focus on specialized roles and the Islamic focus on discipline could be conducive to productivity. Or the Hindu idea of karma and the Islamic emphasis on charity could lead to a value system concerned with social justice, which prioritizes welfare in public life, thus leading to improved poverty outcomes. The other interactive value explanation is that rather than the emergence of specific syncretic beliefs, 
the experience of living side by side may promote generalized values such as tolerance, which would potentially have a beneficial impact on productivity by promoting cooperation. Both these value mechanisms rely on the experience of coexistence between different religions, though it is perhaps difficult to distinguish the effects of one from the other clearly in empirical work.

The last mechanism we propose as an explanation for the impact of diversity on economic outcomes has to do with the institutional environment necessitated by the presence of religious plurality. This may come about due to intentional institutional design or it may emerge as a natural political shift towards secularization as a result of religious competition. The conceptual case for the latter is made in Cantoni et al. (2018). In either case, the institutional result we would expect from the presence of many religious groups is an emphasis on strong, secular institutions. In fact, Alesina (2003) also provides support for this possibility with its finding that religious diversity is correlated with better institutions.

How well does this institutional hypothesis apply to India? The constitutional process in the country happened in the backdrop of great religious violence, and was thus explicitly defined by the need to build a set of institutions that would protect and uphold the nation's secular nature. This took the form of multiple law boards to meet the needs of different religions in civil law while unifying the country under a common penal code. Apart from this, there are many mechanisms built in to the constitution that are designed expressly with the purpose of avoiding inter-religious conflict. For example, though the constitution guarantees the right to free speech, certain forms of religiously offensive speech, with the potential to incite communal violence, are illegal.

While many of these institutional aspects are national and common to the entire country, in practice the extent to which the secular nature of national institutions is upheld could differ from region to region. It may be that in regions where a greater variety of religious groups form part of the political equation, lawmakers are forced to maintain, or at least give the appearance of maintaining, institutions that are impartial and sensitive to the needs of each religious group. Furthermore, the fact of religious diversity would mean that traditional, religious institutions - for example, imams who may have traditionally guided local Muslim communities on applications of Sharia law - would find their power limited due to their authority only holding amongst the members of that group. This would further encourage people to turn to secular, national institutions like the court system. Presumably, the unity of various communities under a common legal system is likely to be beneficial for 
the functioning of markets. Impartial and well-functioning secular institutions may also be better at targeting welfare programs towards those who need it most, thus leading to improved poverty outcomes.

One concern to accepting the institutional hypothesis is that it appears to contradict empirical findings that suggest that increased diversity leads to worse provision of public goods due to the competition between various religious groups. It seems counterintuitive that religious diversity could induce better institutions while diversity in general leads to worse public good provision. However, it should be pointed out here that the reason for poor public good provision under conditions of diversity is an inability to agree rather than the quality of institutions per se. A second objection to the institutional hypothesis in our results is that we already control for institutional differences between states. Institutional differences persisting below the state-level, i.e. at the district-level, seems unlikely given that the particular political party controlling a given state would likely implement policies at the state-level. However, the matter of how much power secular, government institutions enjoy relative to traditional, religious institutions may be determined at a local level. It is reasonable to consider that the particular religious composition of a given district could have impacts on the relative importance given to modern, secular institutions implemented by the state versus traditional, local institutions drawing their authority from the religious beliefs of a particular community.

Almost all the mechanisms that we discuss here - skills, values, and institutions - are more likely to be associated with religious diversity than with linguistic diversity. Within them, the value-based explanation is perhaps most specific to religion because of the prescribed world views that many religions impart to their followers. Linguistic differences, which may involve other differences, such as obstacles to communication, do not create as great a gulf in customary beliefs and values - i.e. the commonly accepted economic definition of what constitutes "culture" (Guiso et al., 2006) — as religious differences do. A value-based explanation of our results would, therefore, explain why we see much stronger positive results for religious heterogeneity than for linguistic heterogeneity.

That said, it is difficult to say which of the above outlined mechanisms is primarily responsible for our results. Most likely, they do not operate in isolation. Religious diversity may impact economic outcomes through multiple mechanisms within which some take primacy. In particular, it seems that diversity of skills is best tapped when the institutions and values of a given society celebrate, rather than penalize heterogeneity. At the same time, 
complementarity of different skill profiles may lead to the development of institutions that promote inter-religious exchange. For example, a study by Saumitra Jha (2007) on the incentives shaping Hindu-Muslim interactions in the medieval and colonial periods proposes that cooperative institutions were likely to arise in places where medieval Hindus and Muslims could provide complementary, non-replicable services and where they could share the gains from trade. Thus a diversity of skill profiles - given that these skills are complementary rather than competitive - might not only aid productivity, but also impact institutions in a manner conducive to reducing conflict, thus mitigating the primary negative impact of diversity.

Within institutions and values, it is more challenging to propose a causative relationship. Institutions have to operate within a cultural environment defined by the values of the people making up the population. Places where values are conducive to cooperation and mutual coexistence likely make better environments for the functioning of political and economic institutions. Since values are relatively constant over time, they make a convincing mechanism for the primary mechanism by which diversity impacts economic outcomes. At the same time, the fact that institutions can be changed more readily than values does not necessarily mean that they are always reactive. Institutions may well have the potential to change values over time. Legally enforced incentives can be powerful instigators of cultural change. The discontinuation of polygamy or the banning of child marriage are historical examples of institutional changes that changed formerly culturally accepted behavior, eventually leading to greater shifts in beliefs above marriage. That said, institutional design is often carried out by a small group of people, i.e. legislators, and the role of their value-based judgements in building institutions cannot be ignored. Furthermore, in most democratic systems, even the best designed institutions cannot operate in a vacuum from the values of the populace at large. The relationship between values and institutions is a thus a complex one, and in general, it seems that they behave as parallel channels through which a set of historical circumstances, i.e. the events that contribute to the degree of religious diversity in a given place, may impact long run economic outcomes.

\section{7}

\section{Conclusion}

The results presented here are notable because they highlight a scenario in which cultural heterogeneity not only does not have negative impacts but, in fact, proves to be beneficial for economic outcomes. These findings are all 
the more remarkable because of their setting in the developing world and their use of an indicator other than birthplace diversity. This latter fact also suggests that mechanisms beyond skill diversity may play a part in explaining the positive impacts of cultural heterogeneity. Perhaps most crucially, however, our results show that even in a country where religious strife is still common, diversity is a cause for celebration rather than despair.

In a more general vein, we provide evidence that cultural differences matter, and sketch out a framework by which initial historical conditions may have long-term impacts on economic outcomes through the incidence of diversity. This work serves to build a causal case for the economic impacts of cultural diversity, which is influenced by cultural diversity in the past, which, in turn, is a function of historical conditions and events. In this sense, we outline here how culture may be a parallel channel, alongside institutions, through which history has a long run impact on development paths. We do not wish to imply, however, that culture operates in isolation from institutions. To the contrary, the mechanism through which religious diversity in our sample impacts long run growth likely has to do with the institutional environment, in particular, a move towards more secular institutions. The main takeaway here is less about whether values change institutions or institutions change values - examples of both are numerous throughout history, and to discuss this question is akin to the question of chicken versus egg - and more about the proposition that together, culture and institutions form a potent force through which initial historical conditions influence long run patterns of development and growth.

If at first glance this appears to be a deterministic view of history and development, it is not. Rather, this work aims to shed some light on the complex interplay between history, institutions, and culture, particularly through the lens of cultural diversity, which remains a heated political topic in many parts of the world, both developed and developing. Of course, we cannot negate the considerable body of empirical literature that highlights the negative consequences of diversity, nor deny the many lives that have been lost in wars fought over cultural differences. However, our hope is that, in a world that is more than ever defined by divisions of race, ethnicity, language, and faith, our results may play a small part in highlighting the great potential of diversity as a force for human progress. 


\section{3 \\ Goddesses and growth: The formation of cultural values and their impact on development}

\section{1 \\ Introduction}

How does culture uphold the ways of life necessitated by our physical surroundings? And what role does it play in defining the trajectory of development? In this work, we attempt to answer these questions by studying the link between geography, culture, and development. In particular, we examine the role of geographic attributes in the formation of cultural values regarding women, and the subsequent impact that these values have on female-centric development outcomes.

To illuminate the connection between geography and culture we use a set of temples in the Indian subcontinent known as the Shakti Peeth, or "power seats". According to mythology, these temples, all of which are dedicated to female deities, mark the spots on which the body of the Goddess Sati fell after her death. This origin story would imply that the location of the Shakti Peeth temples should be random, since there is nothing in the myth to suggest any particular logic for the locations of the body parts. However, we test just how random the location of these temples really is, and find that areas with larger agricultural populations are significantly less likely to have one of these goddess temple. We believe this systematic pattern in the spread of the temples is likely due to the patriarchal values that often arise in primarily agrarian societies. Such values would render the worship of a female deity less likely. Furthermore, since the propensity of a region towards agriculture can be predicted using geographic factors, this links geography and culture, via the size of the agricultural population. Specifically, we find that the spread of Shakti temples is not random, as the myth claims, but, rather, is associated with the different ways of life - and the value systems that support those ways of life - that arose with distinct geographic conditions.

While the first part of this work is concerned with establishing the non-randomness of the spread of the Shakti Peeth, the second part deals with the impact that these temples might have on outcomes for women.We 
use a difference in difference strategy that exploits historical indicators of literacy to find that Shakti temples have a significant and positive impact on the gender gap in literacy. However, the impact of the temples is relatively small when compared to the large and negative impact that the size of the agrarian population has. This suggests that cultural values, as measured by the worship of goddesses, forms one of several channels by which agriculture impacts female-centric development outcomes.

Figure 3.1 illustrates the mechanism we propose for our results. Initial geographic conditions determine the propensity of a region to be oriented towards an agricultural way of life, which impacts how social interactions in that particular society are arranged. We hypothesize that in an agricultural society, these social interactions, and particular those pertaining to the organization of work, are such that women are relegated to housework while men become bread winners. By virtue of men dominating economically productive activities, the importance of women in agricultural societies is often diminished, leading to the prevalence of patriarchal values in such societies.Though it is difficult to quantify "patriarchal values", we can define them generally as values that diminish the importance and agency of women in various spheres of life. In this work, goddess worship serves as a rough measure of the perceived importance of women in a given region. The idea behind this indicator is that in areas where agriculture dominates, people are less likely to hold females in general, and female deities by extension, in high esteem.

As Figure 3.1 shows, the impact of agriculture on female literacy can occur through several different channels. First, there is the likely negative correlation between agriculture and education in general. Such a relationship is likely to persist because of the relatively low importance of formal education in an agricultural setting, and the higher opportunity cost to sending children to school in farm families. This is particularly true of the sort of small scale agriculture that predominates in India, where the level of mechanization is low. An extra pair of hands aids productivity on a farm run by family labour, and additional educational training has little direct advantages in this low-mechanization agricultural scenario. Furthermore, in areas predominated by agriculture, it is likely that educational infrastructure is not as well provided as in more urban areas. And as incomes in the agricultural sector are likely to be lower than those in the industrial and service sectors, it is also probable that education is relatively less affordable for families primarily engaged in agriculture. For these combined host of reasons, agriculture is likely to have a negative impact on education for both females and males. 


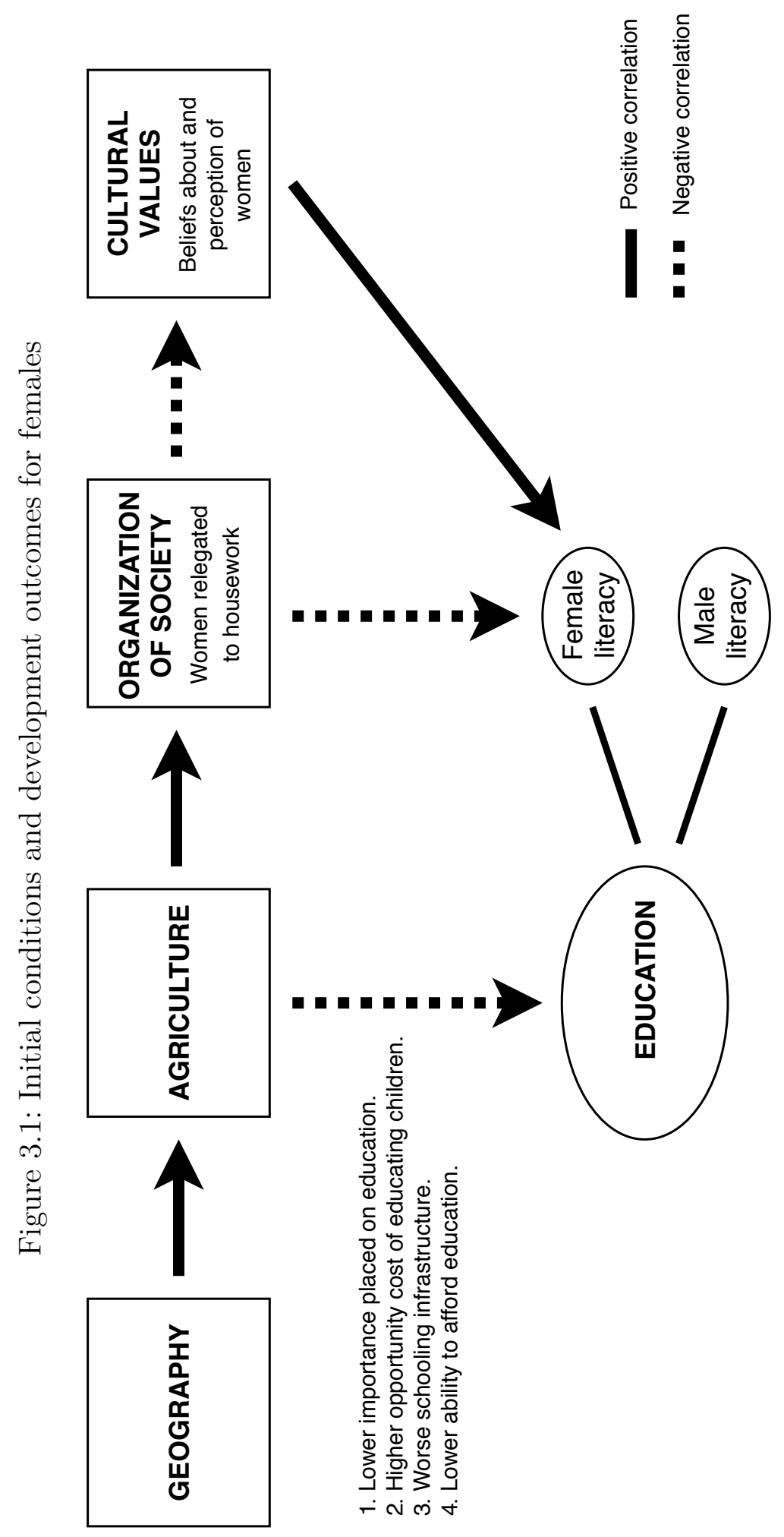


Though these general impacts apply to both males and females, the organization of society in an agricultural setting is likely to have particular disadvantages for females. Since women tend to be relegated to the domain of the home, education may be seen as particularly futile for them. In some cases, education may be denied to women precisely to ensure that they remain satisfied with the role designated to them as child bearers and homemakers. Further, any way of life is associated with a particular set of values that supports that societal structure. In the case of agriculture, we would expect that patriarchal values would predominate since it is largely men who engage in economically productive activity. We see this to be the case in many agricultural societies in the world. Such values are naturally antithetical to the education and progress of women. Thus we argue that while agriculture has a dampening effect on education in general, the structure of agricultural societies as well as the values emanating from such a societal structure negatively impact female education in particular.

The rest of the paper is organized as follows. Section 2 gives an overview of the literature on geography, agriculture, and values, and describes where this work fits within the scope of this literature. Section 3 provides historical context about the Shakti Peeth temples. Sections 4 and 5 describe our data and estimation strategy, respectively. Our results are presented in section 6 and a discussion of the results follows in section 7 . We end with some concluding remarks in section 8 .

\section{2}

\section{Literature}

Much has been written about the complex relationship between geography, institutions, and culture as the key factors explaining regional differences in growth and development. While the question of primacy between geography and institutions has given rise to a rich literature expounding the arguments on both sides, the relationship between geography and culture is one that is less explored. Some controversial claims are found in early sources, such as the 1748 treaty of the French political philosopher Montesquieu, which associates people in the Global North with virtues such as sincerity and truthfulness and those in the Global South with an absence of morality that, according to Montesquieu, has its roots in the hot weather of tropical climates. Slightly less objectionable connections between geography and culture are found in later sources that hypothesize that the heat and humidity in tropical climates inhibits work ethics (Landes 1998). More recently, Gennaioli et al. (2013) study culture alongside geographic, institutional, and human capital 
determinants in a cross-regional analysis. Their results propose that while culture and institutions have explanatory power only at a national level, geography explains broader regional differences.

While the aforementioned sources inform the broader landscape of our work on geography and culture, more specific to the question at hand are the literatures on geography and agriculture, and on agriculture and values, respectively. The relationship between geography and the proclivity of certain regions towards agriculture is the cornerstone of the well-known book, Guns, Germs, and Steel by Jared Diamond (1998). The primary argument of that work holds that certain regions, such as Eurasia, had an advantage in moving from a nomadic hunter-gatherer way of life to settled agrarian society due to a set of geographic factors including access to higher carbohydrate vegetation, dry climates for storage, and animals appropriate for domestication. In a similar vein, Olsson et al. (2005) find that geographic and initial biogeographic conditions exerted a decisive influence on the location and timing of transitions to sedentary agriculture.

The link between agriculture and patriarchal values is perhaps less straightforward to measure, principally because of the difficulties inherent in quantifying values. However, several studies attempt to shed light on this connection using survey data reporting the views of individuals on gender roles. Alesina et al. (2013) find that plough agriculture, as opposed to shifting cultivation, influences the evolution of gender norms negatively, as measured using reported gender-role attitudes. The work of Inglehart (2008) and Inglehart and Norris (2003) similarly finds that agrarian societies tend to emphasize traditional values - entailing a strong emphasis on religion and respect for authority — and are less likely to favor gender equality.

Our contribution to this somewhat disjointed literature is as follows. Firstly, this study attempts to highlight the link between geography, culture, and development outcomes. In doing so, we attempt to add to the proposition in Easterly and Levine (2003) that geography influences economic development primarily through institutions. While we believe that institutions - or more generally, the organization of society - form a key link between geography and development, in this study we elaborate on an alternative channel through which geography may influence economic development, namely, through the construction of cultural values.

Secondly, our use of female deity worship is a novel way of studying values related to gender perception. Apart from novelty, this measure may have certain advantages over the typically used survey measures. In addition to being free of the many measurement issues that plague survey data, this 
indicator provides a narrative of the formation of values. Our finding that the supposedly random spread of the Shakti Peeth is actually clearly correlated to propensity towards agriculture gives a hint into the value systems which prevailed in the past and which persisted over a remarkably long period.

Thirdly, our historical data on female literacy allows us to use a difference in difference strategy using a hundred year period. This gives us a long run view of the different paths of female literacy increase in areas with and without Shakti Peeths. In studying these effects, not only do we explore a cultural channel through which female literacy may be impacted, but we also contribute to a scant and conflicted literature about the welfare impacts of the Shakti temples. While one work qualitatively argues that these temples provide marginalized sections of society with opportunities to improve their standing in society by participating in rituals with members of upper castes (Dixit 2014), another case study of a particular Shakti Peeth argues that the impact on the local community is mixed (Bhel 2012). Our analysis is unique in attempting to build a quantitative case for the impact of Shakti Peeths on a specific development outcome.

Lastly, our work provides considerable evidence on the negative impact of the size of the agricultural population on female-centric development, including female literacy. Our primary difference in difference strategy and the instrumental variables approach we employ for our supplementary evidence builds a causal case for the relationship between agricultural societies and gender imbalanced development.

Thus, this work has several interrelated aims with respect to the literature, primary amongst which is to elucidate the complex and understudied relationship between geography and culture.

\section{3}

\section{Historical context}

The Shakti Peeths consist of a network of 51 temples $^{1}$ dedicated to various female deities that are considered manifestations of the female divine or Devi. These temples have their mythological origin in the Hindu story of the Goddess Sati. According to this myth, Sati, infuriated by her father's insult

\footnotetext{
${ }^{1}$ According to some versions, the number of these temples is as high as 108 . Though the various versions of the story differ in the exact number of locations listed, the smaller lists are subsets of the longer lists. Here we have used the most conservative estimate of the temples comprising the Shakti Peeth. Apart from the 51 Shakti Peeths, the network also includes 18 Maha Shakti Peeths ("great power seats") and 4 Adi Shakti Peeths ("original power seats"), there being little substantial difference between the three categories except for the importance assigned to each. The latter categories are assigned greater importance because according to the myth they mark the locations of particularly important body parts of Sati.
} 
to her husband, the mountain god Shiva, committed suicide in a sacrificial fire rite. Shiva, her grieving husband, then carried Sati's body all around India, until all the parts of her body fell, one by one. The Shakti Peeths mark the locations where the parts of Sati's body fell (Eck 2012).

The list of locations of the Shakti Peeths is mentioned in several later Hindu texts, including the Devi Bhagavata Purana (9th-14th century), its contemporary Brahmanda Purana, and the Shakti Peetha Strotram, written by the 9th-century Hindu philosopher Adi Shankara (Eck 2012, Sircar 1998). Though we know the rough timeline of these lists, none of which predates the 9th-century, it is difficult to to ascertain the date of origin of the physical temples around these mythologically sacred locations, or even whether they were built before or after the mention of these locations in the scriptures. One of the oldest temples, the Kamakhya temple in Guwahati, likely dates from the 8th-13th century, having been rebuilt several times by successive dynasties (Gupta 1959). Because of this chronological uncertainty, it is possible that the lists that provide scriptural evidence for the myth were retroactively generated from the locations of already existing temples.

Despite the random scattering implied by the myth, we believe that location of these temples in certain locations likely came about due to historical reasons. In particular, we believe that geography, through its influence on the prevalence of agriculture, may be a strong explanatory factor for the spread of temples celebrating female power. At the same time, there may exist other explanations behind systematic patterns in the supposedly random spread of the Shakti Peeths. One such reason could be the presence of folk or tribal traditions that honored female spirits before the advent of Hinduism, thus rendering some regions more likely to worship goddesses. Another possibility is that in certain regions, specific goddesses were historically associated with particular positive attributes, such as the goddess Shri, who is widely worshiped in the southern regions of the country for her association with good fortune and wealth. Yet another potential factor contributing towards a propensity towards goddess worship could be the advent of social movements which found in goddess worship a form of rebellion against the conservative Brahminical tradition (McDaniel 2004). While we believe these are valid possibilities, we believe geography, and the subsequent societal organization made likely by geography, is a more likely explanation behind the locations of the Shakti Peeth.

The folk tradition thesis can less explanatory power when reviewed through the lens of the geography thesis. The same agricultural propensity, or lack thereof, that may lead a Hindu village to develop certain values would 
apply to tribal society. Myths celebrating the feminine, or some variation of the "Great Mother" seem particularly prevalent in hunter-gatherer societies (Schlain 1999). This is line with our hypothesis that agrarian societies are relatively less likely to worship goddesses whereas such patriarchal values are likely to be present to a lesser degree in hunter-gatherer societies.

The regional association of specific deities with positive attributes also cannot be a primary explanatory factor for the simple reason that almost all Hindu deities, male or female, are attributed with some positive trait or special power. Furthermore, the pantheon of Hindu deities, and the scriptural myths about the particular deities does not greatly vary from region to region. What changes is the importance given to certain deities, and in some cases, their names. For example, the goddess Shri of the south is known as Lakshmi in the north, and is also associated with wealth and good fortune. While the northern goddess is worshipped during specific festivals and often revered by merchants, the cult of the goddess is not as widespread as in the south. However, a mere change in nomenclature cannot explain this discrepancy. Fundamentally, something about certain regions leads them to prize female deities more than in other regions where the same deities exist. We believe that the agricultural argument can also explain this difference in priorities between north and south, as more regions in southern India have the characteristics - closeness to the coast, red soil - that are correlated in our sample with a relatively smaller agrarian population.

Perhaps most tempting of the alternative explanations is the possibility that goddess worship gained popularity as a form of rebellion against the ritualistic nature of traditional Hinduism in some parts of the country. This argument is most convincing in explaining specific instances where goddess worship emerged as a form of social movement, such as in the Tantric ${ }^{2}$ goddess worship traditions prevalent in the eastern states of Bengal and Assam. Perhaps unsurprisingly, these are also the regions that, according to the lists in the Hindu texts, have the greatest number of sacred locations where the body of the goddess Sati fell. It is thus entirely plausible that the regions where the Tantric cult of the feminine divine had already taken hold had a propensity to worship goddesses, a fact that was exploited either by the originators of the lists or by those who built temples that were retroactively raised to mythical status by the lists. Despite its merits, the social movement argument is relatively limited in its scope by being restricted to specific instances in history. We believe that the agricultural thesis provides a more convincing

\footnotetext{
${ }^{2}$ It should be noted here that though the term Tantrism may be of later Orientalist origin (Padoux 2002), its origins lay in ancient Hindu philosophy that predates the scriptural lists of the Shakti Peeths.
} 
general explanation behind the spread of the supposedly random locations of the Shakti Peeth.

However, in order to assuage concerns that we misinterpret the effects of the above mechanisms as stemming from the agricultural propensity mechanism, we include state effects in our specifications to account for preexisting regional differences in goddess worship. The significant coefficient that we find on agriculture as an explanatory factor behind the spread of the temples is thus obtained after accounting for regional differences that may stem from one of the alternative arguments outlined above.

\section{4}

Data

As in our other papers, we use a combination of current and historical data at the district-level, using district boundaries from $2001^{3}$. The key variables are summarized in Table 3.1.

Our historical indicators for literacy and agricultural population are obtained from the Imperial Gazetteer of India, a 22-volume administrative record published in 1909 by the British government of India. These volumes contain detailed district-level information about most of colonial-era India, including regions that were not directly colonized. We used a digitized version of this source to collect the female and male literacy rate and the percentage of population engaged in agriculture in every region in colonial India. These indicators - provided at the district-level in British India and larger independent kingdoms, and at the state level for smaller kingdoms were then matched to 2001 districts. Some of our indicators for geography, such as soil types and hilly regions, also come from the Imperial Gazetteer.

The contemporary data on development, as well as the size and population of districts, are largely obtained from the Census of 2001. The district level data was only available to us through a data aggregator ${ }^{4}$, through which we also obtained our rainfall data, which was collected by the Indian Meteorological Department. The proportion of agrarian population comes from the Third Human Development Report of the United Nations Development Program, as this information was not available at the district-level through the census. We also use crime data obtained from the National Crime Records Bureau for some supplementary analyses.

\footnotetext{
${ }^{3}$ We use 2001 data here rather then the more recent 2011 Census because our agricultural population data is from 2001. Additionally, this gives us an exact century's difference between our two periods.

${ }^{4}$ We used Knoema to download an excerpt of the Census.
} 
Table 3.1: Summary statistics

\begin{tabular}{lcccccc}
\hline VARIABLE & Mean & $\begin{array}{c}\text { Standard } \\
\text { deviation }\end{array}$ & Min. & Max. & Districts & States \\
\hline 1901 & & & & & & \\
Agricultural \% of population & 66.44 & 13.98 & 29 & 99 & 473 & 25 \\
Female literacy & 0.522 & 0.785 & 0 & 8.5 & 489 & 25 \\
Gender gap in literacy & 7.73 & 4.34 & 0 & 26.5 & 485 & 25 \\
2001 & & & & & & \\
Agricultural \% of population & 65.38 & 17.03 & 1.7 & 90.4 & 306 & 13 \\
Female literacy & 52.62 & 15.47 & 18.58 & 96.26 & 593 & 35 \\
Gender gap in literacy & 22.0 & 7.56 & -3.59 & 40.57 & 593 & 35 \\
& & & & & & \\
Shakti temples/1000 sq. km. & 0.395 & 4.605 & 0 & 108.108 & 576 & 32 \\
\hline
\end{tabular}

Detailed data on the locations of the Shakti Peeth temples is available through various sources online, using definitions from various Hindu texts. The number of temples listed varies depending on the source. This discrepancy is due to disagreements about whether some temples fall under the category of Shakti Peeth. Here we have used the most conservative estimate, using only those temples that are acknowledged universally as being part of the sacred set. In total, we have 68 temples, of which 53 are in India ${ }^{5}$. The remaining 15 temples are in neighboring South Asian countries and have not been included in this analysis. The full list of temples and their locations can be found in Appendix B.

\section{5}

\section{Estimation strategy}

\subsection{1}

\section{Formation of cultural values}

To establish the link between geography and culture we first study the relationship between geography and agricultural population using the following:

$$
\text { Agro }_{i}=\text { constant }+X_{i} \gamma+u_{i}
$$

where $A_{g r o}$ is the proportion of the population in district $i$ primarily engaged in the agricultural sector, $X_{i}$ is a set of geographic characteristics

\footnotetext{
${ }^{5}$ The definition we use consists of 51 Shakti Peeths (38 of which are in India),18 Maha Shakti Peeths (16 of which are in India), and 4 Adi Shakti Peeths (4 of which are in India). However, three temples are considered both a Shakti Peeth as well as a Maha Shakti Peeth (Avantidevi temple in Ujjain district, Lalitadevi temple in Allahabad district, and Vishalakshmi temple in Varanasi district) and one temple is counted as a Shakti Peeth, Maha Shakti Peeth, and Adi Shakti Peeth (The Kamakhya temple in Guwahati). These cases have been counted as one single Peeth, rather than two separate Peeths.
} 
that includes mean annual rainfall ${ }^{6}$ and dummy variables for soil type, coastal districts, and hilly regions, while $u_{i}$ is an unobserved error term.

We then measure the relationship between agricultural population and the spread of Shakti temples using the following:

$$
S_{i}=\text { constant }+\beta \text { Agro }_{i}++X_{i} \lambda+\alpha_{j}+v_{i}
$$

where $S_{i}$ is the number of Shakti Peeth temples per 10,000 sq. km. in district $i, \alpha_{j}$ is a state fixed effect, $X_{i}$ is the set of geographic controls described above, and $v_{i}$ is an unobserved error term. Shakti temples are measured as a function of geography because of the large spread of district sizes. We use fixed effects at the state rather than district level because we believe that state fixed effects are more appropriate to capture broader regional differences in the propensity towards goddess worship. The reasons why some regions might have a greater tendency to worship female deities are outlined in greater detail in Section 3. In both regressions our errors are corrected for state-level clustering.

\section{5 .2}

\section{Shakti Peeth and female literacy}

We employ a difference in difference style strategy to estimate the impact of Shakti temples on female literacy and the gender gap in literacy:

$$
Y_{i}=\alpha+\beta T_{i}+\gamma S_{i}+\delta\left(T_{i} \cdot S_{i}\right)+\psi X_{i}+\theta_{j}+\epsilon_{i}
$$

where $Y_{i}$ is the dependent variable - either female literacy or the gender gap in literacy - in district $i, T_{i}$ is a dummy variable which takes on the value 0 in the colonial period (1901) and 1 in the modern period (2001), $S_{i}$ is a dummy variable that takes on the value 1 in districts with one or more Shakti temples and the value 0 otherwise, $\theta_{j}$ is a state fixed effect, and $\epsilon_{i}$ is the unobserved error term. $X_{i}$ is the following set of control variables, which we progressively introduce in various specifications to test the stability of our results: agricultural percentage of population of district $i$ in the year in which the dependent variable is measured, GDP per capita in 2004 in district $i$ and growth rate in 2004 in district $i$. These last two variables are included to control for relative differences in district wealth, which could impact literacy outcomes. In these specifications, $\beta$ captures the time trend common to districts with and without Shakti temples, $\gamma$ captures the average permanent difference between districts with and without Shakti temples, and $\delta$, our main coefficient of interest, captures the difference that arises between districts with and without Shakti temples in the 100 year period from 1901 to 2001.

\footnotetext{
${ }^{6}$ Calculated as the average of annual rainfall from 2008-2014.
} 


\section{6 \\ Results}

\subsection{1}

\section{Formation of cultural values}

The results shown in Tables 3.2 and 3.3 confirm our hypothesis that the location of Shakti temples is negatively and significantly correlated with the size of the agrarian population, which in turn is influenced by certain geographic factors.

In particular, proximity to the coast and rainfall seem to be the most important determinant of the proportion of the population engaged in agriculture in both 1901 and 2001. Coastal areas have a 10-percent lower agrarian population in 1901 and a 22-percent lower agrarian population in 2001. Rainfall has a mixed impact. While its effect is significant in both periods, it is positive in 1901 and negative in 2001. However, the magnitude of the impact is relatively small in both cases. An additional $100 \mathrm{~cm}$. of annual rainfall is significantly associated with a 1-percent increase in the proportion of population engaged in agriculture in 1901, and a decrease of a similar magnitude in 2001. This seemingly contradictory effect of rainfall is likely explained by the advent of irrigation. In the colonial era, when irrigation was relatively limited, areas with abundant rain were likely to have larger agrarian populations. However, post-Green Revolution advances in agricultural technology have led to a situation where rain-fed, unirrigated areas largely grow lower value crops like pulses, while lucrative crops like rice, wheat, and sugarcane are usually grown in irrigated settings. This association of rain-fed areas with lower value agriculture explains why rainfall would, in the modern period, be associated with a smaller agrarian population. Red soil also appears to have a negative impact on agricultural population in 2001, which can likely be attributed to the relatively unproductive nature of red soil relative to the black and alluvial soil types, particularly in rain-fed conditions.

While Table 3.2 establishes the connection between geographic attributes and the size of the agrarian population, Table 3.3 shows the significant, negative relationship between the size of the agrarian population and Shakti temples. An increase of 1-percent in the agrarian population in 1901 is associated with 3-percent fewer Shakti temples, while an equivalent increase in 2001 is associated with a decrease of 2-percent in the occurrence of Shakti temples. The reduction in magnitude of this correlation over the periods we consider is likely a function of changes in the agricultural sector over the 100 year period, suggesting that the further back we go, the more pronounced 
Table 3.2: Geographical factors and agricultural propensity

\begin{tabular}{lcc}
\hline \hline & $\begin{array}{c}(1) \\
\text { Agriculture \% of } \\
\text { population in 1901 }\end{array}$ & $\begin{array}{c}(2) \\
\text { Agricultural \% of } \\
\text { population in 2001 }\end{array}$ \\
\hline Climate factors & & \\
Annual rainfall (cm.) & $0.00720^{* * *}$ & $-0.00519^{*}$ \\
Coastal dummy & $(0.00172)$ & $(0.00290)$ \\
Hills dummy & $-6.548^{* *}$ & $-14.35^{*}$ \\
Soil types in 1901 & $(2.921)$ & $(6.802)$ \\
Black & 4.369 & 4.929 \\
& $(2.745)$ & $(3.294)$ \\
Red & & \\
Alluvial & -2.461 & 1.675 \\
& $(2.233)$ & $(2.288)$ \\
Mean of dependent variable & $(1.691$ & $-7.838^{*}$ \\
Observations & $(3.048)$ & $(3.598)$ \\
R-squared & $(2.094$ & 1.135 \\
& 66.44 & $(3.053)$ \\
Robust standard errors in parentheses. ${ }^{* * *} \mathrm{p}<0.01,{ }^{* *} \mathrm{p}<0.05,{ }^{*} \mathrm{p}<0.1$.
\end{tabular}

the connection between agriculture and the Shakti Peeth. Since the Shakti Peeth temples are long-standing entities that long predate the time periods we consider, we cannot infer from these coefficients a causal relationship in the sense that an actual increase in the agrarian population will lead to more Shakti Peeth temples. Rather, the intent of this part of the exercise is to show the persistent and long-run correlation between agrarian population and the temples, and infer from this the causal relationship that may have existed in the distant past when these temples originated.

Table 3.3: Agricultural propensity and Shakti Peeth

\begin{tabular}{lcc}
\hline \hline & $(1)$ & $(2)$ \\
& 1901 & 2001 \\
\hline $\begin{array}{l}\text { Dependent variable: Shakti temples/10000 sq. } \mathrm{km} . \\
\text { Mean of dependent variable }=0.395\end{array}$ & \\
& & \\
Agricultural \% of population & $-0.0131^{*}$ & $-0.00910^{*}$ \\
& $(0.00659)$ & $(0.00453)$ \\
& & \\
Geographical controls & YES & YES \\
State fixed effects & YES & YES \\
Observations & 472 & 304 \\
R-squared & 0.139 & 0.194 \\
\hline Robust standard errors in parentheses. ${ }^{* * *} \mathrm{p}<0.01,{ }^{* *} \mathrm{p}<0.05,{ }^{*} \mathrm{p}<0.1$
\end{tabular}


Table 3.4: Agricultural population, rice cultivation, and Shakti temples

\begin{tabular}{|c|c|c|}
\hline & $\begin{array}{c}(1) \\
1901\end{array}$ & $\begin{array}{c}(2) \\
2001\end{array}$ \\
\hline \multicolumn{3}{|c|}{$\begin{array}{l}\text { Dependent variable: Shakti temples } / 10000 \mathrm{sq.} . \mathrm{km} . \\
\text { Mean of dependent variable }=0.395\end{array}$} \\
\hline $\begin{array}{l}\text { Agricultural } \% \text { of population } \\
\times \% \text { of acreage dedicated to rice }\end{array}$ & $\begin{array}{c}-0.0211^{* *} \\
(0.00806)\end{array}$ & $\begin{array}{r}-0.0242^{*} \\
(0.0119)\end{array}$ \\
\hline$\%$ of acreage dedicated to rice & $\begin{array}{l}1.550^{*} \\
(0.778)\end{array}$ & $\begin{array}{l}2.056^{*} \\
(0.963)\end{array}$ \\
\hline Geographical controls & YES & YES \\
\hline State fixed effects & YES & YES \\
\hline Observations & 371 & 250 \\
\hline R-squared & 0.177 & 0.149 \\
\hline
\end{tabular}

In addition to the connection between agriculture and Shakti Peeth temples, we are also interested in whether this effect holds for all types of agricultural societies, or is particularly pronounced in some. We test this by including a specification where we interact agricultural \% of population with the acreage allotted to rice cultivation. The idea here is that women play a relatively larger role in paddy cultivation due to the labor intensive practice of pre-harvest transplantation. We would thus expect that women should hold a higher position in societies that widely practice paddy cultivation, and this in turn should translate to a higher propensity towards female worship. Our results in Table 3.4 show that in fact, rice cultivation appears to significantly increase the occurrence of Shakti Peeth temples, while its interaction with agricultural $\%$ of population has negative impacts. This goes to show that though agriculture in general appears to have an overall negative impact on female deity worship, this impact is sensitive to the role of women within particular agricultural settings.

\subsection{2}

\section{Shakti Peeth and female literacy}

Tables 3.5 and 3.6 show that Shakti temples have a significant, positive impact on female literacy and a significant, negative impact on the gender gap in literacy. In both cases, this effect is less significant than the impact that agriculture appears to have. In Table 3.5, for example, we see that our coefficient of interest, i.e. $\delta$, is positive in all specifications, but significantly so only in the specification that does not include agrarian population as a control. 
Table 3.5: Impact of Shakti temples on female literacy, DID

\begin{tabular}{|c|c|c|c|c|}
\hline & $(1)$ & $(2)$ & $(3)$ & $(4)$ \\
\hline \multicolumn{5}{|l|}{ Mean of female literacy $=52.62$} \\
\hline Shakti temples $\times$ Modern period ${ }^{a}$ & $\begin{array}{c}3.600^{* *} \\
(1.834)\end{array}$ & $\begin{array}{c}2.064 \\
(1.941)\end{array}$ & $\begin{array}{c}2.431 \\
(2.246)\end{array}$ & $\begin{array}{l}2.400 \\
(2.267)\end{array}$ \\
\hline Shakti temples & $\begin{array}{l}0.0978 \\
(0.875)\end{array}$ & $\begin{array}{c}-0.0900 \\
(0.654)\end{array}$ & $\begin{array}{l}-0.158 \\
(0.723)\end{array}$ & $\begin{array}{l}-0.180 \\
(0.720)\end{array}$ \\
\hline Modern period & $\begin{array}{c}51.94^{* * *} \\
(0.597)\end{array}$ & $\begin{array}{c}50.00^{* * *} * \\
(0.718)\end{array}$ & $\begin{array}{c}49.70^{* * *} \\
(0.765)\end{array}$ & $\begin{array}{c}49.68^{* * * *} \\
(0.768)\end{array}$ \\
\hline Agricultural $\%$ of population ${ }^{b}$ & & $\begin{array}{c}-0.271^{* * *} \\
(0.0274)\end{array}$ & $\begin{array}{c}-0.257^{* * *} \\
(0.0292)\end{array}$ & $\begin{array}{c}-0.273^{* * *} \\
(0.0286)\end{array}$ \\
\hline GDP per capita in 2004 & & & $\begin{array}{c}0.000130^{* *} \\
(5.17 \mathrm{e}-05)\end{array}$ & \\
\hline Growth per capita in 2004 & & & & $\begin{array}{l}-2.040 \\
(4.120)\end{array}$ \\
\hline State fixed effects & YES & YES & YES & YES \\
\hline Observations & 1,082 & 744 & 657 & 657 \\
\hline R-squared & 0.895 & 0.933 & 0.933 & 0.932 \\
\hline
\end{tabular}

Once agrarian population is introduced, $\delta$ ceases to be significant, though it remains positive in all the specifications. In Table 3.6, however, the coefficient $\delta$ maintains its significance even after the addition of agrarian population and the wealth controls, though here too the coefficient on agricultural percentage of population is of greater significance than the coefficient on Shakti Peeths.

In all the specifications, the magnitude of the effect of Shakti Peeth temples and agriculture remains quite stable. Female literacy is 4 to 7 -percent higher while the the gender gap in literacy is between 9 to 14-percent lower in districts with one or more Shakti Peeth temples. Meanwhile, a 1-percentage point increase in the agrarian population has an impact in the opposite direction. Such an increase is associated with a 0.5 -percent reduction in female literacy and a 0.5 to 0.6 -percent increase in the gender gap in literacy. We also find similar results when we interact the agricultural $\%$ of population with Shakti Peeth temples over time, results for which can be found in Appendix C.1.

Unsurprisingly, in both Tables 3.5 and 3.6, we find large and highly significant coefficients on the time period. This is to be expected due to the massive strides made between 1901 and 2001 in increasing overall literacy and reducing the gender imbalance in literacy. Wealth, as measured by GDP per capita in 2004, appears to positively impact female literacy but does not impact 
Table 3.6: Impact of Shakti temples on gender gap in literacy, DID

\begin{tabular}{|c|c|c|c|c|}
\hline & $(1)$ & $(2)$ & $(3)$ & $(4)$ \\
\hline \multicolumn{5}{|l|}{ Mean of gender gap in literacy $=22.0$} \\
\hline Shakti temples $\times$ Modern period $^{a}$ & $\begin{array}{c}-2.968^{* *} \\
(1.373)\end{array}$ & $\begin{array}{c}-2.062 \\
(1.536)\end{array}$ & $\begin{array}{c}-3.090^{*} \\
(1.783)\end{array}$ & $\begin{array}{l}-3.098^{*} \\
(1.776)\end{array}$ \\
\hline Shakti temples & $\begin{array}{c}0.831 \\
(0.801)\end{array}$ & $\begin{array}{c}0.725 \\
(0.738)\end{array}$ & $\begin{array}{c}1.177 \\
(0.797)\end{array}$ & $\begin{array}{c}1.171 \\
(0.796)\end{array}$ \\
\hline Modern period & $\begin{array}{c}14.54^{* * *} \\
(0.357)\end{array}$ & $\begin{array}{c}14.43^{* * *} \\
(0.509)\end{array}$ & $\begin{array}{c}15.07^{* * *} \\
(0.512)\end{array}$ & $\begin{array}{c}15.06^{\text {**** }} \\
(0.513)\end{array}$ \\
\hline Agricultural $\%$ of population ${ }^{b}$ & & $\begin{array}{c}0.113^{* * *} \\
(0.0159)\end{array}$ & $\begin{array}{c}0.130^{* * *} \\
(0.0182)\end{array}$ & $\begin{array}{c}0.127^{* * *} \\
(0.0169)\end{array}$ \\
\hline GDP per capita in 2004 & & & $\begin{array}{c}2.03 \mathrm{e}-05 \\
(3.27 \mathrm{e}-05)\end{array}$ & \\
\hline Growth \% in 2004 & & & & $\begin{array}{l}0.0824 \\
(2.328)\end{array}$ \\
\hline State fixed effects & YES & YES & YES & YES \\
\hline Observations & 1,078 & 740 & 653 & 653 \\
\hline R-squared & 0.687 & 0.760 & 0.774 & 0.774 \\
\hline
\end{tabular}

Robust standard errors in parentheses. ${ }^{* * *} \mathrm{p}<0.01,{ }^{* *} \mathrm{p}<0.05,{ }^{*} \mathrm{p}<0.1$

${ }^{a}$ The colonial period is measured in 1901 and the modern period measured in 2001.

${ }^{b}$ In the year that dependent variable is measured.

the gender gap in literacy, suggesting that wealth effects likely improve literacy outcomes for the population as a whole, but do not necessarily ameliorate the inequality between men and women in the sphere of education.

\section{7 \\ Discussion}

\subsection{1}

\section{Shakti Peeth as an indicator of preference for female deities}

Our results suggest that there is a link between geography and cultural values. The spread of Shakti Peeth temples, which according to mythology, is random, is in fact correlated with the size of the agrarian population in given districts, which in turn is influenced by geographic traits. The correlation between the temples and the agrarian population is larger in the colonial period than in the modern period, and we would expect this correlation to be even larger the further back in history that we go. Our hypothesis is that at the origin of the Shakti Peeths, in the medieval period, regional propensities towards agriculture played a considerable role in determining where exactly these temples were built, thus providing the historical basis on which the myth was built. 
One concern in interpreting our results is the impact that ancient population dynamics might have had on the location of the Shakti Peeths. Our approach, of weighing Shakti Peeths by the inverse of geography rather than population, makes sense if we assume the myth's logic of randomness, i.e. that body parts can fall anywhere and are not attracted to population centers. Under this randomness assumption, a larger area is more likely to have more Shakti Peeths, and so we use the number of Shakti Peeths by area as our main indicator. However, it is plausible that when the "random" list of Shakti Peeths originated, sacred status was assigned to locations that were already pre-existing population centers ${ }^{7}$. This would be problematic for our analysis if dense, urban regions were more likely to have a Shakti Peeth temple, thus creating a negative correlation in our data between low-density, agricultural areas and the Shakti Peeth temples. Nevertheless, we believe that in those pre-Industrial Revolution times, because of the paucity of urban centers and the fact that major population hubs were sustained by the productivity of agriculture, the dichotomy between high-density, urban areas and low-density, agricultural areas did not exist then the way it does now.. For this reason we believe it is unlikely that our results are due to some bias in the location of the Shakti Peeth temples in high-density areas. Furthermore, because of the vast historical changes that have taken place since the origin of the Shakti Peeth temples, it seems unreasonable to assume that the population patterns of today reflect the population patterns of the time when they were first listed. Weighting Shakti temples by present, or even colonial, populations would thus not alleviate this problem if in fact it did plague our analysis.

Another related concern is that throughout the ages, Shakti temples could have sustained an increased population through a temple town economy, i.e. an economy centered around religious visitors and commercial activities like the sale of food or flower offerings. In this situation, we could be concerned about reverse causation, whereby Shakti temples provide jobs away from agriculture. However, we believe this is unlikely to be the driving factor behind our results since industrialization is a much more likely culprit for large scale sectoral shifts than individual temple towns with a limited capacity to expand.

Apart from the population in general, we may also be concerned with the size of the Hindu population, since Shakti Peeths are revered only in the Hindu tradition, and the worship of female deities is virtually unknown in the other major religions of India. Thus, our claim that the occurrence of these temples provides an insight into the cultural values of a society is valid only as long

\footnotetext{
${ }^{7}$ There is a complex relationship between Hindu mythology and actual historical occurrence, with archaeological evidence providing support for certain locations and events as they are described in epics and other religious works.
} 
as everyone in that society is Hindu, which is not the case for most districts in present-day or even colonial India. However, we believe that the present religious composition of particular districts is not a concern since the Shakti Peeths are dated to a period before widespread Islamic conquests of India. Thus, it is a fair assumption that the Hindu belief system was the predominant one at the time of their origin, such that a district's greater propensity to have these temples says something about that district's preference for female deities, rather than simply the degree to which Hinduism dominates the religious composition of that district.

We should mention that although we take the mere occurrence of Shakti temples to be indicative of preference for female deities, we cannot actually measure a relative preference since we do not have an equivalent measure for temples dedicated to male deities. A preferable indicator would have been the ratio of temples dedicated to female versus male deities. However, despite the prevalence of many famous temples dedicated to male deities, it is difficult to define one particular set as well as we can define the Shakti Peeth. Certainly we cannot find any with a similar mythological origin that result in purportedly random locations. The problem with using only the Shakti Peeth temples is that a certain area might have had more temples overall, whether due to higher religiosity, wealth, or even some geographic factor such as the availability of material for temple building. Such a place might be a susceptible candidate to be picked as sacred for the purpose of the Shakti Peeth myth. This would be particularly problematic for our analysis if such areas tended to be non-agricultural, which is particularly plausible for the wealth argument. However, searching the histories of the individual temples shows that there is little to suggest that the temples were primarily located near temple clusters. Furthermore, we include the overall number of temples as an additional control in our specification estimating the correlation between agriculture and Shakti Peeth temples (Table 3.7). While Shakti Peeth temples are positively correlated with the overall number of medieval period temples, this is to be expected as this was the period in which the temples were built. The temples are, however, not correlated with overall number of temples. Moreover, in both cases, the relationship between agricultural \% of population and Shakti Peeth temples continues to be negative and significant. Thus, we are not unduly concerned that our results are due to historically larger concentrations of temples, whether due to religiosity or wealth, in non-agricultural regions.

One last concern that remains is that we restrict our measure to a set of very famous temples, whereas India is a country where the proliferation of small shrines and neighborhood temples is noticeable even to the casual 
Table 3.7: Agricultural propensity and Shakti Peeth, controlling for overall number of temples

\begin{tabular}{|c|c|c|c|c|}
\hline & $\begin{array}{c}(1) \\
1901\end{array}$ & $\begin{array}{c}(2) \\
2001\end{array}$ & $\begin{array}{c}(3) \\
1901\end{array}$ & $\begin{array}{c}(4) \\
2001\end{array}$ \\
\hline \multicolumn{5}{|c|}{$\begin{array}{l}\text { Dependent variable: Shakti temples } / 10000 \mathrm{sq} . \mathrm{km} . \\
\text { Mean of dependent variable }=0.395\end{array}$} \\
\hline Agricultural $\%$ of population & $\begin{array}{l}-0.0126^{*} \\
(0.00702)\end{array}$ & $\begin{array}{c}-0.0107^{*} \\
(0.00520)\end{array}$ & $\begin{array}{c}-0.0122^{* *} \\
(0.00593)\end{array}$ & $\begin{array}{c}-0.00927^{*} \\
(0.00456)\end{array}$ \\
\hline Medieval Hindu temples & $\begin{array}{c}0.0161^{*} \\
(0.00849)\end{array}$ & $\begin{array}{c}0.0170^{*} \\
(0.00916)\end{array}$ & & \\
\hline Total Hindu temples ${ }^{a}$ & & & $\begin{array}{c}-0.533 \\
(0.689)\end{array}$ & $\begin{array}{c}0.360 \\
(0.222)\end{array}$ \\
\hline Geographical controls & YES & YES & YES & YES \\
\hline State fixed effects & YES & YES & YES & YES \\
\hline Observations & 402 & 271 & 472 & 304 \\
\hline R-squared & 0.138 & 0.240 & 0.142 & 0.196 \\
\hline
\end{tabular}

visitor. In fact, the everyday religious life of the majority of people is more likely to revolve around these humble shrines rather than famous temples, visits to which are often restricted to special occasions. A problem arises here if the pattern of occurrence of Shakti Peeth temples does not correctly reflect the popular sentiment towards goddess worship. For example, we could have a district where there are no Shakti temples but where every local shrine is dedicated to a female deity. In this case our measure of cultural values would incorrectly identify this district as being one where females are not considered important. In an ideal world, we would have had detailed data on every place of religious worship, no matter how big or small, and constructed our measure of the relative importance of female deities based on this comprehensive data. However, such an endeavor is nearly impossible because of the tiny scale and fleeting nature of some these shrines, apart from the challenges inherent in weighting temples based on their perceived importance to the local populace. Given this restriction, we must operate under the assumption that the pattern of Shakti temples is parallel to patterns of deity worship in smaller shrines and temples in our sample. We believe it is unlikely for a severe anomaly in this pattern to occur at the district level. If we have in our sample districts without Shakti temples yet where females are highly venerated throughout the district, it is likely that such a district will be reflective of the broader region it is situated in. In this case our state effects dummies should be able to capture this general trend of goddess worship. 


\subsection{2}

\section{Agriculture and female-centric development}

One thing that our results make abundantly clear is the importance of agriculture as a determinant of development outcomes for females. While we expect that agriculture should have a dampening effect on literacy in general due to various reasons - the relatively lower importance of education in an agrarian economy, the higher opportunity cost of schooling for farm families, and relatively lower affordability and availability of schooling — our results provide evidence that the effect is particularly stark for females. Tables 3.8 and 3.9 further suggest that this gender discrimination is not restricted solely to the sphere of education.

Table 3.8: Impact of agriculture on female-centric development indicators, IV

\begin{tabular}{|c|c|c|c|c|}
\hline & (1) & (2) & (3) & (4) \\
\hline \multicolumn{5}{|l|}{$\begin{array}{l}\text { Female mortality disadvantage } \\
\text { Mean }=1.34\end{array}$} \\
\hline Agricultural \% of population in 2001 & $\begin{array}{c}0.0145^{*} \\
(0.00818)\end{array}$ & $\begin{array}{c}0.0119^{*} \\
(0.00698)\end{array}$ & $\begin{array}{c}0.0109^{*} \\
(0.00597)\end{array}$ & $\begin{array}{c}0.0126^{*} \\
(0.00686)\end{array}$ \\
\hline GDP per capita in 2004 & & $\begin{array}{l}1.77 \mathrm{e}-05 \\
(1.22 \mathrm{e}-05)\end{array}$ & & $\begin{array}{l}1.90 \mathrm{e}-05 \\
(1.18 \mathrm{e}-05)\end{array}$ \\
\hline Growth \% in 2004 & & & $\begin{array}{c}0.215 \\
(0.438)\end{array}$ & $\begin{array}{c}0.290 \\
(0.404)\end{array}$ \\
\hline Observations & 288 & 254 & 254 & 254 \\
\hline \multicolumn{5}{|l|}{$\begin{array}{l}\text { Adult sex ratio (females/1000 males) } \\
\text { Mean }=934.91\end{array}$} \\
\hline Agricultural \% of population in 2001 & $\begin{array}{c}-1.022^{* *} \\
(0.481)\end{array}$ & $\begin{array}{c}-1.444^{* *} \\
(0.673)\end{array}$ & $\begin{array}{c}-1.114^{* * *} \\
(0.388)\end{array}$ & $\begin{array}{c}-1.433^{* *} \\
(0.616)\end{array}$ \\
\hline GDP per capita in 2004 & & $\begin{array}{c}-0.00404^{* * *} \\
(0.00118)\end{array}$ & & $\begin{array}{c}-0.00396 * * * \\
(0.00111)\end{array}$ \\
\hline Growth \% in 2004 & & & $\begin{array}{c}73.57^{* *} \\
(35.77)\end{array}$ & $\begin{array}{c}61.80 \\
(40.38)\end{array}$ \\
\hline Observations & 301 & 259 & 259 & 259 \\
\hline State fixed effects & YES & YES & YES & YES \\
\hline
\end{tabular}

In Table 3.8 we see that a 1-percentage point increase in the agricultural population results in a 1-percent higher female mortality disadvantage, defined here as the ratio of the under- 5 female and male rates of mortality. We also see this gender disadvantage reflected in the adult sex ratio, which is significantly and negatively correlated with the size of the agrarian population. In Table 3.9 , indices of crime against women show that an increase of 1-percentage point in the population engaged in agriculture is significantly correlated with 2 to 4-percent increases in the rates of rape and assault against women. The impacts are positive, though insignificant, for most of the other crimes as well. 
Table 3.9: Impact of agriculture on crimes against women, IV

\begin{tabular}{|c|c|c|c|c|}
\hline Log crime rates against women $^{a}$ & (1) & $(2)$ & $(3)$ & $(4)$ \\
\hline \multicolumn{5}{|l|}{ Rape } \\
\hline Agricultural \% of population in 2001 & $\begin{array}{c}0.0207^{* *} \\
(0.00876)\end{array}$ & $\begin{array}{c}0.0336^{* * *} \\
(0.0116)\end{array}$ & $\begin{array}{c}0.0201 * * * \\
(0.00754)\end{array}$ & $\begin{array}{c}0.0328^{* * *} \\
(0.0110)\end{array}$ \\
\hline GDP per capita in 2004 & & $\begin{array}{c}6.05 \mathrm{e}-05^{* * *} \\
(2.14 \mathrm{e}-05)\end{array}$ & & $\begin{array}{c}5.90 \mathrm{e}-05^{* * *} \\
(2.03 \mathrm{e}-05)\end{array}$ \\
\hline Growth \% in 2004 & & & $\begin{array}{l}-0.289 \\
(0.593)\end{array}$ & $\begin{array}{l}-0.409 \\
(0.649)\end{array}$ \\
\hline Observations & 303 & 261 & 261 & 261 \\
\hline \multicolumn{5}{|l|}{ Assaults } \\
\hline Agricultural \% of population in 2001 & $\begin{array}{c}0.0283^{* * *} \\
(0.0109)\end{array}$ & $\begin{array}{c}0.0404^{* * *} \\
(0.0124)\end{array}$ & $\begin{array}{c}0.0224^{* * *} \\
(0.00812)\end{array}$ & $\begin{array}{c}0.0385 * * * \\
(0.0115)\end{array}$ \\
\hline GDP per capita in 2004 & & $\begin{array}{c}7.79 \mathrm{e}-05^{* * *} \\
(2.42 \mathrm{e}-05)\end{array}$ & & $\begin{array}{c}7.35 \mathrm{e}-05^{* * *} * \\
(2.26 \mathrm{e}-05)\end{array}$ \\
\hline Growth \% in 2004 & & & $\begin{array}{c}-1.397^{* *} \\
(0.589)\end{array}$ & $\begin{array}{c}-1.589^{* *} \\
(0.647)\end{array}$ \\
\hline Observations & 295 & 259 & 259 & 259 \\
\hline \multicolumn{5}{|l|}{ Abductions } \\
\hline Agricultural \% of population in 2001 & $\begin{array}{c}0.0120 \\
(0.0110)\end{array}$ & $\begin{array}{c}0.0103 \\
(0.0134)\end{array}$ & $\begin{array}{c}0.00688 \\
(0.00930)\end{array}$ & $\begin{array}{c}0.0102 \\
(0.0122)\end{array}$ \\
\hline GDP per capita in 2004 & & $\begin{array}{l}4.12 \mathrm{e}-05^{*} \\
(2.32 \mathrm{e}-05)\end{array}$ & & $\begin{array}{l}3.90 \mathrm{e}-05^{*} \\
(2.15 \mathrm{e}-05)\end{array}$ \\
\hline Growth \% in 2004 & & & $\begin{array}{c}-1.910^{* * *} \\
(0.668)\end{array}$ & $\begin{array}{c}-1.750^{* * *} \\
(0.655)\end{array}$ \\
\hline Observations & 287 & 250 & 250 & 250 \\
\hline \multicolumn{5}{|l|}{ Dowry deaths } \\
\hline Agricultural \% of population in 2001 & $\begin{array}{c}0.0156 \\
(0.0141)\end{array}$ & $\begin{array}{c}0.0181 \\
(0.0187)\end{array}$ & $\begin{array}{c}0.0167 \\
(0.0118)\end{array}$ & $\begin{array}{c}0.0179 \\
(0.0170)\end{array}$ \\
\hline GDP per capita in 2004 & & $\begin{array}{c}2.62 \mathrm{e}-05 \\
(2.90 \mathrm{e}-05)\end{array}$ & & $\begin{array}{c}2.38 \mathrm{e}-05 \\
(2.70 \mathrm{e}-05)\end{array}$ \\
\hline Growth \% in 2004 & & & $\begin{array}{c}-2.053^{* *} \\
(0.852)\end{array}$ & $\begin{array}{c}-1.942^{* *} \\
(0.947)\end{array}$ \\
\hline Observations & 256 & 233 & 233 & 233 \\
\hline \multicolumn{5}{|l|}{ Cruelty } \\
\hline Agricultural \% of population in 2001 & $\begin{array}{c}0.00330 \\
(0.00907)\end{array}$ & $\begin{array}{l}0.00165 \\
(0.0116)\end{array}$ & $\begin{array}{l}-0.000699 \\
(0.00744)\end{array}$ & $\begin{array}{c}0.000573 \\
(0.0106)\end{array}$ \\
\hline GDP per capita in 2004 & & $\begin{array}{c}2.81 \mathrm{e}-05 \\
(2.01 \mathrm{e}-05)\end{array}$ & & $\begin{array}{c}2.46 \mathrm{e}-05 \\
(1.88 \mathrm{e}-05)\end{array}$ \\
\hline Growth \% in 2004 & & & $\begin{array}{c}-1.731^{* * *} \\
(0.552)\end{array}$ & $\begin{array}{c}-1.601^{* * *} \\
(0.575)\end{array}$ \\
\hline Observations & 289 & 254 & 254 & 254 \\
\hline \multicolumn{5}{|l|}{ Insult to modesty } \\
\hline Agricultural \% of population in 2001 & $\begin{array}{c}-0.000884 \\
(0.0312)\end{array}$ & $\begin{array}{c}0.000907 \\
(0.0308)\end{array}$ & $\begin{array}{c}-0.000762 \\
(0.0294)\end{array}$ & $\begin{array}{c}0.00162 \\
(0.0308)\end{array}$ \\
\hline GDP per capita in 2004 & & $\begin{array}{c}5.08 \mathrm{e}-05 \\
(5.56 \mathrm{e}-05)\end{array}$ & & $\begin{array}{c}4.81 \mathrm{e}-05 \\
(5.34 \mathrm{e}-05)\end{array}$ \\
\hline Growth \% in 2004 & & & $\begin{array}{l}-2.138 \\
(2.136)\end{array}$ & $\begin{array}{l}-1.365 \\
(1.430)\end{array}$ \\
\hline Observations & 211 & 189 & 189 & 189 \\
\hline State fixed effects & YES & YES & YES & YES \\
\hline
\end{tabular}

${ }^{a}$ Crime rate calculated as incidents per 100 million females.

(All these crimes are reported exclusively against women.)

Robust standard errors in parentheses. ${ }^{* * *} \mathrm{p}<0.01,{ }^{* *} \mathrm{p}<0.05,{ }^{*} \mathrm{p}<0.1$ 
All this evidence suggests that there are considerable barriers facing the development of women in agricultural societies. As we outlined in Figure 3.1, the organization of work in agricultural societies is often such that women are restricted to roles that do not directly generate income. Even when they occupy economically productive roles, their work may be deliberately downplayed or underpaid. What makes this possible, and which further contributes to the perceived lack of importance of women, is the set of cultural beliefs that perpetuates the notion that women are less important than men. Though it is difficult to empirically disentangle the impact of the organization of society from the values emerging from such an organization, we attempt to do this via the Shakti Peeth temples. We find that the impact of agriculture on female literacy is even more significant than that of the Shakti Peeths. At the same time, the considerable impact of agriculture that we see on female-centric outcomes would not be possible without the cultural values that reinforce the prejudices associated with that way of life.

\section{8}

\section{Conclusion}

The Shakti Peeth temples are an incredible historical example of the celebration of feminine power, made especially remarkable because of their setting in a male-dominated society. The story of their origin is also fascinating, both for the literary content of the story, but especially for the alluring possibility that even something as opaque in its origin as myth can be traced back to historical circumstances and to the prevailing values of the time. We believe that this particular myth is a potent example of how the cultural values of a time and place come to be manifested in a physical outcome which further perpetuates that value system.

We argue here that agricultural societies place less importance on women in everyday life, and that these values also render them less likely to prioritize women in the spiritual realm. This in turn influences how future generations view women because of the cultural cues they find in places such as temples, which play such an important role in Hindu social life. The association of women deities with power within the realm of temples does not guarantee that actual women will be treated on par with men. But it does beget the possibility that societal perception of women will not be that of weak, dependent creatures unworthy of education and other opportunities for success. The propensity to worship female deities is both a symptom and a cause of a value system that can have measurable impacts on development outcomes, apart from playing a perpetuating role in the organization of society. 
The association of our myth, and the cultural values surrounding it, to geographic conditions suggests that initial conditions are very important. It implies that our histories, our culture, and subsequently, even our myths, may be attributed to the outcome we draw in a random game governed by nature. However, the purpose of this work is not to extol the role of geography in determining our development as individuals and societies. The point is to understand, given this initial restraint, how people choose to define their lives, through the institutions that organize their interactions as a society and through the culture that gives meaning to these interactions. The "random" generation of a body of sacred temples shows the power of human agency in defining culture, which is often treated as innate in economic thought. Granted, our argument in this work is that the pattern of cultural generation followed one laid out by geographical circumstances. Nonetheless, this need not always be the case. While we cannot exactly go back and rewrite the scriptures, we can certainly take this example to learn that cultural beliefs have real power to impact actions and thus influence outcomes. This knowledge is valuable in harnessing culture as a progressive force while designing policies that hope to change the world to be a better, and more equitable, place. 


\section{Bibliography}

Acemoglu, D., Johnson, S., and Robinson, J. A. (2005). Institutions as a fundamental cause of long-run growth. Handbook of economic growth, $1: 385-472$.

Ager, P. and Brückner, M. (2013a). Cultural diversity and economic growth: Evidence from the us during the age of mass migration. European Economic Review, 64:76-97.

Ager, P. and Brückner, M. (2013b). Immigrants' genes: Genetic diversity and economic development in the us.

Alesina, A., Baqir, R., and Easterly, W. (1999). Public goods and ethnic divisions. The Quarterly Journal of Economics, 114(4):1243-1284.

Alesina, A., Devleeschauwer, A., Easterly, W., Kurlat, S., and Wacziarg, R. (2003). Fractionalization. Journal of Economic growth, 8(2):155-194.

Alesina, A. and Ferrara, E. L. (2005). Ethnic diversity and economic performance. Journal of economic literature, 43(3):762-800.

Alesina, A., Giuliano, P., and Nunn, N. (2013). On the origins of gender roles: Women and the plough. The Quarterly Journal of Economics, 128(2):469-530.

Alesina, A., Harnoss, J., and Rapoport, H. (2016). Birthplace diversity and economic prosperity. Journal of Economic Growth, 21(2):101-138.

Alesina, A. and Spolaore, E. (1997). On the number and size of nations. The Quarterly Journal of Economics, 112(4):1027-1056.

Arslan, M. (2001). The work ethic values of protestant british, catholic irish and muslim turkish managers. Journal of Business Ethics, 31(4):321-339.

Banerjee, A. and Iyer, L. (2005). History, institutions, and economic performance: The legacy of colonial land tenure systems in india. American economic review, 95(4):1190-1213.

Banerjee, A. V. et al. (2000). Prospects and strategies for land reform. In Annual World Bank Conference on Development Economics 1999, pages 253-84. World Bank.

Barro, R. J. and McCleary, R. (2003). Religion and economic growth. Technical report, National Bureau of Economic Research.

Bates, C. et al. (2013). Subalterns and Raj: South Asia since 1600. Routledge. Bathla, S. (2014). Public and private capital formation and agricultural growth 
in india: State level analysis of inter-linkages during pre-and post-reform periods. Agricultural Economics Research Review, 27(1).

Bellini, E., Ottaviano, G. I., Pinelli, D., and Prarolo, G. (2013). Cultural diversity and economic performance: evidence from european regions. In Geography, institutions and regional economic performance, pages 121-141. Springer.

Besley, T. and Burgess, R. (2000). Land reform, poverty reduction, and growth: Evidence from india. The Quarterly Journal of Economics, 115(2):389-430.

Bhaduri, A. (1973). A study in agricultural backwardness under semi-feudalism. The Economic Journal, 83(329):120-137.

Bhalla, S. (1995). Development, poverty and policy: the haryana experience. Economic and Political Weekly, pages 2619-2634.

Bhanu, D. (1979). The Province of Agra: Its History and Administration. Concept Publishing Company.

Bhel, Y. (2012). Religious tourism in himachal pradesh _ a study of shakti peeth circuit of himachal pradesh.

Chakravarti, A. (1973). Green revolution in india. Annals of the Association of American Geographers, 63(3):319-330.

Challa, O., Ramamurthy, V., and Venugopalan, M. (2004). Dynamics of land use in relation to green revolution in india. Land cover and land use, Encyclopedia of Life Support Systems. EOLSS-UNESCO Publ., Oxford.

Cleaver, H. M. (1972). The contradictions of the green revolution. The American Economic Review, 62(1/2):177-186.

Commission, P. et al. (1973). Report of the task force on agrarian relations. New Delhi, page 14.

de Secondat, C. and De Montesquieu, B. (1748). The Spirit of Laws. Cambridge University Press, Cambridge.

Diamond, J. M. (1998). Guns, germs and steel: a short history of everybody for the last 13,000 years. Random House.

Dixit, R. K. S. S. (2014). Scenario of sanskritization at shaktipeeths-a step towards empowerment of the marginalised. International Journal of Scientific and Research Publications, page 204.

Easterly, W. and Levine, R. (1997). Africa's growth tragedy: policies and ethnic divisions. The quarterly journal of economics, 112(4):1203-1250.

Easterly, W. and Levine, R. (2003). Tropics, germs, and crops: how endowments influence economic development. Journal of monetary economics, 50(1):3-39.

Eck, D. L. (2012). India: A sacred geography. Harmony. 
Farmer, B. (1981). The" green revolution" in south asia. Geography, pages 202-207.

Fujita, K. (2009). Green revolution in india and its significance in economic development: Implications for sub-saharan africa. JICA-IR Working Paper (Tokyo: JICA Research Institute, 2010)[https://www. jica. go. jp/jica-ri/publication/workingpaper/jrft3q000000231s-att/JICA-RI_WP_No. 17_2010. pdf, accessed 9 June 2015].

Gennaioli, N., La Porta, R., Lopez-de Silanes, F., and Shleifer, A. (2012). Human capital and regional development. The Quarterly journal of economics, 128(1):105-164.

Ghatak, M. and Roy, S. (2007). Land reform and agricultural productivity in india: a review of the evidence. Oxford Review of Economic Policy, 23(2):251-269.

Guha, R. (2007). India after gandhi. The History of the World's Largest Democracy, op. cit, page 159.

Guiso, L., Sapienza, P., and Zingales, L. (2006). Does culture affect economic outcomes? Journal of Economic perspectives, 20(2):23-48.

Gupta, R. D. (1959). An architectural survey of the kamakhya temple, gauhati. In Proceedings of the Indian History Congress, volume 22, pages 483-492. JSTOR.

Inglehart, R., Norris, P., Ronald, I., et al. (2003). Rising tide: Gender equality and cultural change around the world. Cambridge University Press.

Inglehart, R. F. (2008). Changing values among western publics from 1970 to 2006. West european politics, 31(1-2):130-146.

Jha, S. (2008). Trade, institutions and religious tolerance: evidence from india. Johl, S. (1975). Gains of the green revolution: how they have been shared in punjab. The Journal of Development Studies, 11(3):178-189.

John, R. M. and Mutatkar, R. (2005). Statewise estimates of poverty among religious groups in india. Economic and Political Weekly, pages $1337-1345$.

Krishnaji, N. (1975). Inter-regional disparities in per capita production and productivity of foodgrains: A preliminary note on trends. Economic and Political Weekly, pages 1377-1385.

Krishnakumar, R. (2004). Reversing land reforms. Frontline, 21(4):14-27.

Landes, D. S. (1998). The wealth and poverty of nations: Why are some so rich and others so poor.

McDaniel, J. (2004). Offering Flowers, Feeding Skulls: Popular Goddess Worship in West Bengal. Oxford University Press.

Montalvo, J. G. and Reynal-Querol, M. (2005a). Ethnic diversity and economic 
development. Journal of Development economics, 76(2):293-323.

Montalvo, J. G. and Reynal-Querol, M. (2005b). Ethnic polarization, potential conflict, and civil wars. American economic review, 95(3):796-816.

Montalvo, J. G., Reynal-Querol, M., et al. (2002). Why ethnic fractionalization? polarization, ethnic conflict and growth. Technical report.

Munshi, K. (2004). Social learning in a heterogeneous population: technology diffusion in the indian green revolution. Journal of development Economics, 73(1):185-213.

Ninan, K. and Chandrashekar, H. (1993). Green revolution, dryland agriculture and sustainability: insights from india. Economic and Political Weekly, pages A2-A7.

Olsson, O. and Hibbs Jr, D. A. (2005). Biogeography and long-run economic development. European Economic Review, 49(4):909-938.

Ottaviano, G. I. and Peri, G. (2004). Cities and cultures.

Ottaviano, G. I. and Peri, G. (2006). The economic value of cultural diversity: evidence from us cities. Journal of Economic geography, 6(1):9-44.

Padoux, A. (2002). What do we mean by tantrism? The Roots of Tantra, pages $17-24$.

Panagariya, A., More, V., et al. (2013). Poverty by social, religious and economic groups in india and its largest states 1993-94 to 2011-12. Program on Indian Economic Policies, Columbia University Working Paper, (2013-02).

Parayil, G. (1992). The green revolution in india: A case study of technological change. Technology and Culture, 33(4):737-756.

Rigg, J. (1989). The green revolution and equity: who adopts the new rice varieties and why? Geography, pages 144-150.

Sachs, J. D. (2001). Tropical underdevelopment. Technical report, National Bureau of Economic Research.

Sandhu, J. S. (2014). Green revolution: A case study of punjab. In Proceedings of the Indian History Congress, volume 75, pages 1192-1199. JSTOR.

Sawant, S. and Achuthan, C. (1995). Agricultural growth across crops and regions: emerging trends and patterns. Economic and Political Weekly, pages A2-A13.

Sharma, H. (1994). Distribution of landholdings in rural india, 1953-54 to 1981-82: Implications for land reforms. Economic and Political weekly, pages A12-A25.

Shlain, L. (1999). The alphabet versus the goddess: The conflict between word and image. Penguin. 
Singh, P. (2014). Trends of public and private investment in indian agriculture: An inter state analysis. Journal of Humanities and Social Science, 19(11):48-58.

Sircar, D. (1998). The Śākta Pịthas, volume 8. Motilal Banarsidass Publ.

Spolaore, E. and Alesina, A. (2003). The size of nations. Mit Press Cambridge, MA.

Srinivasan, T. (1979). Trends in agriculture in india, 1949-50-1977-78. Economic and Political Weekly, pages 1283-1294.

Tabellini, G. (2010). Culture and institutions: economic development in the regions of europe. Journal of the European Economic association, $8(4): 677-716$.

Thiesenhusen, W. C. (1974). What changing technology implies for agrarian reform. Land Economics, 50(1):35-50.

Thorner, D. (1976). Agrarian prospect in india. 
Appendices

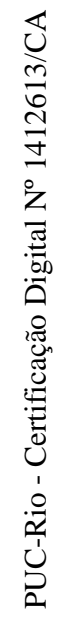


A

\section{Appendices for Paper 1}

\section{A.1 \\ Comparison of historical data on landlord control}

Table A.1: Historical data comparison

\begin{tabular}{|c|c|c|c|c|c|c|c|c|c|}
\hline \multirow[b]{2}{*}{ STATE } & \multicolumn{3}{|c|}{ Banerjee and Iyer } & \multicolumn{3}{|c|}{$\begin{array}{l}\text { Imperial Gazetteer } \\
\text { (Full sample) }\end{array}$} & \multicolumn{3}{|c|}{$\begin{array}{c}\text { Imperial Gazetteer } \\
\text { (British districts only) }\end{array}$} \\
\hline & $\begin{array}{l}\text { Mean non- } \\
\text { landlord } \\
\text { proportion }\end{array}$ & $\begin{array}{l}\text { Landlord } \\
\text { districts }\end{array}$ & $\begin{array}{c}\text { Total } \\
\text { districts }\end{array}$ & $\begin{array}{l}\text { Mean non- } \\
\text { landlord } \\
\text { proportion }\end{array}$ & $\begin{array}{c}\text { Landlord } \\
\text { districts }\end{array}$ & $\begin{array}{c}\text { Total } \\
\text { districts }\end{array}$ & $\begin{array}{l}\text { Mean non- } \\
\text { landlord } \\
\text { proportion }\end{array}$ & $\begin{array}{l}\text { Landlord } \\
\text { districts }\end{array}$ & $\begin{array}{c}\text { Total } \\
\text { districts }\end{array}$ \\
\hline Andhra Pradesh & 0.66 & 2 & 10 & 0.66 & 4 & 20 & 0.60 & 4 & 11 \\
\hline Bihar & 0.00 & 12 & 12 & 0.16 & 14 & 17 & 0.16 & 14 & 17 \\
\hline Gujarat & 1.00 & 0 & 7 & 0.79 & 3 & 16 & 0.57 & 3 & 6 \\
\hline Haryana & 0.85 & 0 & 5 & 0.31 & 5 & 6 & 0.37 & 4 & 5 \\
\hline Karnataka & 1.00 & 0 & 15 & 0.89 & 1 & 19 & 0.91 & 0 & 7 \\
\hline Madhya Pradesh & 0.10 & 14 & 15 & 0.17 & 38 & 43 & 0.04 & 14 & 14 \\
\hline Maharashtra & 0.78 & 4 & 18 & 0.67 & 7 & 25 & 0.64 & 6 & 19 \\
\hline Orissa & 0.32 & 6 & 8 & 0.27 & 9 & 13 & 0.16 & 5 & 7 \\
\hline Punjab & 0.87 & 0 & 6 & 0.41 & 6 & 10 & 0.42 & 4 & 7 \\
\hline Rajasthan & 0.00 & 1 & 1 & 0.35 & 20 & 26 & 0.00 & 1 & 1 \\
\hline Tamil Nadu & 0.75 & 2 & 11 & 0.73 & 2 & 13 & 0.71 & 2 & 12 \\
\hline Uttar Pradesh & 0.42 & 12 & 47 & 0.02 & 46 & 47 & 0.02 & 45 & 46 \\
\hline West Bengal & 0.00 & 11 & 11 & 0.00 & 15 & 15 & 0.00 & 14 & 14 \\
\hline Total & 0.51 & 64 & 166 & 0.37 & 170 & 270 & 0.29 & 116 & 166 \\
\hline
\end{tabular}

1) Highlighted states are those for which Banerjee and Iyer have district-level information on the proportion of villages, estates or land area not under the revenue liability of landlords. For the remaining states the non-landlord measure is assigned as zero or one in Banerjee and Iyer (2005).

2) The sample shown here is restricted by the number of districts covered in the World Bank dataset. The full historical cross-section consists of 327 districts, including 194 British districts.

3) The binary definition of landlord districts differs in Bannerjee and Iyer (2005) and this work. We consider any district with more than half of its area under non-landlord control to be a non-landlord district. Bannerjee and Iyer (2005) consider non-landlord districts to be those districts that are fully under non-landlord control. 


\section{A. 2 \\ Results excluding Uttar Pradesh}

Table A.2: Agricultural investments 1957-86, excluding Uttar Pradesh

\begin{tabular}{|c|c|c|c|c|c|c|}
\hline \multirow[b]{2}{*}{$\begin{array}{l}\text { TYPE OF } \\
\text { MIDDLEMAN }\end{array}$} & \multicolumn{3}{|c|}{ FULL SAMPLE } & \multicolumn{3}{|c|}{ BRITISH DISTRICTS ONLY } \\
\hline & $\begin{array}{c}\text { Mean of } \\
\text { dependent } \\
\text { variable }\end{array}$ & $\begin{array}{l}\text { Coefficient } \\
\text { on non- } \\
\text { middleman } \\
\text { proportion } \\
\quad(1)\end{array}$ & $\begin{array}{c}\text { Coefficient } \\
\text { on Majority } \\
\text { dummy } \\
(2)\end{array}$ & $\begin{array}{l}\text { Mean of } \\
\text { dependent } \\
\text { variable }\end{array}$ & $\begin{array}{l}\text { Coefficient } \\
\text { on non- } \\
\text { middleman } \\
\text { proportion } \\
(3)\end{array}$ & $\begin{array}{c}\text { Coefficient } \\
\text { on Majority } \\
\text { dummy } \\
(4)\end{array}$ \\
\hline \multicolumn{7}{|l|}{$\overline{\text { Irrigation (\% area) }}$} \\
\hline All middlemen & 0.214 & $\begin{array}{l}0.110^{* *} \\
(0.0435)\end{array}$ & $\begin{array}{c}0.0850^{* * *} \\
(0.0308)\end{array}$ & 0.258 & $\begin{array}{l}0.0991^{*} \\
(0.0595)\end{array}$ & $\begin{array}{l}0.0789^{*} \\
(0.0444)\end{array}$ \\
\hline Landlords & & $\begin{array}{l}0.0909^{* *} \\
(0.0409)\end{array}$ & $\begin{array}{c}0.0732^{* *} \\
(0.0299)\end{array}$ & & $\begin{array}{c}0.0585 \\
(0.0557)\end{array}$ & $\begin{array}{c}0.0551 \\
(0.0429)\end{array}$ \\
\hline Observations & & 7,040 & 7,040 & & 3,744 & 3,744 \\
\hline \multicolumn{7}{|l|}{ Fertilizer use $(\mathrm{kg} / \mathrm{ha})$} \\
\hline All middlemen & 18.56 & $\begin{array}{c}17.98^{* * *} \\
(4.248)\end{array}$ & $\begin{array}{c}12.21^{* * *} \\
(3.310)\end{array}$ & 22.84 & $\begin{array}{c}20.26^{* * *} \\
(5.684)\end{array}$ & $\begin{array}{c}15.61^{* * *} \\
(4.524)\end{array}$ \\
\hline Landlords & & $\begin{array}{c}14.25^{* * *} \\
(3.963)\end{array}$ & $\begin{array}{c}10.25^{* * *} \\
(3.105)\end{array}$ & & $\begin{array}{c}16.34^{* * *} \\
(5.295)\end{array}$ & $\begin{array}{c}13.61^{* * *} \\
(4.233)\end{array}$ \\
\hline Observations & & 7,040 & 7,040 & & 3,744 & 3,744 \\
\hline \multicolumn{7}{|l|}{ Rice (\% HYV) } \\
\hline All middlemen & 0.249 & $\begin{array}{c}0.0796^{* *} \\
(0.0391)\end{array}$ & $\begin{array}{c}0.0712^{* * *} \\
(0.0267)\end{array}$ & 0.273 & $\begin{array}{c}0.123^{* * *} \\
(0.0416)\end{array}$ & $\begin{array}{c}0.0540 \\
(0.0332)\end{array}$ \\
\hline Landlords & & $\begin{array}{l}0.0597^{*} \\
(0.0343)\end{array}$ & $\begin{array}{l}0.0595^{* *} \\
(0.0241)\end{array}$ & & $\begin{array}{l}0.0927^{* *} \\
(0.0378)\end{array}$ & $\begin{array}{c}0.0415 \\
(0.0290)\end{array}$ \\
\hline Observations & & 6,615 & 6,615 & & 3,734 & 3,734 \\
\hline \multicolumn{7}{|l|}{ Wheat (\% HYV) } \\
\hline All middlemen & 0.513 & $\begin{array}{c}0.420^{* * *} \\
(0.0888)\end{array}$ & $\begin{array}{c}0.263^{* * *} \\
(0.0636)\end{array}$ & 0.480 & $\begin{array}{l}0.168^{* * *} \\
(0.0634)\end{array}$ & $\begin{array}{c}0.137^{* * *} \\
(0.0391)\end{array}$ \\
\hline Landlords & & $\begin{array}{l}0.305^{* * *} \\
(0.0823)\end{array}$ & $\begin{array}{l}0.197^{* * *} \\
(0.0595)\end{array}$ & & $\begin{array}{c}0.0805 \\
(0.0725)\end{array}$ & $\begin{array}{c}0.0752 \\
(0.0499)\end{array}$ \\
\hline Observations & & 6,138 & 6,138 & & 3,069 & 3,069 \\
\hline \multicolumn{7}{|l|}{ Other cereals (\% HYV) } \\
\hline All middlemen & 0.210 & $\begin{array}{l}-0.00686 \\
(0.0678)\end{array}$ & $\begin{array}{l}-0.00555 \\
(0.0657)\end{array}$ & 0.277 & $\begin{array}{r}-0.0586 \\
(0.129)\end{array}$ & $\begin{array}{l}-0.0254 \\
(0.133)\end{array}$ \\
\hline Landlords & & $\begin{array}{c}0.0157 \\
(0.0544)\end{array}$ & $\begin{array}{l}0.00833 \\
(0.0565)\end{array}$ & & $\begin{array}{l}0.00316 \\
(0.0997)\end{array}$ & $\begin{array}{l}0.0106 \\
(0.111)\end{array}$ \\
\hline Observations & & 6,860 & 6,860 & & 3,588 & 3,588 \\
\hline Year fixed effects & & YES & YES & & YES & YES \\
\hline Geographical controls & & YES & YES & & YES & YES \\
\hline Institution determinants $^{a}$ & & YES & YES & & YES & YES \\
\hline
\end{tabular}

${ }^{a}$ Includes individual administrators, Mutiny of 1857 , years of colonial rule and pre-existing landlord class.

Robust standard errors in parentheses. ${ }^{* *} \mathrm{p}<0.01,{ }^{* *} \mathrm{p}<0.05,{ }^{*} \mathrm{p}<0.1$ 
B

Appendices for Paper 2

\section{B.1 \\ Reduced form regressions}

Table B.1: Impact of past religious fractionalization on current economic outcomes, reduced form

\begin{tabular}{|c|c|c|c|c|}
\hline & (1) & $(2)$ & $(3)$ & (4) \\
\hline \multicolumn{5}{|l|}{ A: Log GDP per capita (2005) } \\
\hline Religious fractionalization (1901) & $\begin{array}{c}0.751^{*} \\
(0.399)\end{array}$ & $\begin{array}{c}0.423 \\
(0.288)\end{array}$ & $\begin{array}{c}0.566^{*} \\
(0.289)\end{array}$ & $\begin{array}{c}0.566^{*} \\
(0.296)\end{array}$ \\
\hline Colonial period urbanization & $\begin{array}{c}0.0533^{* * *} \\
(0.00765)\end{array}$ & $\begin{array}{c}0.0468^{* * *} \\
(0.00403)\end{array}$ & $\begin{array}{c}0.0395^{* * *} \\
(0.00544)\end{array}$ & $\begin{array}{c}0.0397^{* * *} \\
(0.00545)\end{array}$ \\
\hline Literacy (2001) & & & $\begin{array}{c}1.572^{* * *} \\
(0.189)\end{array}$ & $\begin{array}{c}1.574^{* * *} \\
(0.197)\end{array}$ \\
\hline Population density (2001) & & & & $\begin{array}{l}-4.01 \mathrm{e}-07 \\
(8.49 \mathrm{e}-06)\end{array}$ \\
\hline State fixed effects & $\mathrm{NO}$ & YES & YES & YES \\
\hline Observations & 426 & 426 & 426 & 426 \\
\hline \multicolumn{5}{|c|}{ B: \% of households above poverty line (2008) } \\
\hline Religious fractionalization (2001) & $\begin{array}{c}36.15^{* * *} \\
(11.58)\end{array}$ & $\begin{array}{c}23.88^{*} \\
(11.65)\end{array}$ & $\begin{array}{c}26.72^{* *} \\
(11.81)\end{array}$ & $\begin{array}{c}26.40^{* *} \\
(11.75)\end{array}$ \\
\hline Colonial period urbanization & $\begin{array}{c}0.494^{* * *} \\
(0.120)\end{array}$ & $\begin{array}{c}0.532^{* * *} \\
(0.165)\end{array}$ & $\begin{array}{c}0.355^{* *} \\
(0.143)\end{array}$ & $\begin{array}{c}0.259 \\
(0.254)\end{array}$ \\
\hline Literacy (2001) & & & $\begin{array}{c}39.82^{* * *} \\
(7.546)\end{array}$ & $\begin{array}{c}39.15^{* * *} \\
(7.507)\end{array}$ \\
\hline Population density (2001) & & & & $\begin{array}{c}0.000179 \\
(0.000360)\end{array}$ \\
\hline State fixed effects & $\mathrm{NO}$ & YES & YES & YES \\
\hline Observations & 488 & 488 & 488 & 488 \\
\hline
\end{tabular}


Table B.2: Impact of past linguistic minorities, institutions, literacy and population density on current economic outcomes, reduced form

\begin{tabular}{|c|c|c|c|c|}
\hline & $(1)$ & $(2)$ & $(3)$ & $(4)$ \\
\hline \multicolumn{5}{|l|}{ A: Log GDP per capita (2005) } \\
\hline \multirow[t]{2}{*}{ Linguistic minorities (1901) } & 0.0866 & 0.0698 & 0.176 & 0.148 \\
\hline & $(0.251)$ & $\begin{array}{r}(0.142) \\
-0.0550\end{array}$ & $\begin{array}{r}(0.136) \\
-0.0189\end{array}$ & $\begin{array}{r}(0.146) \\
-0.0237\end{array}$ \\
\hline Institutions (1901) & & $(0.0713)$ & $(0.0439)$ & $(0.0453)$ \\
\hline Literacy (1901) & & & $\begin{array}{c}0.852^{* *} \\
(0.341)\end{array}$ & $\begin{array}{c}0.857^{* *} \\
(0.328)\end{array}$ \\
\hline Population density (1901) & & & & $\begin{array}{c}-0.000119 \\
(0.000110)\end{array}$ \\
\hline Colonial period urbanization & $\begin{array}{c}0.0467^{* * *} \\
(0.0105)\end{array}$ & $\begin{array}{c}0.296^{* * *} \\
(0.0315)\end{array}$ & $\begin{array}{c}0.225^{* * *} \\
(0.0434)\end{array}$ & $\begin{array}{c}0.270^{* * *} \\
(0.0444)\end{array}$ \\
\hline Literacy (2001) & & & $\begin{array}{c}1.392^{* * *} \\
(0.136)\end{array}$ & $\begin{array}{c}1.407^{* * *} \\
(0.137)\end{array}$ \\
\hline Population density (2001) & & & & $\begin{array}{c}4.48 \mathrm{e}-06 \\
(3.48 \mathrm{e}-06)\end{array}$ \\
\hline State fixed effects & $\mathrm{NO}$ & YES & YES & YES \\
\hline Observations & 443 & 410 & 392 & 392 \\
\hline \multicolumn{5}{|c|}{ B: \% of households above poverty line (2008) } \\
\hline Linguistic minorities (1901) & $\begin{array}{l}-4.242 \\
(7.084)\end{array}$ & $\begin{array}{l}-2.508 \\
(3.567)\end{array}$ & $\begin{array}{l}-3.766 \\
(3.872)\end{array}$ & $\begin{array}{l}-4.336 \\
(4.427)\end{array}$ \\
\hline Institutions (1901) & & $\begin{array}{l}-1.208 \\
(1.854)\end{array}$ & $\begin{array}{l}-0.849 \\
(1.561)\end{array}$ & $\begin{array}{l}-0.788 \\
(1.657)\end{array}$ \\
\hline Literacy (1901) & & & $\begin{array}{c}5.566 \\
(11.40)\end{array}$ & $\begin{array}{c}5.254 \\
(10.70)\end{array}$ \\
\hline Population density (1901) & & & & $\begin{array}{c}-0.00244 \\
(0.00339)\end{array}$ \\
\hline Colonial period urbanization & $\begin{array}{c}1.333^{* * *} \\
(0.329)\end{array}$ & $\begin{array}{c}5.280^{* * *} \\
(1.340)\end{array}$ & $\begin{array}{c}3.494^{* * *} \\
(1.067)\end{array}$ & $\begin{array}{c}4.298^{* * *} \\
(1.461)\end{array}$ \\
\hline Literacy (2001) & & & $\begin{array}{c}36.63^{* * *} \\
(7.288)\end{array}$ & $\begin{array}{c}36.44^{* * *} \\
(7.412)\end{array}$ \\
\hline Population density (2001) & & & & $\begin{array}{c}0.000239 \\
(0.000435)\end{array}$ \\
\hline State fixed effects & NO & YES & YES & YES \\
\hline Observations & 502 & 466 & 448 & 448 \\
\hline
\end{tabular}


Table B.3: Impact of historical indicators of diversity, institutions, literacy and population density on current economic outcomes, reduced form

\begin{tabular}{|c|c|c|c|c|}
\hline & $(1)$ & $(2)$ & $(3)$ & $(4)$ \\
\hline \multicolumn{5}{|l|}{ A: Log GDP per capita (2005) } \\
\hline \multirow[t]{2}{*}{ Religious fractionalization (1901) } & $0.776^{*}$ & 0.391 & $0.605^{*}$ & 0.604 \\
\hline & $(0.434)$ & $(0.326)$ & $(0.344)$ & $(0.355)$ \\
\hline \multirow[t]{2}{*}{ Linguistic minorities (1901) } & 0.101 & 0.0668 & 0.206 & 0.165 \\
\hline & $(0.262)$ & $(0.161)$ & $(0.152)$ & $(0.154)$ \\
\hline \multirow[t]{2}{*}{ Institutions (1901) } & & -0.00337 & 0.0336 & 0.0266 \\
\hline & & $(0.0844)$ & $(0.0526)$ & $(0.0515)$ \\
\hline \multirow[t]{2}{*}{ Literacy (1901) } & & & $0.686^{* *}$ & $0.684^{* *}$ \\
\hline & & & $(0.308)$ & $(0.304)$ \\
\hline \multirow[t]{2}{*}{ Population density (1901) } & & & & -0.000135 \\
\hline & & & & $(0.000122)$ \\
\hline \multirow[t]{2}{*}{ Colonial period urbanization } & $0.0391^{* * *}$ & $0.282^{* * *}$ & $0.211^{* * *}$ & $0.266^{* * *}$ \\
\hline & $(0.0124)$ & $(0.0288)$ & $(0.0468)$ & $(0.0513)$ \\
\hline \multirow[t]{2}{*}{ Literacy (2001) } & & & $1.481^{* * *}$ & $1.506^{* * *}$ \\
\hline & & & $(0.170)$ & $(0.172)$ \\
\hline \multirow[t]{2}{*}{ Population density (2001) } & & & & $6.83 \mathrm{e}-07$ \\
\hline & & & & $(5.42 \mathrm{e}-06)$ \\
\hline State fixed effects & NO & YES & YES & YES \\
\hline Observations & 395 & 364 & 348 & 348 \\
\hline \multicolumn{5}{|c|}{ B: \% of households above poverty line (2008) } \\
\hline \multirow[t]{2}{*}{ Religious fractionalization (1901) } & $29.81^{* *}$ & 19.49 & $24.39^{*}$ & $24.01^{*}$ \\
\hline & $(11.80)$ & $(13.09)$ & $(14.01)$ & $(13.96)$ \\
\hline \multirow[t]{2}{*}{ Linguistic minorities (1901) } & -6.604 & -1.636 & -3.373 & -4.140 \\
\hline & $(7.296)$ & $(3.894)$ & $(4.096)$ & $(4.319)$ \\
\hline \multirow[t]{2}{*}{ Institutions (1901) } & & 0.0262 & 0.601 & 0.584 \\
\hline & & $(2.245)$ & $(1.836)$ & $(1.804)$ \\
\hline \multirow[t]{2}{*}{ Literacy (1901) } & & & 5.411 & 5.178 \\
\hline & & & $(9.968)$ & $(9.517)$ \\
\hline \multirow[t]{2}{*}{ Population density (1901) } & & & & -0.00251 \\
\hline & & & & $(0.00380)$ \\
\hline \multirow[t]{2}{*}{ Colonial period urbanization } & $0.994^{* * *}$ & $5.149^{* * *}$ & $3.168^{* * *}$ & $4.075^{* * *}$ \\
\hline & $(0.249)$ & $(1.096)$ & $(0.771)$ & $(1.255)$ \\
\hline \multirow[t]{2}{*}{ Literacy (2001) } & & & $41.51^{* * *}$ & $41.44^{* * *}$ \\
\hline & & & $(8.588)$ & $(8.693)$ \\
\hline \multirow[t]{2}{*}{ Population density (2001) } & & & & 0.000140 \\
\hline & & & & $(0.000364)$ \\
\hline State fixed effects & $\mathrm{NO}$ & YES & YES & YES \\
\hline Observations & 447 & 414 & 398 & 398 \\
\hline
\end{tabular}

Robust standard errors in parentheses. ${ }^{* * *} \mathrm{p}<0.01,{ }^{* *} \mathrm{p}<0.05,{ }^{*} \mathrm{p}<0.1$. 


\section{B.2}

\section{First stage regressions}

Table B.4: Historical instruments for fractionalization (separate), first stage

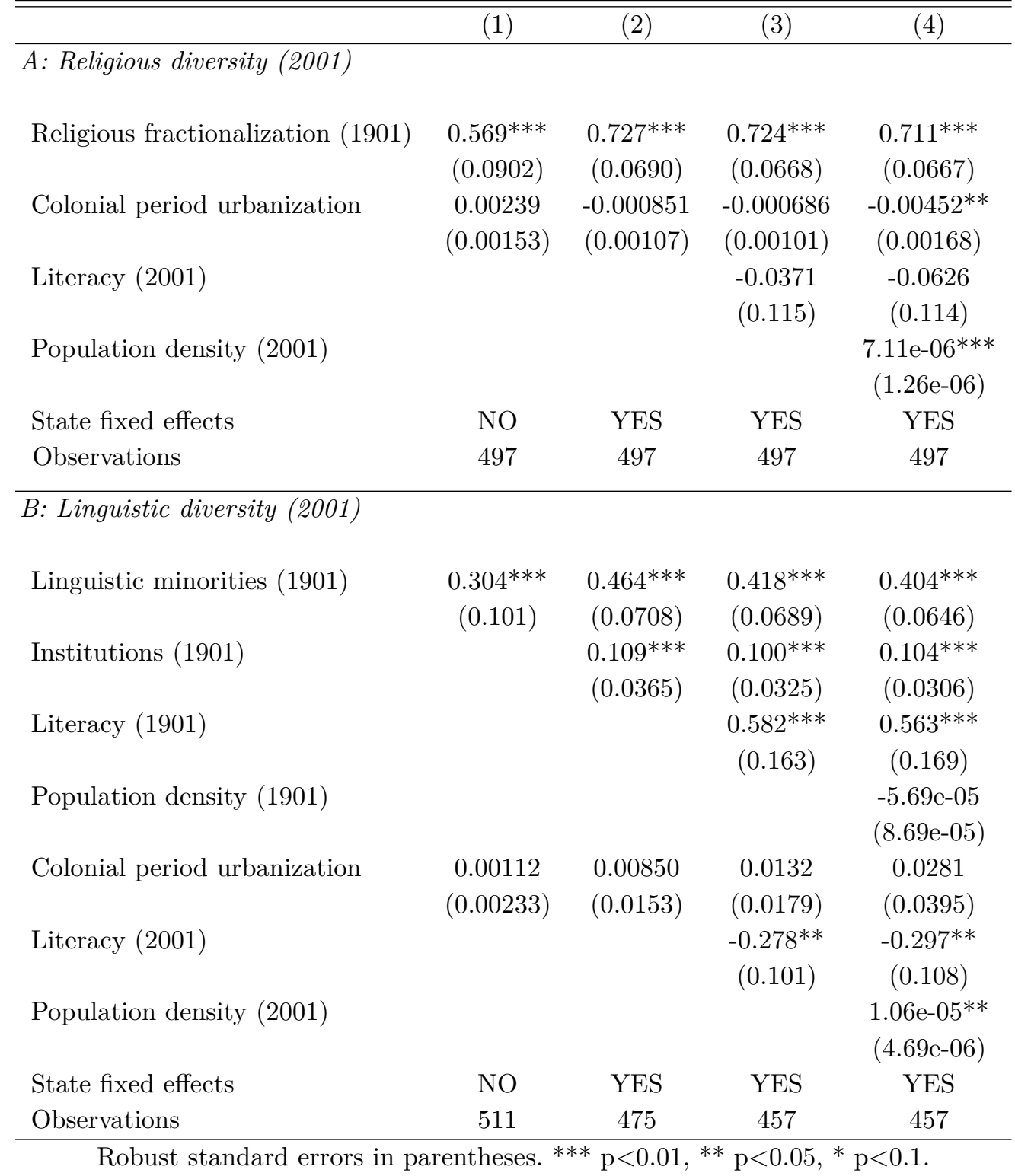


Table B.5: Historical instruments for fractionalization (joint), first stage

\begin{tabular}{|c|c|c|c|c|}
\hline & (1) & $(2)$ & $(3)$ & (4) \\
\hline \multicolumn{5}{|l|}{ A: Religious diversity (2001) } \\
\hline Religious fractionalization (1901) & $\begin{array}{c}0.567^{* * *} \\
(0.0960)\end{array}$ & $\begin{array}{c}0.728^{* * *} \\
(0.0777)\end{array}$ & $\begin{array}{c}0.740^{* * *} \\
(0.0719)\end{array}$ & $\begin{array}{c}0.721^{* * *} \\
(0.0732)\end{array}$ \\
\hline Linguistic minorities (1901) & $\begin{array}{l}0.00424 \\
(0.0576)\end{array}$ & $\begin{array}{c}0.0285 \\
(0.0434)\end{array}$ & $\begin{array}{l}0.0720^{*} \\
(0.0360)\end{array}$ & $\begin{array}{c}0.0764^{* *} \\
(0.0367)\end{array}$ \\
\hline Institutions (1901) & & $\begin{array}{c}0.00773 \\
(0.0232)\end{array}$ & $\begin{array}{c}0.0142 \\
(0.0211)\end{array}$ & $\begin{array}{c}0.0168 \\
(0.0191)\end{array}$ \\
\hline Literacy (1901) & & & $\begin{array}{l}0.00858 \\
(0.0975)\end{array}$ & $\begin{array}{l}-0.00535 \\
(0.0923)\end{array}$ \\
\hline Population density (1901) & & & & $\begin{array}{c}1.98 \mathrm{e}-05 \\
(1.92 \mathrm{e}-05)\end{array}$ \\
\hline Colonial period urbanization & $\begin{array}{r}-0.000447 \\
(0.00214)\end{array}$ & $\begin{array}{c}0.00871 \\
(0.0104)\end{array}$ & $\begin{array}{c}0.0127 \\
(0.0116)\end{array}$ & $\begin{array}{c}-0.000730 \\
(0.0133)\end{array}$ \\
\hline Literacy (2001) & & & $\begin{array}{c}-0.0493 \\
(0.126)\end{array}$ & $\begin{array}{r}-0.0824 \\
(0.125)\end{array}$ \\
\hline Population density (2001) & & & & $\begin{array}{c}7.88 \mathrm{e}-06^{* * *} \\
(1.19 \mathrm{e}-06)\end{array}$ \\
\hline State fixed effects & $\mathrm{NO}$ & YES & YES & YES \\
\hline Observations & 456 & 423 & 407 & 407 \\
\hline \multicolumn{5}{|l|}{ B: Linguistic diversity (2001) } \\
\hline Religious fractionalization (1901) & $\begin{array}{c}-0.0402 \\
(0.161)\end{array}$ & $\begin{array}{c}0.378^{* * *} \\
(0.117)\end{array}$ & $\begin{array}{c}0.324^{* * *} \\
(0.116)\end{array}$ & $\begin{array}{c}0.299 * * \\
(0.109)\end{array}$ \\
\hline Linguistic minorities (1901) & $\begin{array}{c}0.296^{* * *} \\
(0.106)\end{array}$ & $\begin{array}{c}0.553^{* * *} \\
(0.0627)\end{array}$ & $\begin{array}{c}0.517^{* * *} \\
(0.0628)\end{array}$ & $\begin{array}{c}0.497^{* * *} \\
(0.0616)\end{array}$ \\
\hline Institutions (1901) & & $\begin{array}{c}0.151^{* * *} \\
(0.0352)\end{array}$ & $\begin{array}{c}0.146^{* * *} \\
(0.0329)\end{array}$ & $\begin{array}{c}0.147^{* * *} \\
(0.0290)\end{array}$ \\
\hline Literacy (1901) & & & $\begin{array}{c}0.474^{* * *} \\
(0.140)\end{array}$ & $\begin{array}{c}0.457^{* * *} \\
(0.143)\end{array}$ \\
\hline Population density (1901) & & & & $\begin{array}{l}-6.08 \mathrm{e}-05 \\
(7.99 \mathrm{e}-05)\end{array}$ \\
\hline Colonial period urbanization & $\begin{array}{c}0.00197 \\
(0.00273)\end{array}$ & $\begin{array}{l}0.00166 \\
(0.0141)\end{array}$ & $\begin{array}{l}0.00990 \\
(0.0165)\end{array}$ & $\begin{array}{c}0.0274 \\
(0.0404)\end{array}$ \\
\hline Literacy (2001) & & & $\begin{array}{c}-0.295^{* *} \\
(0.112)\end{array}$ & $\begin{array}{c}-0.322^{* *} \\
(0.117)\end{array}$ \\
\hline Population density (2001) & & & & $\begin{array}{c}9.84 \mathrm{e}-06^{* *} \\
(4.31 \mathrm{e}-06)\end{array}$ \\
\hline State fixed effects & $\mathrm{NO}$ & YES & YES & YES \\
\hline Observations & 456 & 423 & 407 & 407 \\
\hline
\end{tabular}

\section{B.3}

Results controlling for shares of different religions 


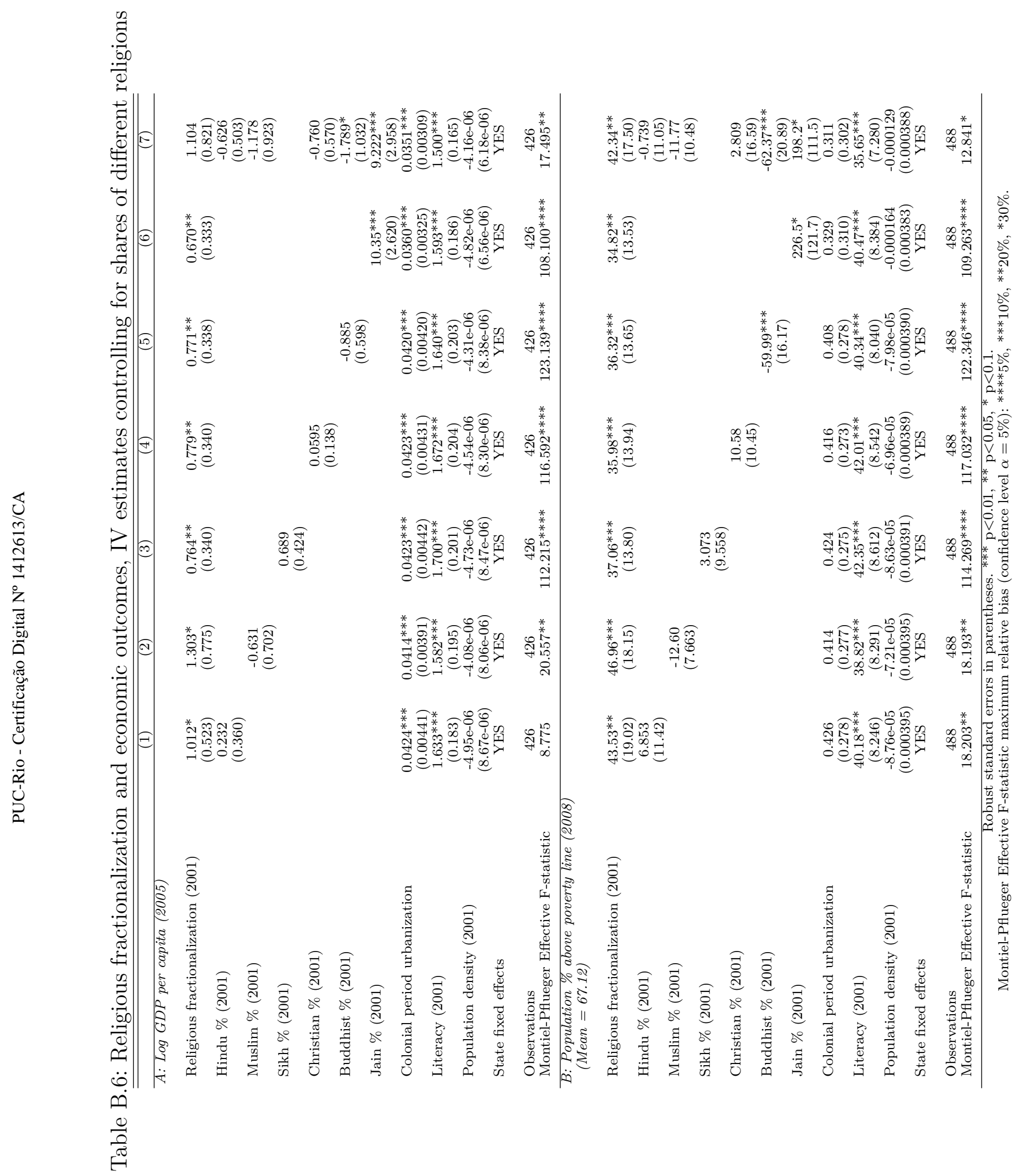




\section{B.4}

Results excluding regions directly impacted by Partition

Table B.7: Religious fractionalization and economic outcomes, IV estimates excluding Partition impacted regions

\begin{tabular}{|c|c|c|c|c|}
\hline & $(1)$ & $(2)$ & $(3)$ & $(4)$ \\
\hline \multicolumn{5}{|l|}{ A: Log GDP per capita (2005) } \\
\hline Religious fractionalization (2001) & $\begin{array}{c}0.845 \\
(0.873)\end{array}$ & $\begin{array}{c}0.787^{* * *} \\
(0.303)\end{array}$ & $\begin{array}{c}0.898^{* * *} \\
(0.337)\end{array}$ & $\begin{array}{c}0.898^{* *} \\
(0.354)\end{array}$ \\
\hline Colonial period urbanization & $\begin{array}{c}0.0585^{* * *} \\
(0.00854)\end{array}$ & $\begin{array}{c}0.0499^{* * *} \\
(0.00279)\end{array}$ & $\begin{array}{c}0.0438^{* * *} \\
(0.00248)\end{array}$ & $\begin{array}{c}0.0439^{* * *} \\
(0.00254)\end{array}$ \\
\hline Literacy (2001) & & & $\begin{array}{c}1.662^{* * *} \\
(0.196)\end{array}$ & $\begin{array}{c}1.663^{* * *} \\
(0.215)\end{array}$ \\
\hline Population density (2001) & & & & $\begin{array}{l}-2.33 \mathrm{e}-07 \\
(7.54 \mathrm{e}-06)\end{array}$ \\
\hline State fixed effects & NO & YES & YES & YES \\
\hline Observations & 376 & 376 & 376 & 376 \\
\hline Montiel-Pflueger Effective F-statistic & $16.294^{* *}$ & $111.752^{* * * *}$ & $125.286^{* * * *}$ & $118.175^{* * * *}$ \\
\hline \multicolumn{5}{|l|}{$\begin{array}{l}\text { B: Population \% above poverty line (2008) } \\
\quad(\text { Mean }=67.12)\end{array}$} \\
\hline Religious fractionalization (2001) & $\begin{array}{c}67.80^{* *} \\
(29.82)\end{array}$ & $\begin{array}{c}42.16^{* * *} \\
(13.45)\end{array}$ & $\begin{array}{c}43.70^{* * *} \\
(13.92)\end{array}$ & $\begin{array}{c}44.27^{* * *} \\
(14.46)\end{array}$ \\
\hline Colonial period urbanization & $\begin{array}{c}0.199 \\
(0.222)\end{array}$ & $\begin{array}{c}0.417^{* * *} \\
(0.119)\end{array}$ & $\begin{array}{c}0.269^{* *} \\
(0.118)\end{array}$ & $\begin{array}{l}0.354^{*} \\
(0.203)\end{array}$ \\
\hline Literacy (2001) & & & $\begin{array}{c}42.70^{* * *} \\
(9.433)\end{array}$ & $\begin{array}{c}43.47^{* * *} \\
(9.887)\end{array}$ \\
\hline Population density (2001) & & & & $\begin{array}{l}-0.000200 \\
(0.000401)\end{array}$ \\
\hline State fixed effects & NO & YES & YES & YES \\
\hline Observations & 435 & 435 & 435 & 435 \\
\hline Montiel-Pflueger Effective F-statistic & $19.132^{* *}$ & $108.816^{* * * *}$ & $119.398^{* * * *}$ & $111.638^{* * * *}$ \\
\hline
\end{tabular}

Note: The regions excluded here are the states of Punjab, West Bengal, and Assam, parts of which went to Pakistan and East Pakistan.

Robust standard errors in parentheses. ${ }^{* * *} \mathrm{p}<0.01,{ }^{* *} \mathrm{p}<0.05,{ }^{*} \mathrm{p}<0.1$.

Montiel-Pflueger Effective F-statistic maximum relative bias (confidence level $\alpha=5 \%$ ):

**** $5 \%, * * * 10 \%, * * 20 \%, * 30 \%$. 


\section{B.5}

Impacts of religious diversity in the past

Table B.8: Religious diversity and literacy in 1901, OLS

\begin{tabular}{|c|c|c|c|}
\hline & $(1)$ & $(2)$ & $(3)$ \\
\hline Religious fractionalization (1901) & $\begin{array}{c}0.0169 \\
(0.0251)\end{array}$ & $\begin{array}{c}0.0324 \\
(0.0245)\end{array}$ & $\begin{array}{c}0.0335 \\
(0.0247)\end{array}$ \\
\hline Colonial period urbanization & $\begin{array}{c}0.00868^{* * *} \\
(0.00120)\end{array}$ & $\begin{array}{c}0.00855^{* * *} \\
(0.00129)\end{array}$ & $\begin{array}{c}0.00858^{* * *} \\
(0.00128)\end{array}$ \\
\hline Population density (1901) & & & $\begin{array}{c}-4.73 \mathrm{e}-08^{* * *} \\
(1.66 \mathrm{e}-08)\end{array}$ \\
\hline State fixed effects & $\mathrm{NO}$ & YES & YES \\
\hline Observations & 465 & 465 & 465 \\
\hline
\end{tabular}

Table B.9: Religious diversity and public goods provision in 1901, OLS

A: Number of rail lines per $1000 \mathrm{~km}$. in 1901

$($ Mean $=0.902)$

Religious fractionalization (1901)

$\begin{array}{llll}1.700 & 1.799 & -0.948 & -0.953\end{array}$

Colonial period urbanization

$\begin{array}{llll}(1.117) & (1.489) & (0.929) & (0.931)\end{array}$

Colonial period urbanization

$\begin{array}{llll}1.424 & 1.436 & 5.957^{* * *} & 5.957^{* * *}\end{array}$

Literacy (1901)

$\begin{array}{llll}(1.546) & (1.538) & (0.286) & (0.286)\end{array}$

Literacy $(1901)$

$0.314 \quad 0.321$

Population density (1901)

(3.626) (3.626)

State fixed effects

NO YES YES YES

Observations

$497 \quad 497 \quad 465 \quad 465$

B: Roads (miles) per 1000 km. in 1901

$($ Mean $=872.273)$

Religious fractionalization (1901)

$\begin{array}{cccc}7,118 & 11,094 & 12,346 & -84.13 \\ (7,159) & (11,413) & (12,785) & (115.1) \\ 8.959 & 4.029 & 362.2^{* * *} & -160.9^{* * *} \\ (108.3) & (114.2) & (120.0) & (14.70) \\ & & -18,746 & -392.5 \\ & & (20,609) & (416.9) \\ & & & 0.498^{* * *} \\ & & & (3.80 \mathrm{e}-05) \\ \text { NO } & \text { YES } & \text { YES } & \text { YES } \\ & & & \\ 497 & 497 & 465 & 465\end{array}$

Observations

$<0.01,{ }^{* *} \mathrm{p}<0.05,{ }^{*} \mathrm{p}<0.1$. 
C

Appendices for Paper 3

\section{C.1}

Interaction between agriculture and Shakti peeth temples

Table C.1: Interaction between Shakti temples and agriculture

\begin{tabular}{|c|c|c|c|}
\hline & $(1)$ & $(2)$ & $(3)$ \\
\hline \multicolumn{4}{|l|}{ Female literacy } \\
\hline \multicolumn{4}{|l|}{ Mean $=52.62$} \\
\hline Shakti temples $\times$ Agricultural $\% \times$ Modern period & $\begin{array}{c}0.0400 \\
(0.0316)\end{array}$ & $\begin{array}{c}0.0493 \\
(0.0370)\end{array}$ & $\begin{array}{c}0.0494 \\
(0.0366)\end{array}$ \\
\hline Agricultural $\%$ of population & $\begin{array}{c}-0.272^{* * *} \\
(0.0273)\end{array}$ & $\begin{array}{c}-0.274^{* * *} \\
(0.0285)\end{array}$ & $\begin{array}{c}-0.258^{* * *} \\
(0.0291)\end{array}$ \\
\hline Shakti temples & $\begin{array}{l}-0.226 \\
(0.679)\end{array}$ & $\begin{array}{l}-0.385 \\
(0.745)\end{array}$ & $\begin{array}{l}-0.353 \\
(0.748)\end{array}$ \\
\hline Modern periods & $\begin{array}{c}49.97^{* * *} \\
(0.715)\end{array}$ & $\begin{array}{c}49.64^{* * *} \\
(0.765)\end{array}$ & $\begin{array}{c}49.65^{* * *} \\
(0.762)\end{array}$ \\
\hline Growth \% in 2004 & & $\begin{array}{l}-2.041 \\
(4.116)\end{array}$ & \\
\hline GDP per capita in 2004 & & & $\begin{array}{r}0.000130 * * \\
(5.17 \mathrm{e}-05)\end{array}$ \\
\hline State fixed effects & YES & YES & YES \\
\hline Observations & 744 & 657 & 657 \\
\hline \multicolumn{4}{|l|}{ Gender gap in literacy } \\
\hline Shakti temples $\times$ Agricultural $\% \times$ Modern period & $\begin{array}{c}-0.0420^{*} \\
(0.0234)\end{array}$ & $\begin{array}{c}-0.0610^{* *} \\
(0.0267)\end{array}$ & $\begin{array}{c}-0.0609^{* *} \\
(0.0268)\end{array}$ \\
\hline Shakti temples & $\begin{array}{c}0.914 \\
(0.763)\end{array}$ & $\begin{array}{l}1.380^{*} \\
(0.828)\end{array}$ & $\begin{array}{l}1.388^{*} \\
(0.830)\end{array}$ \\
\hline Agricultural $\%$ of population & $\begin{array}{l}0.114^{* * *} \\
(0.0159)\end{array}$ & $\begin{array}{c}0.128^{* * *} \\
(0.0169)\end{array}$ & $\begin{array}{l}0.131^{* * *} \\
(0.0181)\end{array}$ \\
\hline Modern period & $\begin{array}{c}14.46^{* * *} \\
(0.508)\end{array}$ & $\begin{array}{c}15.10^{* * *} \\
(0.513)\end{array}$ & $\begin{array}{c}15.11^{* * *} \\
(0.512)\end{array}$ \\
\hline Growth \% in 2004 & & $\begin{array}{l}0.0825 \\
(2.325)\end{array}$ & \\
\hline GDP per capita in 2004 & & & $\begin{array}{c}2.07 \mathrm{e}-05 \\
(3.27 \mathrm{e}-05)\end{array}$ \\
\hline State fixed effects & YES & YES & YES \\
\hline Observations & 740 & 653 & 653 \\
\hline
\end{tabular}

Robust standard errors in parentheses

${ }^{* * *} \mathrm{p}<0.01,{ }^{* *} \mathrm{p}<0.05,{ }^{*} \mathrm{p}<0.1$ 


\section{2}

\section{List of Shakti peeth temples}

Table C.2: Full list of Shakti peeth and their locations

\begin{tabular}{|c|c|c|c|c|c|}
\hline Shakti $^{a}$ & Location & District & State/Division/Province & Country & Classification \\
\hline $\begin{array}{l}\text { In India: } \\
\text { 1. Kamakhya/Kamarupa Devi }\end{array}$ & Kamgiri, Kamakhya & Guwahati & Assam & India & $\begin{array}{l}\text { Adi Shakti peeth, Maha } \\
\text { Shakti peeth, Shakti peeth }\end{array}$ \\
\hline 2. Dakshina Kalika & Kalighat & Kolkata & West Bengal & India & Adi Shakti peeth \\
\hline 3. Tara Tarini & Berhampur & Berhampur & Odisha & India & Adi Shakti peeth \\
\hline 4. Vimala & Puri & Puri & Odisha & India & Adi Shakti peeth \\
\hline 5. Avanti/Mahakali Devi & Bhairavparvat & Ujjain & Madhya Pradesh & India & $\begin{array}{l}\text { Maha Shakti peeth, } \\
\text { Shakti peeth }\end{array}$ \\
\hline $\begin{array}{l}\text { 6. Lalita/Madhaveswari } \\
\text { Devi/Alopi Mata }\end{array}$ & Prayag & Allahabad & Uttar Pradesh & India & $\begin{array}{l}\text { Maha Shakti peeth, } \\
\text { Shakti peeth }\end{array}$ \\
\hline 7. Vishalakshmi and Manikarni & Varanasi & Varanasi & Uttar Pradesh & India & $\begin{array}{l}\text { Maha Shakti peeth, } \\
\text { Shakti peeth }\end{array}$ \\
\hline 8. Bhramaramba Devi & Srisailam & Kurnool & Andhra Pradesh & India & Maha Shakti peeth \\
\hline 9. Viraja/Girija Devi & Jajpur & Jajpur & Odisha & India & Maha Shakti peeth \\
\hline 10. Chamundeshwari Devi & Mysore & Mysore & Karnataka & India & Maha Shakti peeth \\
\hline 11. Ekaveerika Devi & Mahur & Nanded & Maharashtra & India & Maha Shakti peeth \\
\hline 12. Jogulamba/Yogamba Devi & Alampur & Mahbubnagar & Andhra Pradesh & India & Maha Shakti peeth \\
\hline 13. Kamakshi Devi & Kanchi & Kanchi & Tamil Nadu & India & Maha Shakti peeth \\
\hline 14. Mahalakshmi Devi & Kolhapur & Kolhapur & Maharashtra & India & Maha Shakti peeth \\
\hline 15. Manikyamba Devi & Draksharamam & East Godavari & Andhra Pradesh & India & Maha Shakti peeth \\
\hline 16. Puruhutika Devi & Pithapuram & East Godavari & Andhra Pradesh & India & Maha Shakti peeth \\
\hline 17. Sarvamangala Devi & Gaya & Gaya & Bihar & India & Maha Shakti peeth \\
\hline 18. Shrikkhala/Srigala Devi & Pandua & Hooghly & West Bengal & India & Maha Shakti peeth \\
\hline 19. Vaishnavi Devi & Jwalamukhi & Kangra & Himachal Pradesh & India & Maha Shakti peeth \\
\hline 20. Ambika & Virat & Bharatpur & Rajasthan & India & Shakti peeth \\
\hline 21. Bahula & Bahula & Burdwan & West Bengal & India & Shakti peeth \\
\hline 22. Bhramari & Boda village & Jalpaiguri & West Bengal & India & Shakti peeth \\
\hline 23. Bhramari & Vani & Nasik & Maharashtra & India & Shakti peeth \\
\hline 24. Chandrabhaga & Prabhas & Junagadh & Gujarat & India & Shakti peeth \\
\hline 25. Chinnamastika & Chintpurni & Una & Himachal Pradesh & India & Shakti peeth \\
\hline 26. Gayatri & Manibandh & Ajmer & Rajasthan & India & Shakti peeth \\
\hline 27. Jaya Durga & Baidyanath Dham & Deoghar & Jharkhand & India & Shakti peeth \\
\hline 28. Jaya Durga & Brajeshwari Devi & Kangra & Himachal Pradesh & India & Shakti peeth \\
\hline 29. Jayanti & Nartiang village & Jaintia Hills & Meghalaya & India & Shakti peeth \\
\hline 30. Jugaadya & Khurgram & Burdwan & West Bengal & India & Shakti peeth \\
\hline 31. Kali & Kalmadhav & Anuppur & Madhya Pradesh & India & Shakti peeth \\
\hline 32. Kalika & Kalighat & Kolkata & West Bengal & India & Shakti peeth \\
\hline 33. Kankaleshwari/Devgarbha & Kankalitala & Birbhum & West Bengal & India & Shakti peeth \\
\hline 34. Kapalini/Bhimarupa & Vibhash & Purba Medinipur & West Bengal & India & Shakti peeth \\
\hline 35. Kumari & Ratnavali & Hooghly & West Bengal & India & Shakti peeth \\
\hline 36. Mahamaya & Amarnath & Pahalgam & Jammu and Kashmir & India & Shakti peeth \\
\hline 37. Mahishmardini & Bakreshwar & Birbhum & West Bengal & India & Shakti peeth \\
\hline 38. Mangal Chandika & Ujaani & Burdwan & West Bengal & India & Shakti peeth \\
\hline 39. Nandini & Sainthia & Birbhum & West Bengal & India & Shakti peeth \\
\hline 40. Narayani & Shuchi & Kanyakumari & Tamil Nadu & India & Shakti peeth \\
\hline 41. Narmada & Shondesh & Anuppur & Madhya Pradesh & India & Shakti peeth \\
\hline 42. Phullara & Attahas village & Birbhum & West Bengal & India & Shakti peeth \\
\hline 43. Rakini/Vishweshwari & Sarvashail & East Godavari & Andhra Pradesh & India & Shakti peeth \\
\hline 44. Sarvani & Kanyakumari & Kanyakumari & Tamil Nadu & India & Shakti peeth \\
\hline 45. Savitri/Bhadrakali & Thanesar & Kurukshetra & Haryana & India & Shakti peeth \\
\hline 46. Shivani & Ramgiri & Chitrakoot & Uttar Pradesh & India & Shakti peeth \\
\hline 47. Shrisundari & Srisailam & Kurnool & Andhra Pradesh & India & Shakti peeth \\
\hline 48. Siddhida & Jwalaji & Kangra & Himachal Pradesh & India & Shakti peeth \\
\hline 49. Tripura Sundari & Udaipur & Udaipur & Tripura & India & Shakti peeth \\
\hline 50. Tripurmalini & Devi Talav & Jalandhar & Punjab & India & Shakti peeth \\
\hline 51. Uma & Vrindavan & Mathura & Uttar Pradesh & India & Shakti peeth \\
\hline 52. Varahi & Panchsagar & Haridwar & Uttarakhand & India & Shakti peeth \\
\hline 53. Vimla & Kireetkona village & Murshidabad & West Bengal & India & Shakti peeth \\
\hline \multicolumn{6}{|l|}{ Outside India: } \\
\hline 54. Arpana & Ratnapore & Bogra & Rajshahi & a & Shakti peeth \\
\hline 55. Jassoreshwari & Shyamnagar & Khulna & Khulna & Bangladesh & Shakti peeth \\
\hline 56. Bhawani & Chandranath Hill & Chittagong & Chittagong & Bangladesh & Shakti peeth \\
\hline 57. Mahalakshmi & Joinpur village & Sylhet & Sylhet & Bangladesh & Shakti peeth \\
\hline 58. Sugandha & Shikarpur & Barisal & Barisal & Bangladesh & Shakti peeth \\
\hline 59. Saraswathi Devi & Sharada peeth & Muzaffrabad & Pak. Occupied Kashmir & Pakistan & Maha Shakti peeth \\
\hline 60. Kottari & Hinglaj & Gwadar & Baluchistan & Pakistan & Shakti peeth \\
\hline 61. Mahishmardini & Shivaharkaray & Karachi & Sindh & Pakistan & Shakti peeth \\
\hline 62. Shankari Devi & Trincomalee & Trincomalee & Northern Province & Sri Lanka & Maha Shakti peeth \\
\hline 63. Indrakshi & Manipallavam & Jaffna & Northern Province & Sri Lanka & Shakti peeth \\
\hline 64. Gandaki Chandi & Gandaki & Kaski & Gandaki Pradesh & Nepal & Shakti peeth \\
\hline 65. Mahashira & Guhyeshwari Temple & Kathmandu & Province No. 3 & Nepal & Shakti peeth \\
\hline 66. Uma & Janakpur & Dhanusha & Province No. 2 & Nepal & Shakti peeth \\
\hline 67. Paropit & Birajong & Paro & Paro & Bhutan & Shakti peeth \\
\hline 68. Dakshayani & Manasarovar & & Autonomous Region & Tibet & Shakti peeth \\
\hline
\end{tabular}

